\title{
Highway Performance and Time-Sensitive Industries
}





\title{
Highway Performance and Time-Sensitive Industries
}

\author{
Lisa A. Schweitzer \\ Research Associate, Public Policy Center \\ David J. Forkenbrock \\ Director, Public Policy Center \\ H. Michael Zhang \\ Assistant Professor, Public Policy Center \\ and Department of Civil and Environmental Engineering \\ Michael R. Crum \\ Professor, Department of Transportation and Logistics \\ lowa State University
}

This study was funded by the lowa Department of Transportation. The conclusions are the independent products of university research and do not necessarily reflect the views of the funding agency. 
Copyright (C) 1998 by the

Public Policy Center

The University of Iowa

lowa City, IA 52242

All rights reserved 


\section{PREFACE}

Communities and states are using every means available to them to attract and retain economic activity. One such strategy is to plan for the changing needs of new and existing businesses. In the past two decades, firms have come to view time as one of their most precious resources. Some businesses have adopted efficiently timed production methods like just-in-time, in which inventory and safety stock are minimized; deliveries of intermediate goods at all stages of production are synchronized with suppliers so that at no point do products linger.

Highway projects that reduce unanticipated delays enhance the ability of timesensitive businesses to maintain closely timed production and sales schedules. Perhaps the most important type of delay in this context is that produced by incidents, which are events that disrupt normal traffic flow. In addition to accidents, incidents include stalled vehicles, debris on the road, or other impediments to orderly flow. While they are rare events, incidents do happen, and they can greatly affect travel times, especially on roads operating at near capacity. Highway improvements can reduce the likelihood of incidents and reduce the severity of impacts when incidents do occur. How to measure increases in highway system performance for time-sensitive businesses when these systems are upgraded is a focus of this monograph.

We begin by examining the changes in the business environment that precipitated the movement toward time-sensitive production. Then, from an extensive survey, we conclude that although businesses in lowa are somewhat less time-sensitive than businesses in many other places, lowa's businesses anticipate tighter production schedules in the future. We show how traffic incidents and incident-produced congestion erode highway performance for time-sensitive industries. An analysis of the causes and consequences of incident-produced delays provides the foundation for our model of incident-produced delay, which we have developed to gauge highway performance for time-sensitive firms.

This research was a joint effort between researchers at the University of lowa Public Policy Center and lowa State University's Department of Transportation and Logistics. The lowa Department of Transportation provided funding for this project. 



\section{ACKNOWLEDGMENTS}

We are grateful to the lowa Department of Transportation for providing the funding to enable this research to be carried out.

Our project demanded copious amounts of data. We thank Harry Cohen for helping us find useful data on incident rates. Kevin Gilchrist and Alicia Caton of the Des Moines Area Metropolitan Planning Organization (DMAMPO) responded cheerfully and tirelessly to our numerous requests for data. As a member of our advisory committee, DMAMPO Director Tom Kane purveyed much insight into the freight policy and planning objectives for the Des Moines metro area. He also was a superb sounding board for ideas.

Other members of the advisory committee assisted us in our efforts to model freight demand and travel demand. Michael Lipsman, who was associated with the lowa Department of Transportation Office of Project Management during the study, contributed his knowledge of the economic aspects of freight demand and logistics. Lorne Wazny, Craig Marvik, and Marty Sanky of the lowa Department of Transportation provided us with insights into the case study corridor and the Des Moines area freeway system. We thank all the members of the advisory committee for sharing their time and insights with us.

Students contributed much to the project. At the Public Policy Center, Yuwei Li, graduate student in Urban and Regional Planning, unearthed myriad journal articles on travel demand, logistics, and just-in-time operations. Wu Tongquiang and $\mathrm{He}$ Jianchun, graduate students in the Department of Civil and Environmental Engineering, worked long hours on the travel demand modeling portion of the analysis. At lowa State University, Miren Arango and Gaye Goker helped administer the survey, as well as analyze the data collected.

Finally, we acknowledge the contributions made by our colleagues at the Public Policy Center. Our efforts were enhanced by the work of two fine editors at the Center; Anita Makuluni and Teresa Lopes helped make complex subject matter understandable. In addition, our secretary, Mary Almquist, reviewed and proofread early drafts of the report. The Center's administrative assistant, Linda Walshire, kept close track of our resources and helped us in innumerable other ways. Gracious and skilled colleagues such as these make our work a pleasure. 



\title{
TECHNICAL ADVISORY COMMITTEE
}

\author{
Kevin Gilchrist \\ Des Moines Area Metropolitan \\ Planning Organization \\ Tom Kane \\ Des Moines Area Metropolitan \\ Planning Organization \\ Michael Lipsman \\ lowa Department of Transportation \\ Office of Project Management \\ Craig Marvik \\ lowa Department of Transportation \\ Office of Systems Planning \\ Marty Sanky \\ lowa Department of Transportation \\ Project Development \\ Lorne Wazny \\ lowa Department of Transportation \\ Planning Division
}





\section{CONTENTS}

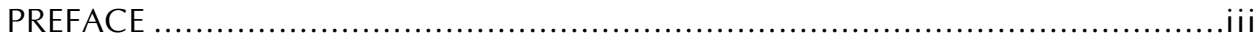

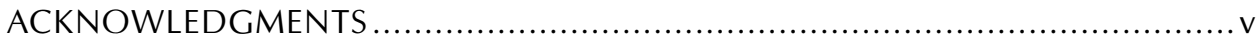

TECHNICAL ADVISORY COMMITTEE .............................................. vii

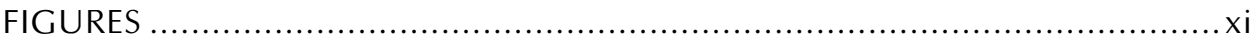

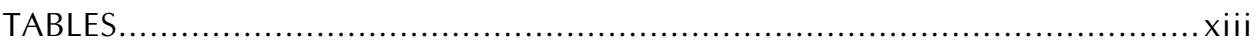

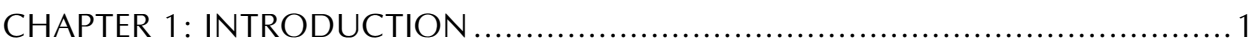

A trial application: The Des Moines metropolitan area ............................. 2

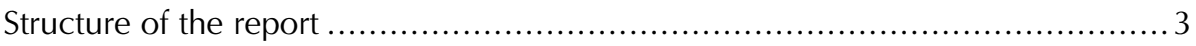

CHAPTER 2: RELIABILITY AT THE FOREFRONT OF
FREIGHT TRANSPORT DEMAND

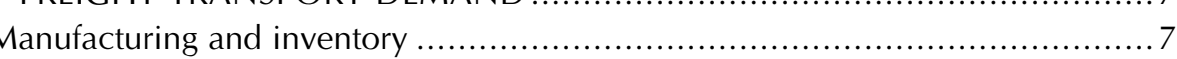

Just-in-time operations in the U.S. ................................................. 9

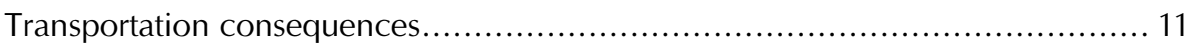

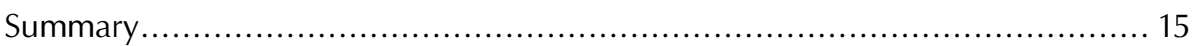

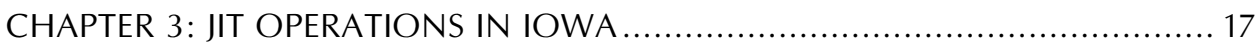

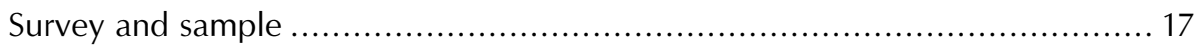

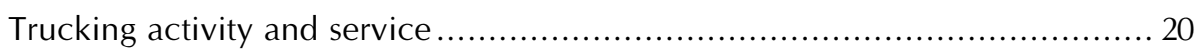

Just-in-time truck transportation in lowa ................................................ 22

Assessment of factors affecting truck transportation service .......................... 25

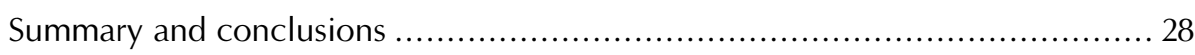

CHAPTER 4: TRAVEL TIME UNCERTAINTY INDUCED BY INCIDENTS ............ 31

A probabilistic model for incident occurences and durations ..................... 32

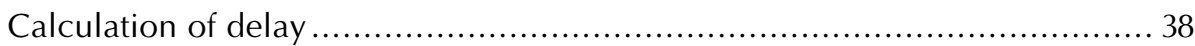

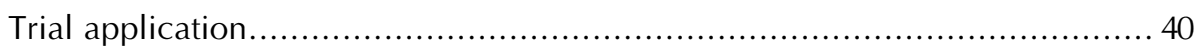

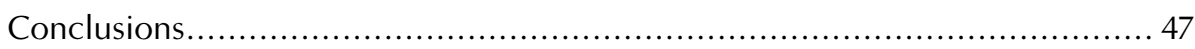

CHAPTER 5: CONCLUSIONS AND RECOMMENDATIONS ........................ 51

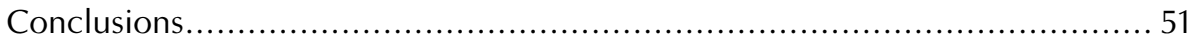

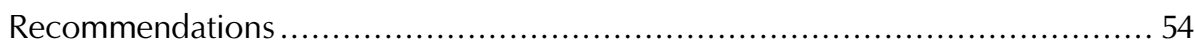




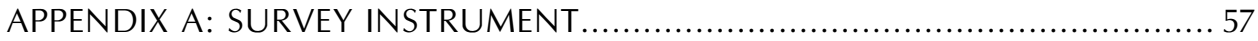

APPENDIX B: INCIDENT OCCURRENCES AND DURATIONS, OBTAINING LINK FLOWS, AND AVERAGE EXPECTED DELAY ..............................6 65

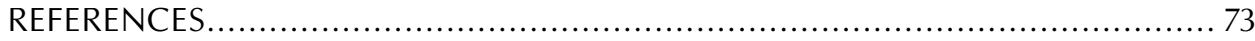




\section{FIGURES}

$1-1$. Ton-miles of truck shipments by state for the Midwest, $1993 \ldots \ldots \ldots \ldots \ldots \ldots \ldots \ldots$

1-2. Major transportation facilities in the Des Moines area............................. 4

2-1. Three types of work activities in the Toyota Production System.....................9

2-2. The spread of JIT manufacturing and its derivatives, 1950 to the present........ 10

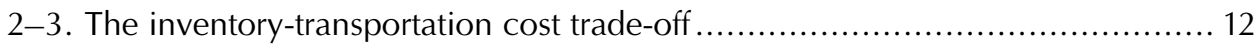

3-1. Location of JIT and non-JIT respondents in the Des Moines area ................... 19

$3-2$. Average percentage of expenditure by type of motor carriage .................... 21

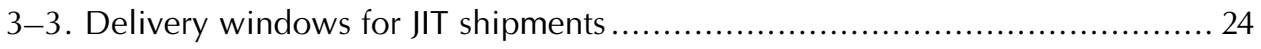

3-4. Frequency of the external causes of late shipment deliveries .................... 26

$3-5$. Summary of respondents' perceptions of transportation quality in lowa ......... 27

4-1. Probability of incident duration: abandonment and debris

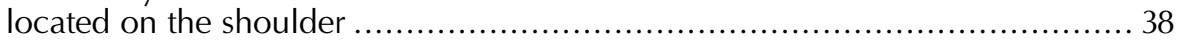

4-2. Calculation of delay caused by an incident ............................................ 39

4-3. Network and O-D districts in the Des Moines area................................ 41

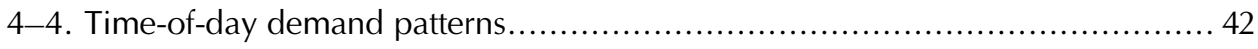

4-5. AADT, flow speed, travel time, and delay on the highest-traffic freeway segment.................................................................. 45 



\section{TABLES}

2-1. Differences between traditional and JIT manufacturing systems .................. 11

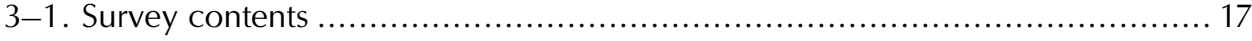

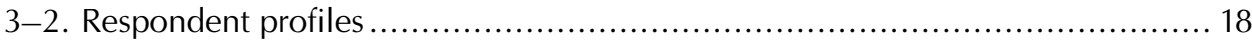

3-3. Annual truck transportation expenditures.......................................... 20

3-4. Percentage on-time delivery of all shipments..................................... 21

3-5. Number and percentage of JIT truck shipments ................................. 22

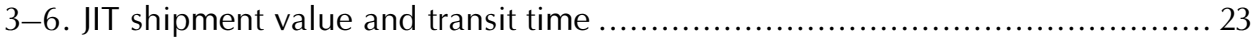

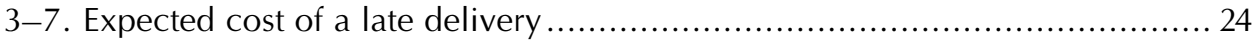

$3-8$. Annual cost estimates of late delivery of JIT shipments

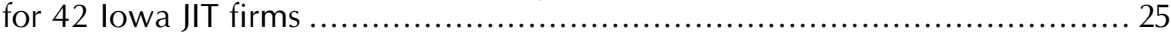

4-1. Freeway incident rates as a function of ADT/C .................................... 34

4-2. Lateral locations of incidents and percentage of lanes blocked ................... 35

4-3. Percent capacity remaining after incidents of different severity

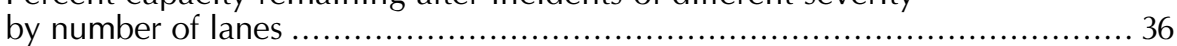

4-4. Average duration by type of incident ................................................ 37

4-5. Probability of each incident duration by type and location......................... 37

4-6. Results of traffic assignment analysis and delay calculation ..................... 43

4-7. Delays for various accidents and incidents during the three-hour morning peak ............................................................. 47 



\section{CHAPTER 1 INTRODUCTION}

Efficient transportation of freight is essential to the success of lowa's businesses. Because the state has a small population base and small local market, many lowa firms must compete in larger markets, and must therefore be able to bring in raw materials and ship out finished or intermediate goods at the lowest possible cost.

As Figure 1-1 shows, a large volume of freight is shipped by truck in lowa. In 1993, a total of 25.93 billion ton-miles of freight was moved by truck within the state, exceeded in the Midwest only by Illinois (47 billion) and Missouri (29 billion).

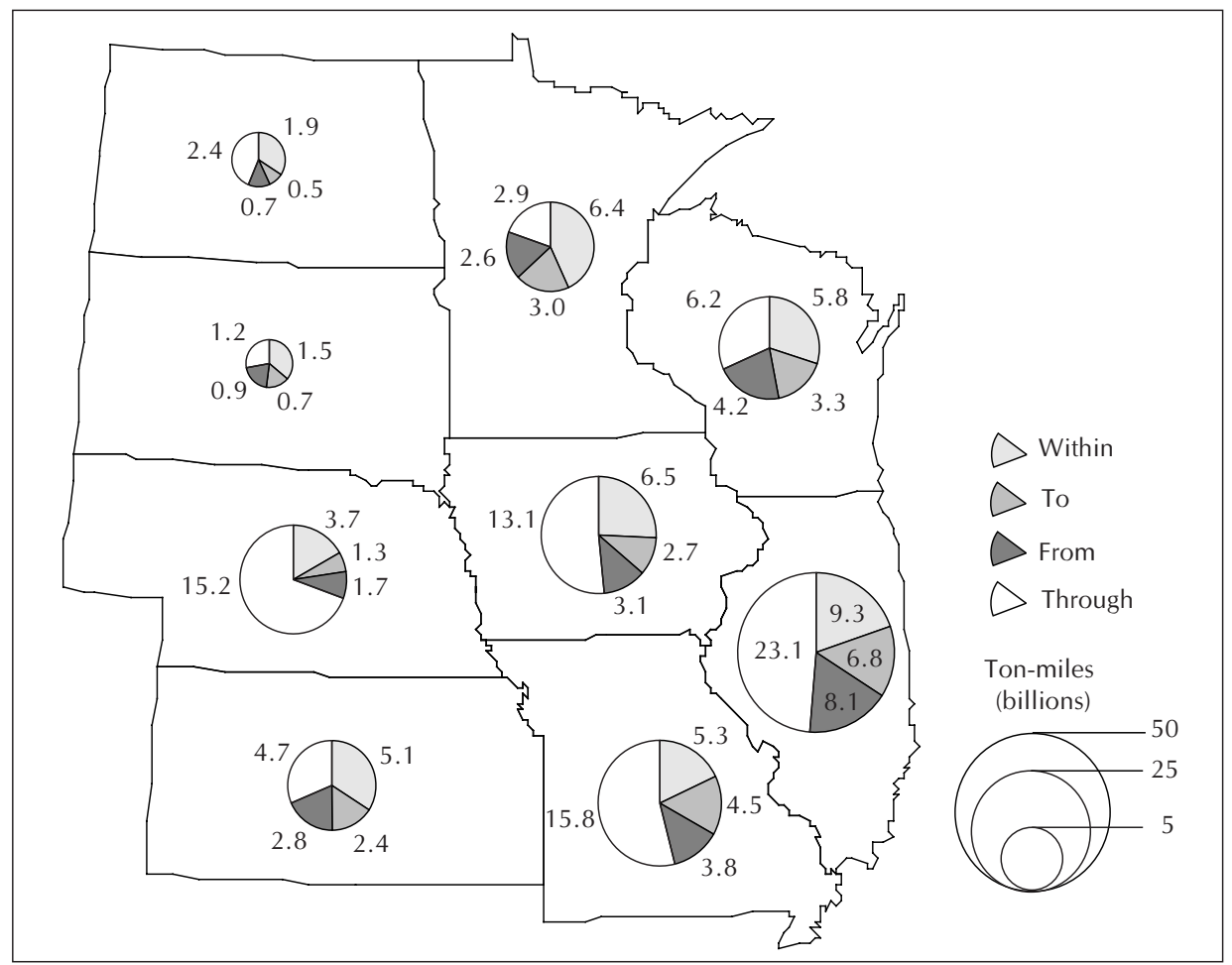

Figure 1-1. Ton-miles of truck shipments by state for the Midwest, 1993 SOURCE: Chin et al. (1998, Table 1).

Because total shipments in lowa include those that simply pass through the state, the amount of freight shipping within lowa is a better indicator of how much truck shipping on the state's roadways is associated with lowa businesses. Compared to other midwestern states, lowa (with 6.5 billion ton-miles) ranks second only to 
Illinois (9.3 billion ton-miles) for shipments occurring within the state. Because lowa has considerable internal shipping activity, roadway projects that make shipping easier, faster, or more reliable are valuable to the state and its business interests.

Using the logic of benefit-cost analysis, if the benefits from a road project under consideration exceed its costs, then the project will profit society. Because finite public resources restrict the number of projects that can be built, an inaccurate appraisal of benefits or costs may cause decision makers to forgo a beneficial project or deploy scarce resources on an inefficient project, the costs of which exceed its benefits. Prudent public investment therefore relies on accurate appraisals and an understanding of the full spectrum of project costs and benefits.

When benefit-cost analyses of potential highway investments are conducted, little explicit attention is generally given to costs related to freight movement. Typically, such costs are expressed solely in terms of travel-time savings, following a three-step approach:

1) estimate the hourly operating costs of trucks (and drivers' wages);

2) project the number of hours that would be saved annually if the project were built; and

3) multiply the first estimate by the second to project the total savings in travel time for trucking firms.

Recently, however, Allen et al. (1994) argued that total travel-time saving is an incomplete measure of project benefits to freight shippers. Reductions in mean travel times and accidents save not only wages and lives but also result in logistical cost savings. For instance, if a new facility is predicted to reduce crashes, it will also reduce traffic backup and delay during cleanup after a crash; motorists and freight shippers (even if they have no part in the crash) gain because they spend less time waiting as the roadway is cleared. Thus, travel times vary less from trip to trip and carriers require less "safety lead time" or time added to mean travel time to ensure that a freight shipment meets a deadline.

In this report, we develop a methodology to estimate how businesses that rely on freight shipping benefit from highway improvements that reduce incidents and accidents (thereby reducing variability in travel times). We concentrate on how freight shippers, especially those using just-in-time (JIT) production and inventory methods, may value decreases in the variability of travel time as much or more than they value lower total travel time. To test our methodology, we develop a trial application of the method for a new freeway in the Des Moines metropolitan area in lowa.

\section{A TRIAL APPLICATION: THE DES MOINES METROPOLITAN AREA}

Projections for the Des Moines metropolitan area indicate continuing population (and therefore traffic) growth, making it an appropriate site for our trial application. In 1990 (the base year of our analysis), the population was 337,507, and the Des Moines Area Metropolitan Planning Organization (DMAMPO) projects that the population will grow to 505,414 by the year 2020 (DMAMPO 1998). Employment in 
the area is also expected to grow from 218,456 in 1990 to 338,180 in 2020 . With this potential for growth, the risk of traffic congestion in Des Moines is perhaps higher than for any other place in lowa.

To aid traffic circulation around the southeastern portion of the metro area, a decision has been made to relocate lowa Highway 5 and U.S. Highway 65 , referred to in this report as "Highway 5/65" (see Figure 1-2). Built to freeway standards, the new highway will enhance intermodal transportation by improving access to the Des Moines International Airport, railroads, and pipeline terminals south of the metro area. Industrial and commercial areas surround the airport, so freight shipments will be greatly expedited by the four-lane facility. Once completed, Highway 5/65 will provide an alternative route for freight shippers to reach both I-35 (north and south) and I-80 (east and west), and thus should alleviate some of the traffic on clogged $\mathrm{I}-235$.

Our trial application examines what can be expected in terms of delay caused by traffic incidents on the Des Moines area freeway system both with and without Highway 5/65, which will run along the southern portion of the city of Des Moines. Our approach consists of the following steps:

1) Develop a small-scale traffic demand model of the Des Moines metro area by

a) selecting and coding a study network consisting of freeways and arterials within the entire metro area, and

b) performing stochastic assignment to obtain traffic flows on the street links.

2) Develop an incident occurrence model based on previous engineering research.

3) Calculate the expected delay due to incidents on freeways for the base case and expanded road network.

\section{STRUCTURE OF THE REPORT}

While delays are annoying and costly to all motorists, our analysis focuses on delays to freight shippers and does not address commuter delays. In Chapter 2, we discuss how shipment deadlines have become less flexible in the past two decades as businesses have reduced inventories in favor of JIT production. We provide a review of the extensive research that has established how businesses using JIT practices have come to depend on deliveries of parts and goods that arrive just in time to be used or sold. Although we focus on JIT businesses, we argue that even for non-JIT businesses, idle or delayed trucks are resources that are not as productive as they could be had they not been delayed. 


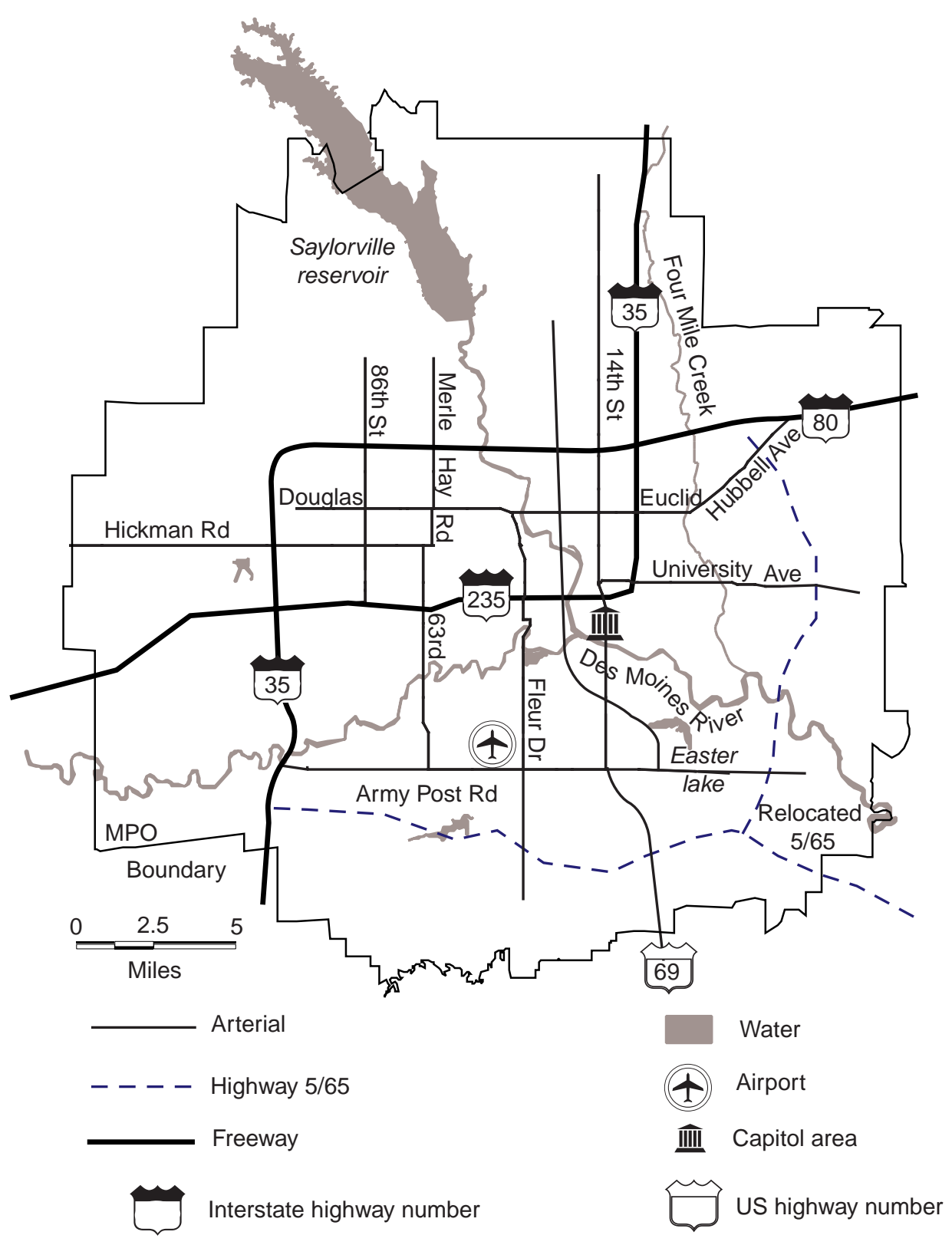

Figure 1-2. Major transportation facilities in the Des Moines area

Chapter 3 discusses the results of a survey we conducted on the use of JIT shipping by central lowa businesses. The survey offers considerable insight into current shipping practices and satisfaction with performance of the transportation system; it also reveals respondents' beliefs about the demands JIT operations will place on lowa's transportation system in the future. 
In Chapter 4 we examine the effects of incidents on transportation system reliability. We examine the factors contributing to incident-produced congestion, modeling the probability of incidents as a function of traffic volume. We then integrate the incident occurrence probability model into our modified traffic demand model to examine how the relocated and upgraded Highway 5/65 would change expected delays throughout the freeway network of the Des Moines area.

The key findings of our study are brought together in Chapter 5. We offer a series of conclusions and recommendations related to highway planning in urban areas to support time-sensitive industries. Appendices following the main text of the report present our survey and modeling approach in a more condensed technical format. 


\section{CHAPTER 2 RELIABILITY AT THE FOREFRONT OF FREIGHT TRANSPORT DEMAND}

Successful firms always look for a competitive edge: businesses change their products, manufacturing methods, and management techniques to find more profitable ways to compete. Over the past three decades, as manufacturing logistics and inventory management have evolved technologically and philosophically, what firms require from the transportation system has also changed. To plan transportation facilities that will attract and retain businesses, it is instructive to examine why manufacturing firms have changed their approaches to freight handling.

Our review of the emergence of time-sensitive manufacturing sets the stage for an appraisal of the changing expectations U.S. industry has of the transportation sector. Specifically, a need on the part of freight carriers to keep deviations from scheduled arrival times as small as possible requires significant revisions in how we plan urban highway systems.

\section{MANUFACTURING AND INVENTORY}

Until the mid-1970s, U.S. firms stored substantial quantities of finished products and supplies in inventory. According to Raia (1990, p. 65), as much as 40 percent of U.S. business assets in the early 1970s were tied up in inventory, and manufacturers held enough raw materials on average for 9.5 weeks of production. By 1990, however, manufacturers had halved their inventory of raw materials (Raia 1990, p. 69). What prompted U.S. firms to trim their inventories?

\section{Interest rates and inflation}

The answer in part lies in interest and inflation. The nominal interest rate is how much it costs a firm to borrow money; inflation is the rise in prices over time. If inflation is higher than interest, ${ }^{1}$ it is possible for firms to spend less by borrowing money to buy supplies immediately instead of paying cash for the same items after prices have gone up.

Beman $(1981$, p. 77$)$ argued that companies in 1974 could borrow at interest rates below ten percent to finance their stock of parts and products. Rising prices added 15 percent a year to the value of inventories. After the costs of storing, insuring, and accounting for inventories, the financial burden to U.S. firms in 1974 was less than $\$ 10$ billion to carry stockpiles that were worth $\$ 332$ billion (Beman 1981, p. 77). Because holding assets in inventory was inexpensive, firms could use inventories to

1 Here we mean the real interest rate (net of inflation). 
buffer against shortages of supplies or finished products (Loar 1992, p. 70; Beman 1981, p. 78).

As U.S. interest rates began to rise in the early 1980s, American firms found themselves waterlogged with inventory. Inventories in 1981 were valued at $\$ 710$ billion-more than twice as large as in 1974-but the carrying costs of inventory had risen tenfold, from $\$ 10$ billion in 1974 to a painful $\$ 110$ billion in 1981 (Beman 1981, p. 77). American firms had no choice but to pare down inventories if they wanted to remain competitive.

\section{Lean production systems: Japanese just-in-time systems}

Japanese firms were the undisputed leaders of lean production during the 1980s. Unlike the U.S. economy, which favored firms turgid with inventory, economic conditions in Japan rewarded the frugal acquisition of materials. Since World War II, facilities and machines (capital) had been in short supply in Japan. Also, the Japanese held little foreign exchange and could not purchase enough equipment from foreign suppliers to make up their domestic shortage (Womack et al. 1990, pp. 40-50). Because capital was costly, the Japanese market favored firms that could squeeze the most out of limited facilities.

Toyota Motor Company pioneered a production system that allowed frequent design changes in order to manufacture a variety of vehicles in small batches at one facility. The guiding principle of the Toyota Production System was to seek improvement by eliminating waste (Ohno 1988, p. 4). Toyota's managers recognized that rearranging stock or looking for tools took time away from activities that made Toyota's products more attractive to consumers (1988, p. 58). The company identified seven "wastes" that added little or nothing to the production of finished automobiles. Included in their list of wasteful activities were inventory and transport. Figure 2-1 shows the relationship of waste, value-added work, and non-value-added work conceptualized in the Toyota Production System. Eliminating waste allowed Toyota's workers to focus on activities that added value to the company's products (Hallihan et al. 1997, p. 902). ${ }^{2}$

Because minimal inventories were allowed, the system required that components arrive "just in time," and so manufacturing systems that used time-phased delivery became known as just-in-time or JIT systems. Toyota's thrifty production system caught on first with another Japanese automaker, Nissan, and then with other Japanese firms that wished to emulate Toyota's profitability during the 1973 oil crisis (Hallihan et al. 1997, p. 904). Japanese companies that used JIT methods for five or more years reported amazing efficiencies: a 30 percent increase in labor productivity; a 60 percent reduction in inventories; a 90 percent reduction in quality rejection rate; and a 15 percent reduction in plant space (Aggarwal 1985, p. 9). These results caught the attention of western firms.

2 The relationship of value-adding time to total factory throughput time is a measure of production system performance (Barker and Barber 1997). 


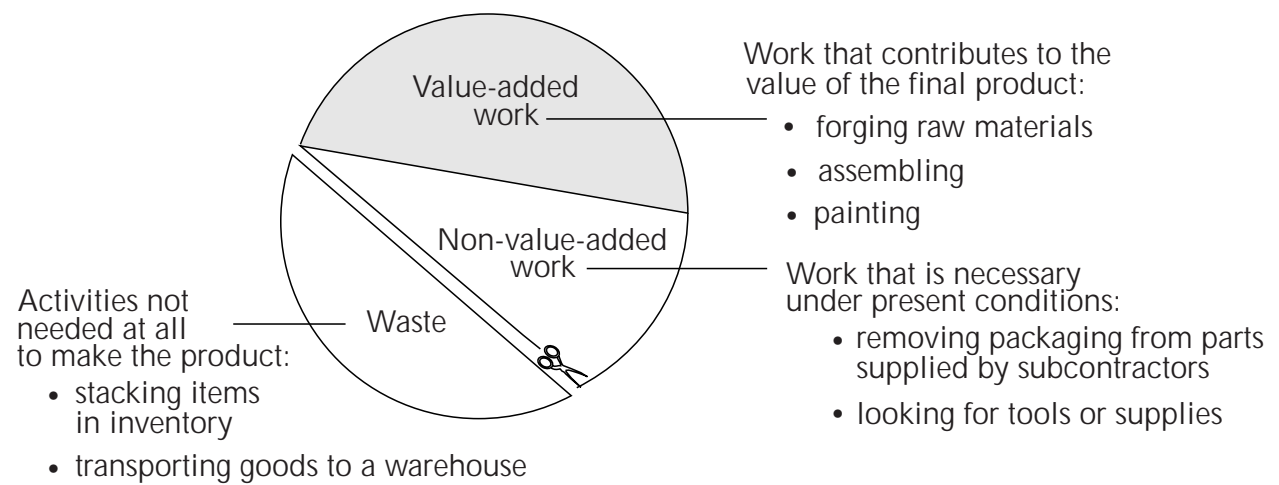

Figure 2-1. Three types of work activities in the Toyota Production System SOURCE: Adapted from Ohno (1988, pp. 57-59).

\section{JUST-IN-TIME OPERATIONS IN THE U.S.}

Whether or not JIT techniques could be transferred successfully to the U.S. remained a question in the 1970s to early 1980s. Although some authors attributed the success of JIT operations to Japanese culture, Japanese firms used JIT methods successfully in their U.S. plants (Hallihan et al. 1997, p. 905). Some U.S. firms, like General Electric, found early on that JIT principles could benefit them. In 1980, General Electric had two plants operating on a JIT basis; by 1983, it had 40 (Sepehri 1986, p. 1). Figure 2-2 traces the evolution of JIT applications over time.

Other leaders of JIT implementation in North America were Black \& Decker, Texas Instruments, IBM, Hewlett-Packard, General Motors, Ford, Chrysler, and John Deere (Musselwhite 1987, p. 27; Im and Lee 1989, p. 5; Gilbert 1990, p. 110). As U.S. firms implemented JIT techniques, research showed that at least some aspects of JIT definitely were improving their competitiveness (Musselwhite 1987, p. 27 and Manoochehri 1985, p. 26).

Few U.S. firms implemented all the practices advocated by Japanese firms. Instead, most custom-tailored JIT concepts to fit their organizations. In some firms, JIT principles have been subsumed in traditional material requirements planning (MRP) systems for planning and controlling production systems. Because MRP systems were designed to drive inventory to zero by having the firm buy only the materials it needs when it needs them, JIT time-phased delivery accentuates MRP performance (Ptak 1991, p. 7; Miltenburg 1997, p. 1169).

In two relatively early studies, Im and Lee (1989) surveyed 33 manufacturing firms, and Gilbert (1990) surveyed 141 such firms to discover which JIT methods had been adopted by American firms. Both studies found the reduction in purchasing and production lot sizes to be a leading objective when U.S. firms adopted JIT methods. Nearly 80 percent of the companies had programs to reduce inventory buffer stock and machine set-up times (Gilbert 1990, p. 1105). 


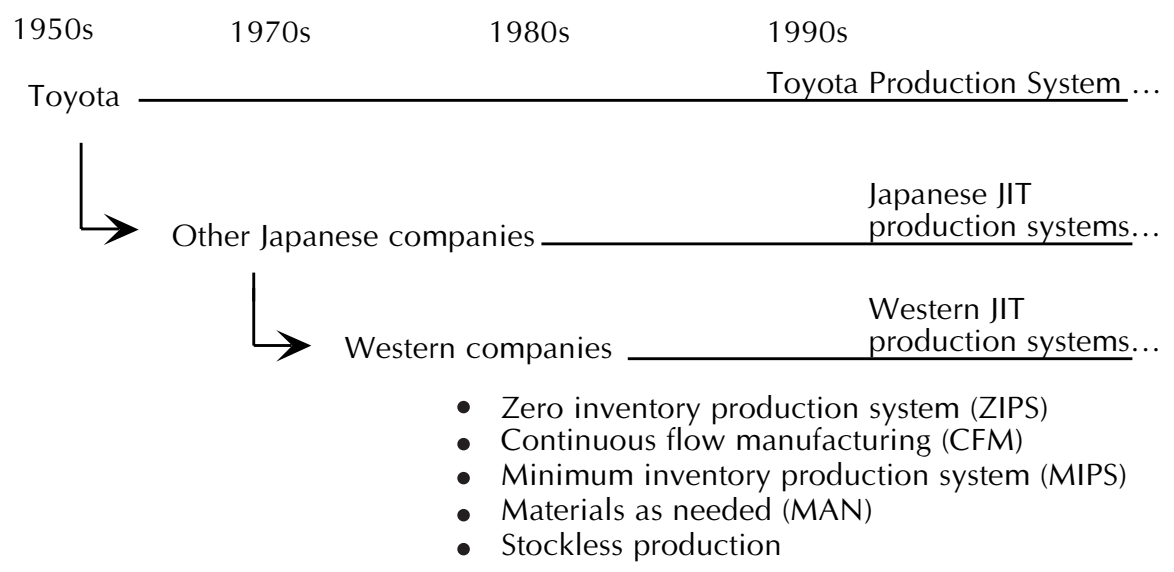

Figure 2-2. The spread of JIT manufacturing and its derivatives, 1950 to the present

SOURCE: Adapted from Hallihan et al. (1997, p. 906).

With few exceptions, North American firms initiating JIT operations reported remarkable gains in productivity. John Smith, president of GM-Canada, estimated that such operations saved his company $\$ 235$ million over four years (Musselwhite 1987, p. 27). In a small survey of automotive and electronic manufacturers in the U.S., Crawford et al. (1988, p. 1563) found that companies on average:

- reduced inventory by 41 percent;

- reduced overall manufacturing costs by 40 percent;

- reduced production and warehouse space by 30 percent; and

- increased profit margins by 54 percent.

In a survey of over a thousand manufacturing firms, White (1993, p. 39) found that 86 percent of respondents believed that JIT practices had been beneficial to their companies-even though most companies surveyed had only partially implemented these practices.

With mounting evidence of the efficacy of the JIT approach, firms worldwide have begun adopting JIT management to mend flaws in their manufacturing systems (Crawford and Cox 1991, pp. 35-36). During the past two decades, JIT principles, now considered good management practice rather than a set of tools imported from Japan, have been built into new operations systems such as the theory of constraints (TOC), optimized production techniques (OPT), and computer-integrated manufacturing (CIM) (Vokurka and Davis 1996, p. 58; Goldhar and Lei 1991, p. 38; Ptak 1991, p. 10). Perhaps no work summarizes the evolution of JIT as a management doctrine better than Hobbs (1997, p. 47):

In the 1980s many American manufacturers regarded the just-in-time manufacturing philosophy as a peculiar Japanese contrivance, suited only to the oriental culture. But as more and more companies with ever more diverse manufacturing environments successfully applied its 
principles, manufacturers recognized its inherent wisdom. Today, most American manufacturers have come to regard JIT as vital to their survival.

\section{TRANSPORTATION CONSEQUENCES}

Until U.S. firms ventured into JIT operations, the U.S. system of mass production had changed little since Frederick Taylor and Henry Ford's assembly lines (Vokurka and Davis 1996, p. 56). As Table 2-1 shows, JIT principles have led to a major rethinking of U.S. manufacturing dogma. As U.S. firms experimented with JIT techniques, they developed methods that suited their needs. Clearly, JIT and traditional U.S. manufacturing approaches differed significantly in worker management, company hierarchy, quality management, and a host of other practices. While these differences may have had profound impacts on U.S. manufacturing philosophy, we focus on those differences likely to impact freight shipping.

Table 2-1. Differences between traditional and JIT manufacturing systems

\begin{tabular}{|c|c|c|}
\hline $\begin{array}{l}\text { Manufacturing } \\
\text { activity }\end{array}$ & $\begin{array}{l}\text { Traditional U.S. system } \\
\text { (prior to JIT) }\end{array}$ & JIT system \\
\hline $\begin{array}{l}\text { Inventory and } \\
\text { buffer stock }\end{array}$ & $\begin{array}{l}\text { Use inventories as buffers for } \\
\text { breakdowns and the erratic } \\
\text { delivery of supplies. }\end{array}$ & $\begin{array}{l}\text { Eliminate inventories by } \\
\text { continuously improving the } \\
\text { timing and quality of the } \\
\text { entire manufacturing system. }\end{array}$ \\
\hline Suppliers & $\begin{array}{l}\text { Encourage competition among } \\
\text { suppliers to get lower prices. }\end{array}$ & $\begin{array}{l}\text { Coordinate company needs } \\
\text { with a small set of core } \\
\text { suppliers to encourage } \\
\text { product and delivery } \\
\text { reliability. }\end{array}$ \\
\hline $\begin{array}{l}\text { Lot size (the } \\
\text { amount of goods } \\
\text { produced or } \\
\text { purchased) }\end{array}$ & $\begin{array}{l}\text { Make a large production run } \\
\text { of one product at a time to } \\
\text { avoid the time it takes to set } \\
\text { up and change machinery. }\end{array}$ & $\begin{array}{l}\text { Develop equipment and } \\
\text { manufacturing methods that } \\
\text { reduce machine set-up and } \\
\text { changeover times so that it is } \\
\text { possible to manufacture a } \\
\text { variety of products in small } \\
\text { quantities. }\end{array}$ \\
\hline $\begin{array}{l}\text { Lead time (the time } \\
\text { it takes to } \\
\text { manufacture an } \\
\text { item) }\end{array}$ & $\begin{array}{l}\text { Allow long lead times to } \\
\text { resolve conflicts caused by } \\
\text { machine set-up and shared } \\
\text { factory resources. }\end{array}$ & $\begin{array}{l}\text { Eliminate activities that waste } \\
\text { time to reduce product lead } \\
\text { time. }\end{array}$ \\
\hline Market demand & $\begin{array}{l}\text { Forecast market demand } \\
\text { months ahead and base } \\
\text { manufacturing plans on } \\
\text { forecasts; "push" products } \\
\text { into the marketplace. }\end{array}$ & $\begin{array}{l}\text { To the greatest possible extent, } \\
\text { make to order and } \\
\text { manufacture to actual demand; } \\
\text { allow market demand to } \\
\text { "pull" products from } \\
\text { manufacturer. }\end{array}$ \\
\hline
\end{tabular}

SOURCES: Stalk (1988, p. 46); Westbrook (1988, p. 6); Crawford and Cox (1991, p. 36); Henning (1994); Hayes and Pisano (1994); Vokurka and Davis (1996, p. 56). 


\section{Inventory and buffer stock}

While JIT disciples are quick to assert that JIT management is more than an inventory system, research shows that JIT inventory reduction has been sanative to U.S. companies with swollen inventories (Gilbert 1990, p. 1105; Stamm and Golhar 1991, p. 48; White 1993, p. 42). An examination by Billesbach and Hayen (1994, p. 64) of 28 companies embracing JIT principles found an average reduction of eight percent in the ratio of inventory to total assets from 1970 to 1980 . Additionally, Loar (1992, p. 70) estimated that four major U.S. industries_food, pharmaceuticals, electronics, and chemicals - reduced the size of their inventories by at least 23 percent from 1970 to 1987 . Well-functioning JIT systems reduce total pipeline inventories, including inventory held by suppliers (Hill and Vollmann 1986, p. 383). In a survey of 68 manufacturers, 47 percent of the companies had implemented JIT methods because their customers - or customer-effectively required them to do so (Billesbach 1991, p. 2).

The lower the inventory costs, the higher the transportation costs, according to conventional logistics theory (the inventory-transportation cost trade-off is shown in Figure 2-3). Shipping large loads infrequently reduces the transportation cost per item but increases the inventory cost per item because of the added time to handle and use the inventory in the load. Firms with minimal inventory, because they require frequent deliveries, would be expected to have higher freight costs.

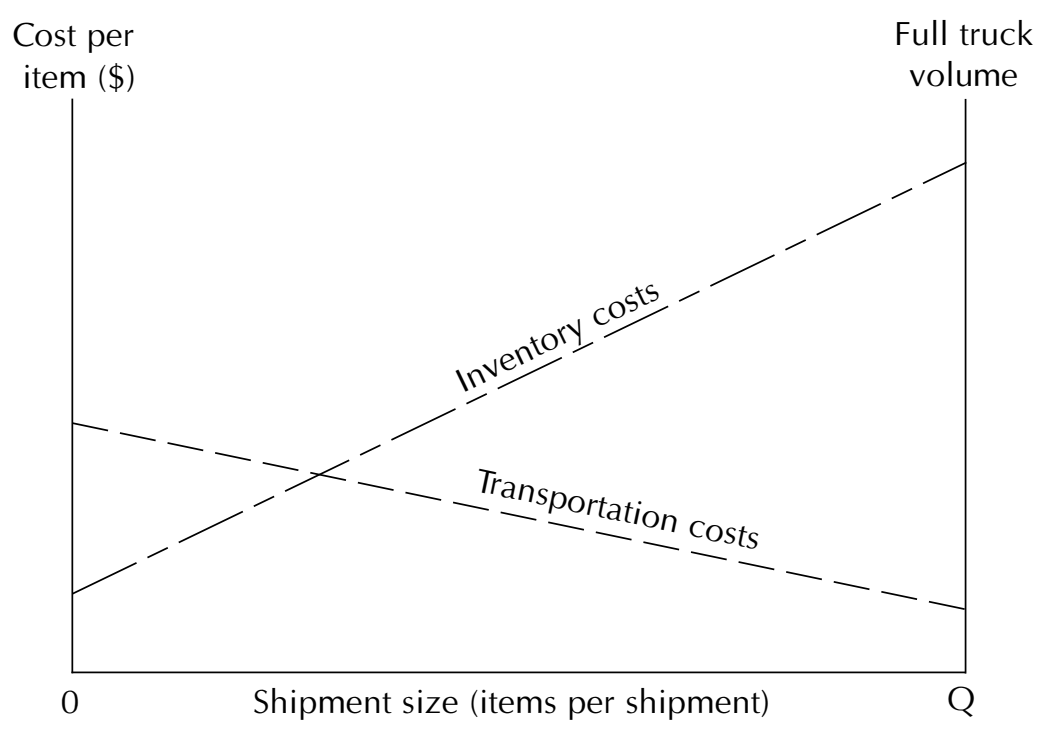

Figure 2-3. The inventory-transportation cost trade-off SOURCE: Adapted from Blumenfeld et al. (1987, p.35).

Two early surveys of freight costs following adoption of JIT manufacturing found no consensus as to whether or to what extent firms have experienced higher transportation costs. A survey by Lieb and Miller $(1988$, p. 9) found that 32 percent of respondents reported no change in freight expenditures, while 38 percent said expenditures increased. Two years later, Raia (1990, p. 76) found a similar split: 41 
percent reported no change; 37 percent reported increased freight costs of 19 percent on average; and 22 percent of respondents reported an average 17 percent decline of total freight costs. More recently, Henning (1994) asserted that competition among freight carriers following deregulation reduced shipping rates to the point at which higher transportation costs were negligible compared to inventory cost savings.

Even if shipping rates were to increase significantly, or if inflation and interest returned to pre-1980s levels, it is doubtful that manufacturers would revert to carrying large inventories. Inventory adds little value to a product, but it has to be financed, insured, tracked, and provided with security. ${ }^{3}$ Also, inventory is not liquid; if a firm needs cash, it may hunt a long time before finding a buyer for its inventory. Finally, product changes and technology erode inventory value, as no manufacturer wants to be stuck holding a warehouse full of obsolete components, particularly in certain industries such as computer manufacturing.

If large inventories are indeed a thing of the past, then manufacturers must depend on frequent and reliable deliveries_and so rely on the transportation system to serve their factories well. A delivery truck inching along in congested traffic is a waste of time and money under any circumstances. When that truck is carrying a tightly scheduled delivery to a firm without inventory, however, the wait can shut down a production line or an entire factory (Rao et al. 1991, p. 107-108). Traffic congestion in Tokyo has been a major constraint in JIT operations in Japan (Dunn 1992, p. 18). ${ }^{4}$

\section{Relationships with suppliers}

In the early days of JIT implementation, it was argued that the fine-tuned deliveries required by JIT firms were possible only if suppliers were located near the main plant (Rinehart and Stokes 1988, p. 11; Santarisi 1993, p. 24). For instance, by the late 1980s more than 75 percent of suppliers to the Honda assembly plant in Marysville, Ohio, were located within a 150-mile radius (Raia 1990, p. 75). Geographic proximity of suppliers is a tantalizing prospect to cities or regions courting firms for economic development; nevertheless, manufacturers like Deere and Company and Toyota coordinate successfully with overseas as well as proximate suppliers (Raia 1990, p. 75; Henning 1994).

Keeping suppliers close at hand has been supplanted by improved freight flow management technology. Highly professional freight shipping and logistics organizations can provide close to real-time information about parts shipments including location, status of the part in the vendor-to-plant-to-customer supply chain, and delivery time estimates (Anderson 1990, p. 26; Crum and Allen 1990, pp. 31-32). In some cases, two-way computer networks called electronic data interchange (EDI) systems augment JIT delivery as manufacturers' needs are monitored electronically by trusted suppliers (Crum and Allen 1990, pp. 31-32;

3 Some authors, however, argue that inventory does add value if holding inventory allows a firm to improve customer service by delivering or replacing a product quickly (Krupp 1991, p.18).

4 Traffic congestion caused in part by frequent JIT deliveries spurred the Japanese government to mount a media campaign encouraging companies to reduce the frequency of their deliveries (Cusumano 1994, p. 29). 
Goldhar and Lei 1991, p. 40). Since the objective of JIT methods is always to have the exact quantity of material required for production available at the exact time it is needed, JIT manufacturers try to coordinate the final operation at the supplier's plant with the first operation in their own production system —an unmanageable task unless a firm works with a small number of dependable, committed suppliers (Ansari 1986, p. 46; Perry 1988, pp. 32-33; Hong and Hayya 1992, p. 180; Turnquist 1993, p. 130; Ferrin 1994, p. 54).

Examples abound of U.S. firms that were able to greatly reduce the number of their suppliers once JIT was implemented: Xerox's Reprographics Division went from 5,000 to 300 suppliers; IBM's Typewriter Division kept 32 suppliers out of 640 (Schonberger 1986, p. 156). Reynolds Metal Company consolidated its freight shipping contracts from over 200 freight carriers to only 14 that met the company's quality control guidelines (Moore et al. 1991, p.107). For JIT firms, on-time delivery is a key measure of customer service quality (Holcomb 1994, p. 37). Suppliers to JIT firms, therefore, are vulnerable to transportation system glitches such as accidents, congestion, or weather conditions because on-time deliveries can make or break a supplier's service record with a JIT customer.

Before JIT implementation, firms in Raia's (1990, p. 65) survey had an average "ontime window" for delivery of 12 days early to six days late. After JIT operations commenced, the on-time window shrunk to five days early to two days late. Many firms cut the timing closer. At Toyota's assembly plant in Georgetown, Kentucky, the on-time window was less than an hour (Raia 1990, p. 65). Henning (1994) suggested that the on-time window will be reduced to only minutes as freight carriers use real-time tracking of freight shipments.

With fewer firms providing a wide range of parts, suppliers are required to ship mixed loads, consolidate shipments, and make multi-stop "milk runs" to meet JIT schedules (Turnquist 1993, p. 132). Of firms with JIT operations, 52 percent reported receiving daily shipments from some of their suppliers. Fifty-three percent used milk runs to handle shipments that are not a full truckload from suppliers located less than 100 miles from their plants (Raia 1990, p. 75). Manufacturers need frequent—as well as reliable-service from the transportation system serving their plants.

\section{Time-based competition: lot sizes and lead times}

JIT systems are "pull" systems—-that is, JIT manufacturers wait for market demand to draw their products, and they, in turn, draw parts from suppliers only when needed. Traditional manufacturing has been characterized as a "push" system where firms forecast sales months in advance and then push their goods into the market.

Because firms that operate on JIT pull systems respond to market signals, manufacturing facilities must have the ability to make a wide variety of products with as little machine changeover time as practicable. Make-to-order markets require short product lead times. With long lead times, buyers, especially retailers, have to place orders with manufacturers or wholesalers for individual items long 
before they know what their own customers are going to demand (lyer and Bergen 1997, p. 559). As a result, retailers can have either:

- too little inventory, cramping sales potential, or

- too much inventory, resulting in forced markdowns and wasted floor space.

To avoid these problems, computerized inventory and check-out in retail outlets allow retailers to have virtually real-time information on sales and stock levels so that retailers can make day-to-day orders for more frequent, smaller deliveries (Turnquist 1993, p. 131). To profit from responding quickly to retail demand, manufacturers must reduce deviation as well as total lead time (Carter et al. 1995, p. 65). When quick response strategies work, firms enjoy an ample payoff: Johnson and Johnson's Vistakon Division secured the biggest sales in the contact lens market due to their 99.99 percent on-time (three days or less) delivery of disposable contact lenses (Steltzer 1991, pp. 37-38).

If speedy delivery of existing products is one way to capture market share, swift introduction of new products is another. A company that introduces new products faster than its competitors can enjoy a significant advantage. Vickery et al. (1995, p. 18) found the speed of new product introduction to be the most consistent predictor of business performance in the furniture industry. Vining (1994, pp. 716-718) summed up the importance of transportation service speed and reliability to new product introduction when he described Whirlpool's decision to locate its new plant in Tulsa, Oklahoma:

Transportation factors can make or break any manufacturing endeavor, especially a new plant with a new product launch. Despite the familiarity of the Whirlpool brand name, if shipments of a new line are curtailed, we risk loss of sales and decreased product recognition during the critical introduction stage.

\section{SUMMARY}

Just-in-time manufacturing caught on with U.S. manufacturers first as an inventory management system and then as a management philosophy. As such, JIT concepts have left a lasting impression on U.S. manufacturing. Specific changes include:

- significant reductions in inventory,

- commitment to a small number of trusted suppliers held to high standards of product quality and delivery reliability, and

- time-based competition in which manufacturers turn out a wide variety of products in small volumes to meet customer orders rapidly and to beat their competitors.

As firms adapt to changes in the competitive environment, they need more frequent dispatching of what are often mixed shipments (so called "milk runs") and tighter standards for on-time delivery. Roads that are frequently congested due to accidents, weather, or traffic compromise business viability by hindering inbound delivery of 
parts and supplies and outbound shipments of finished goods to customers that demand punctual delivery.

Deliveries fumbled due to poor road system performance can at worst cause a firm to lose an important contract; at best, unreliable roadways force firms to dispatch deliveries early to ensure they can meet delivery deadlines even if detained by a roadway mishap. Either situation is far from optimal for firms whose competitors do not face similar disadvantages. Depending on the severity of the problem, firms may be forced in the long run to avoid locating in areas plagued by congestion. 


\section{CHAPTER 3 JIT OPERATIONS IN IOWA}

The just-in-time (JIT) approach, as we argue in Chapter 2, is not a one-size-fits-all manufacturing method. It is instead a flexible strategy that has been implemented by U.S. businesses according to their manufacturing needs. Until now, little evidence has existed on how (or whether) lowa's businesses have JIT operations, or how JIT practices affect transportation demand in lowa. To find out the importance of delivery reliability to lowa's businesses, we surveyed central lowa manufacturers about their experiences and perceptions of the quality of motor carrier service and JIT transportation. In this chapter, a description of the survey and sample precedes the discussion of the survey's results and transportation consequences.

\section{SURVEY AND SAMPLE}

The survey questionnaire, a copy of which appears in Appendix A, has four major sections summarized in Table 3-1. The first section of the survey asked for basic facts about each firm's size (number of employees and sales revenue), location, and primary activities. Sections that followed probed for detailed information about the firm's truck transportation and the nature of JIT shipping.

Table 3-1. Survey contents

\begin{tabular}{ll}
\hline \multicolumn{1}{c}{ Section } & \multicolumn{1}{c}{ Information requested } \\
\hline Company data & Number of employees \\
& Annual sales revenue \\
& Primary products shipped \\
& Facility location(s) \\
& Primary business activities \\
Trucking activity & Expenditures \\
& Number of shipments \\
& Types of truck freight services used \\
& Carrier's on-time delivery performance \\
JIT truck transportation & Current and expected future practices \\
& JI shipment value and transit time \\
& Usual and most stringent delivery windows \\
& Likelihood and cost of late JIT deliveries \\
& Frequency and causes of late deliveries \\
Assessment of truck transportation & Perceived value of the reduction in travel \\
time variability
\end{tabular}


The survey population included all central lowa ${ }^{5}$ manufacturing firms with at least 25 employees as identified in the Thomas Registry of American Manufacturers. The response rate was approximately 34 percent, with 125 usable responses from delivered questionnaires.

More important than the overall response rate, though, is the question of response bias: do the respondents have the same characteristics as the population of businesses surveyed? Background information given in Table 3-2 shows the respondents' size and primary business activities. To test for response bias, we used the Pearson chi-square, which verified that we can infer with 90 to 95 percent confidence that our sample is representative of the targeted population based on number of employees. ${ }^{6}$

Table 3-2. Respondent profiles (percentages*)

\begin{tabular}{|c|c|c|c|c|c|c|c|c|}
\hline Business type & \multicolumn{2}{|c|}{ Sample } & \multicolumn{2}{|c|}{ Population } & \multicolumn{2}{|c|}{ Non-JIT } & \multicolumn{2}{|c|}{ JIT } \\
\hline \multicolumn{9}{|l|}{ Number of employees } \\
\hline 1 to 50 & 57 & $(45)$ & 168 & $(46)$ & 41 & $(49)$ & 16 & $(38)$ \\
\hline 51 to 100 & 33 & $(27)$ & 97 & (26) & 18 & $(22)$ & 15 & $(36)$ \\
\hline 101 to 250 & 23 & (19) & 66 & (18) & 15 & $(18)$ & 8 & (19) \\
\hline 251 to 500 & 4 & $(3)$ & 19 & (5) & 4 & (5) & 0 & - \\
\hline 501 to 1,000 & 5 & (4) & 12 & (3) & 3 & (4) & 2 & (5) \\
\hline Over 1,000 & 3 & $(2)$ & 6 & $(2)$ & 2 & $(2)$ & 1 & $(2)$ \\
\hline Total firms & 125 & & 368 & & 83 & & 42 & \\
\hline \multicolumn{9}{|l|}{ Annual sales revenue (millions \$) } \\
\hline Less than 5 & 29 & $(25)$ & - & & 19 & $(24)$ & 10 & $(25)$ \\
\hline 5 to 10 & 29 & $(25)$ & - & & 17 & $(22)$ & 12 & $(30)$ \\
\hline 10 to 50 & 38 & $(32)$ & - & & 27 & (35) & 11 & $(28)$ \\
\hline 50 to 100 & 9 & $(8)$ & - & & 5 & (6) & 4 & $(10)$ \\
\hline Greater than 100 & 13 & $(11)$ & 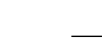 & & 10 & $(12)$ & 3 & (8) \\
\hline Total firms & 118 & & 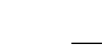 & & 78 & (99) & 40 & \\
\hline \multicolumn{9}{|l|}{ Primary activity } \\
\hline Light manufacturing & 49 & $(46)$ & - & & 32 & $(46)$ & 17 & $(47)$ \\
\hline Heavy manufacturing & 32 & $(30)$ & - & & 19 & $(27)$ & 13 & $(36)$ \\
\hline Warehouse/distribution & 12 & $(11)$ & - & & 9 & (13) & 3 & (8) \\
\hline Retail/wholesale & 6 & (6) & $\ldots$ & & 3 & (4) & 3 & (8) \\
\hline Other & 7 & (7) & $\underline{-}$ & & 7 & $(10)$ & & \\
\hline Total firms & 106 & & & & 70 & & 36 & \\
\hline
\end{tabular}

*Percentages do not always sum to 100 due to rounding.

5 The targeted population consisted of firms in Polk County and its seven neighboring counties of Boone, Dallas, Jasper, Marion, Marshall, Story, and Warren.

6 The Thomas Registry of American Manufacturers provided the number of employees for all firms in the population but did not have annual sales revenue for nearly 20 percent of the firms. Thus, the goodness-of-fit test was applied only to the number of employees. 
Almost one-half of the sample firms have 25 to 50 employees; almost three-fourths employ 100 or fewer workers. Additionally, one-half of the responding firms generate $\$ 10$ million or less annual sales revenue, and more than 80 percent generate $\$ 50$ million or less. Approximately three-fourths of the respondents reported manufacturing as their primary business activity. The sample firms produce and distribute a variety of products and, consequently, bring in myriad parts and materials to their facilities. There was no one prevalent product category or classification among the JIT firms. Similarly, there is no apparent difference in facility location pattern between the JIT and non-JIT firms. Figure 3-1 maps the location of the JIT and non-JIT respondents in the Des Moines metropolitan area.

The statistics in Table 3-2 show that the size distribution of the JIT firms is similar to that of the non-JIT firms. Based on these statistics, neither our JIT nor our non-JIT sample appears to differ radically from the overall population these samples represent.

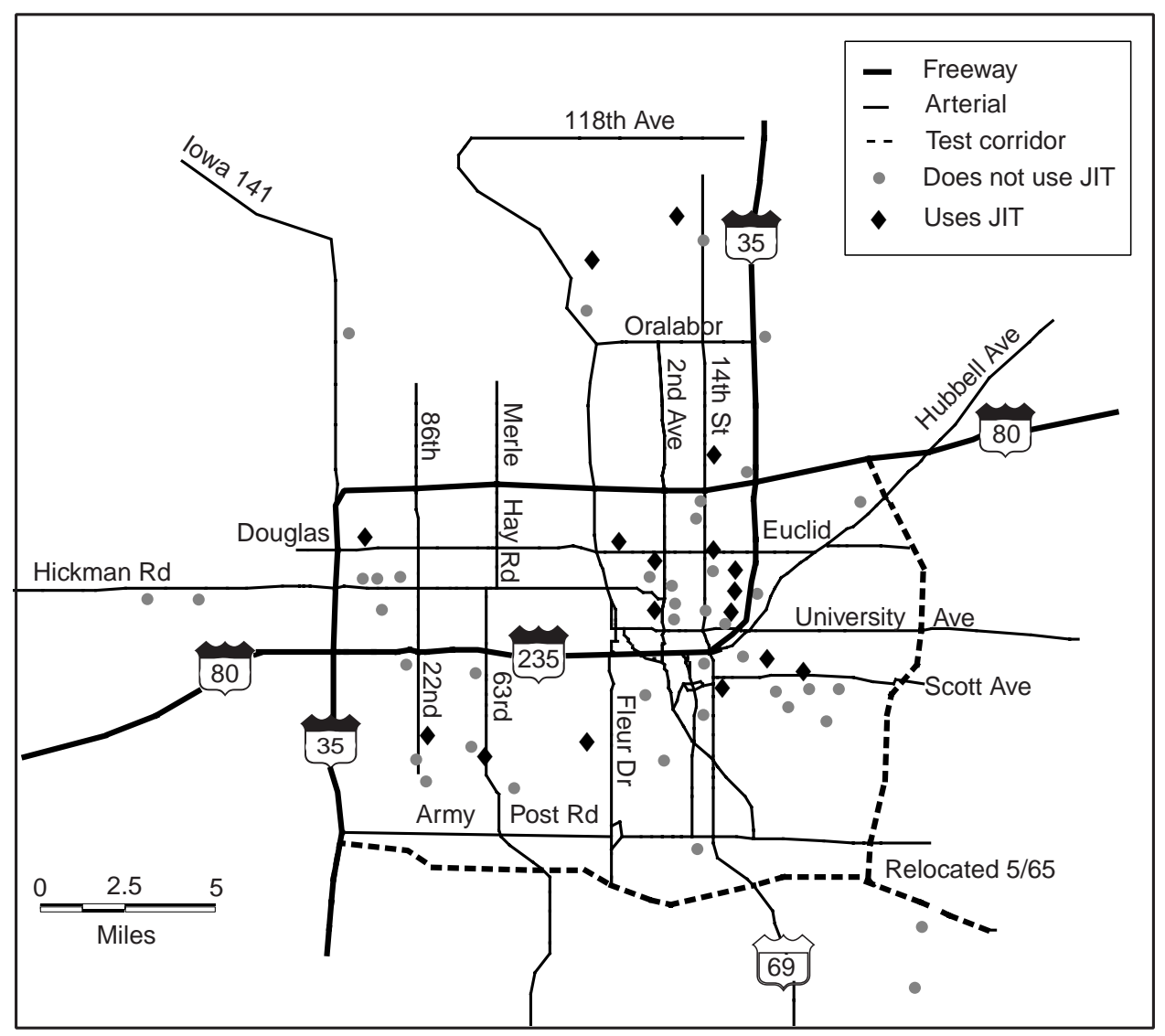

Figure 3-1. Location of JIT and non-JIT respondents in the Des Moines area 


\section{TRUCKING ACTIVITY AND SERVICE}

The survey gathered information about firms' trucking activities. For both inbound and outbound shipments, we asked firms about their total truck freight expenditure and, more specifically, about their usage of each type (e.g., truckload) of truck transportation. We also asked respondents to report their carrier's on-time performance.

The amounts in Table 3-3 show the annual expenditures reported by responding JIT and non-JIT firms. Using the midpoint of the size range as an estimate of the average expenditure (and $\$ 2.5$ million for the highest range), we can estimate the total annual expenditure for truck freight service to be about $\$ 118$ million- $\$ 46$ million for inbound shipments and $\$ 72$ million for outbound shipments. The sample firms spend a little over 50 percent more on outbound shipments than on inbound shipments.

Table 3-3. Annual truck transportation expenditures (percentages in parentheses)

\begin{tabular}{|c|c|c|c|c|c|c|c|c|}
\hline \multirow{3}{*}{$\begin{array}{l}\text { Annual expenditure } \\
\text { for freight truck } \\
\text { service (thousands } \$ \text { ) } \\
\text { Less than } 50\end{array}$} & \multicolumn{4}{|c|}{ Inbound } & \multicolumn{4}{|c|}{ Outbound } \\
\hline & \multicolumn{2}{|c|}{$\begin{array}{l}\text { No. of } \\
\text { Non-JIT } \\
\text { firms }\end{array}$} & \multicolumn{2}{|c|}{$\begin{array}{l}\text { No. of } \\
\text { JIT } \\
\text { firms }\end{array}$} & \multicolumn{2}{|c|}{$\begin{array}{l}\text { No. of } \\
\text { Non-JIT } \\
\text { firms }\end{array}$} & \multicolumn{2}{|c|}{$\begin{array}{l}\text { No. of } \\
\text { JIT } \\
\text { firms }\end{array}$} \\
\hline & 29 & (35) & 10 & $(27)$ & 21 & $(26)$ & 6 & (16) \\
\hline 50 to 100 & 16 & (20) & 4 & (11) & 10 & (13) & 7 & (19) \\
\hline 100 to 250 & 11 & (13) & 8 & $(22)$ & 15 & (19) & 6 & (16) \\
\hline 250 to 500 & 12 & (15) & 5 & (14) & 12 & (15) & 6 & (16) \\
\hline 500 to 1,000 & 6 & (7) & 8 & $(22)$ & 5 & (6) & 5 & (14) \\
\hline 1,000 to 2,500 & 2 & (2) & 0 & & 7 & (9) & 4 & (11) \\
\hline Greater than 2,500 & 6 & (7) & 2 & (5) & 10 & (13) & 3 & (8) \\
\hline Total firms & 82 & & 37 & & 80 & & 37 & \\
\hline
\end{tabular}

For-hire truckload transportation service, as illustrated in Figure 3-2, is about onethird of the inbound truck freight bill; less-than-truckload is about one-fourth. Parcel carriage is more than one-fifth of the non-JIT firms' total inbound and outbound freight bill, but only about 15 percent of the JIT firms' total truck freight bill. The JIT firms make greater use of private fleets (i.e., about 25 percent of JIT firms' total truck expenditures versus about 17 percent for non-JIT firms). The difference may reflect the JIT firms' need for greater control over available capacity and service performance. As Figure 3-2 indicates, the sample firms use truck intermodal service 


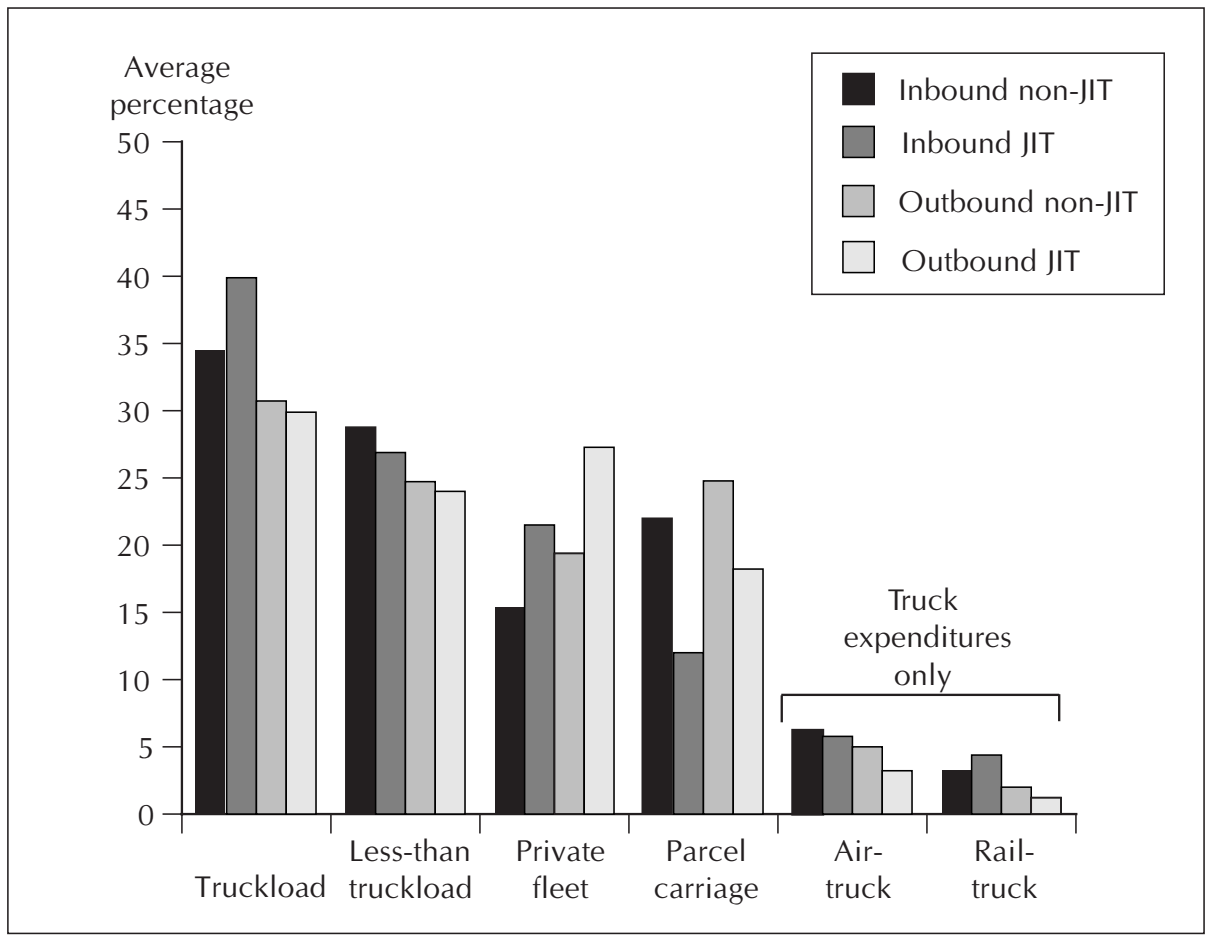

Figure 3-2. Average percentage of expenditure by type of motor carriage

far less than shipping by truck only, yet intermodal service constitutes approximately 10 percent of inbound shipping for both JIT and non-JIT shippers. ${ }^{7}$

Even though JIT and non-JIT shippers use different types of truck transportation, ontime deliveries, listed in Table 3-4, are in the high 80 percent range for both JIT and non-JIT respondents. Additionally, one-half of all respondents receive at least 95 percent average on-time delivery performance on outbound shipments. The on-time record reported by our respondents foreshadows their satisfaction with the time dependability of motor carriers expressed later in the survey.

Table 3-4. Percentage on-time delivery of all shipments

\begin{tabular}{cccccc}
\hline & \multicolumn{2}{c}{ Inbound } & & \multicolumn{2}{c}{ Outbound } \\
\cline { 2 - 3 } \cline { 5 - 6 } \cline { 5 - 6 } Non-JIT & JIT & & Non-JIT & JIT \\
\hline Median & 85.0 & 85.7 & & 88.5 & 88.9 \\
\hline
\end{tabular}

7 Freight truck intermodal service can take many forms, including trailer-on-flat-car (TOFC), container shipments joint with air, rail, or ocean vessels, and use of several modes in sequence to effect a shipment. 


\section{JUST-IN-TIME TRUCK TRANSPORTATION IN IOWA}

As noted previously, 42 respondents reported shipping on a JIT basis. The respondents whose firms base their operation on JIT principles were asked to fill out an additional section of the survey that described their firm's JIT practices and performance. Firms that have adopted JIT operations presumably have done so to increase their competitive advantage; they may, therefore, be guarded with information that could jeopardize their competitive edge. We note topics with few responses in our discussion.

Of the annual JIT shipments reported in Table 3-5, 50 percent of firms' inbound truck shipments (about 800 shipments annually) and 60 percent of outbound truck shipments (roughly 2,000 shipments annually) are on a JIT basis. Many respondents do not expect these numbers to change much over the next five years, although the median percentage for inbound shipments is expected to increase from the current 50 percent to 60 percent five years from now.

Table 3-5. Number and percentage of JIT truck shipments

\begin{tabular}{lrrrrr}
\hline & \multicolumn{2}{c}{ Inbound } & & \multicolumn{2}{c}{ Outbound } \\
\cline { 2 - 3 } \cline { 5 - 6 } JIT truck shipments & Current & $\begin{array}{c}\text { Five years } \\
\text { from now }\end{array}$ & & Current & $\begin{array}{c}\text { Five years } \\
\text { from now }\end{array}$ \\
\hline $\begin{array}{l}\text { Average number of } \\
\text { shipments }\end{array}$ & 791 & - & & 2,043 & - \\
Average percentages & 50 & 54 & & 60 & 60 \\
Median percentages & 50 & 60 & & 70 & 70 \\
\hline
\end{tabular}

Noteworthy in Table 3-5 is the imbalance between inbound and outbound shipments. Outbound shipments number almost three times as many as inbound. The respondents use JIT methods to serve their customers more than they demand JIT arrivals by their own suppliers. Experience with JIT manufacturing confirms that all firms in a JIT supply chain regulate their own manufacturing and delivery activities according to the overall just-in-time schedule, so that nowhere do large inventories occur. The disparity between inbound and outbound shipments means either that lowa's firms are stockpiling for their JIT customers (who do not want the cost of inventory) or that lowa's firms do not as yet demand JIT arrivals from their suppliers, although they may in the future. ${ }^{8}$

While the volume of JIT shipping outbound is far greater than inbound, the average inbound shipment value is congruous with the average outbound value as shown in Table 3-6. The outbound value is marginally higher (i.e., about 15 percent) than the average inbound because respondents, who are primarily manufacturers, add value to the products before shipping them out. Based on the average JIT shipment values

8 The survey did not include detailed questions about any form of transportation other than trucking. It is possible that rail or air transportation comprises a larger share of inbound than outbound shipments. Our respondents reported little confidence in intermodal JIT transportation, and it is therefore unlikely that they would entrust their own shipments to a combination of transportation modes. 
Table 3-6. JIT shipment value and transit time

\begin{tabular}{lcc}
\hline & Inbound & Outbound \\
\hline Average shipment value & $\$ 14,564$ & $\$ 16,651$ \\
Average transit time (days) & 1.94 & 1.78 \\
\hline
\end{tabular}

cited in Table 3-6 and the number of shipments from Table 3-5, we can estimate the total annual value of JIT shipments for the respondent firms as nearly $\$ 2$ billion— $\$ 484$ million for inbound shipments and \$1.429 billion for outbound shipments. ${ }^{9}$

The average transit time from Table 3-6 confirms the disparity discussed earlier between outbound and inbound JIT use. Outbound trips have on average shorter transit times than inbound. But total transit time does not measure JIT efficiency: the delivery window, the block of time during which a delivery is considered on-time, is a clearer measure of JIT discipline than overall transit time. Tight delivery windows (such as a half hour or less) are a mark of JIT discipline.

Figure 3-3 shows usual and tightest delivery windows for the JIT respondents. Fifteen percent of respondents reported usual windows of one hour or less for inbound shipments. For outbound shipments, 21 percent of the respondents reported a usual delivery window of one hour or less. Another 16 percent for inbound and 12 percent for outbound reported their usual delivery window to be between one and three hours. Finally, 22 percent of the respondents reported their tightest inbound window is one hour or less. Thirty percent of the respondents reported the same for outbound shipments. The upshot is that respondents did not confirm the extreme JIT demands found in the literature (e.g. windows of 15 minutes or less) but do face time constraints - an hour is not much time to make up for traffic delays in addition to manufacturing or planning gaffes.

Table 3-7 contains the estimated cost of a late delivery of an inbound and outbound JIT shipment. To calculate the estimates, the average on-time delivery percentages from Table 3-4 are applied to the average annual number of JIT shipments from Table 3-5. Before explaining the cost estimation methodology, we must caution that the probability and average cost data (and resulting cost estimates) come from a small number of respondents (fewer than ten) to each of these questions. With the low response rate, the cost estimates must be regarded as very rough.

The potential consequences of a late delivery listed in the first column of Table 3-7 are the most frequently cited costs of product unavailability (Coyle et al. 1996; Lambert et al. 1998). Inbound costs reflect the costs of product unavailability for the survey respondents' firms. For outbound costs, the survey respondents estimated the costs to their customers of a late shipment from the respondents' firms. One should keep in mind that the outbound costs are in a sense hearsay, but studies have shown

9 These estimates are determined by multiplying the average number of JIT shipments per year (i.e., the product of the total number of respondents shipping on JIT basis and the average number of JIT shipments per year) by the average value of a JIT shipment. 


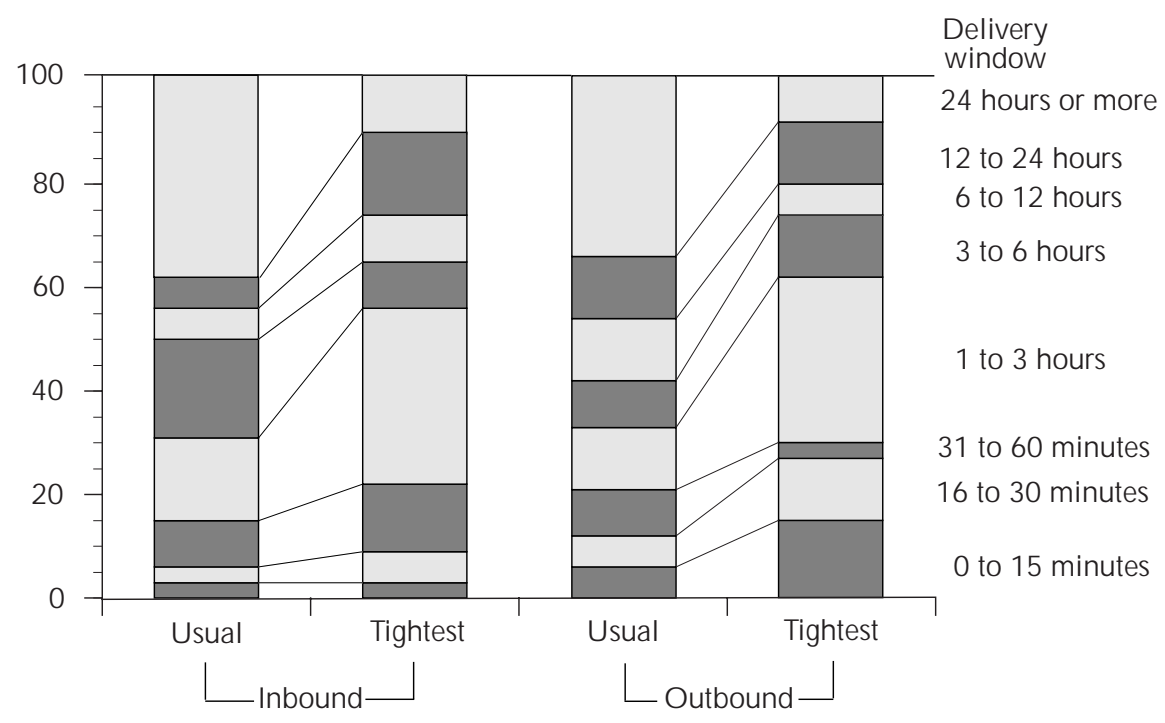

Figure 3-3. Delivery windows for JIT shipments

that JIT firms generally can predict accurately the costs to their immediate customers in a supply chain. The accuracy diminishes as firms try to estimate the costs to their customers' customers. Further, the costs shown on the outbound side may be understated, depending on where our respondents are in the supply chain. If firms early in the supply chain are tardy, it can disturb the production schedule for more than one downstream firm. The columns on the right of the table present estimates of expected cost of a late delivery, which is the product of the probability of a late delivery multiplied by the average cost.

Table 3-7. Expected cost of a late delivery

\begin{tabular}{|c|c|c|c|c|c|c|}
\hline \multirow[b]{2}{*}{ Consequences } & \multicolumn{2}{|c|}{ Probability } & \multicolumn{2}{|c|}{$\begin{array}{l}\text { Average cost } \\
\text { per event }(\$)\end{array}$} & \multicolumn{2}{|c|}{$\begin{array}{l}\text { Expected cost } \\
(\$)\end{array}$} \\
\hline & In & Out & In & Out & In & Out \\
\hline Plant shutdown & 0.023 & 0.056 & 2,889 & 4,000 & 67 & 224 \\
\hline $\begin{array}{l}\text { Production line } \\
\text { shutdown }\end{array}$ & 0.128 & 0.157 & 5,167 & 5,100 & 663 & 802 \\
\hline $\begin{array}{l}\text { Production line } \\
\text { changeover }\end{array}$ & 0.265 & 0.207 & 2,773 & 1,430 & 736 & 296 \\
\hline $\begin{array}{l}\text { Lost or } \\
\text { postponed sales }\end{array}$ & 0.146 & 0.173 & 16,167 & 57,231 & 2,365 & 9,895 \\
\hline Lose a customer & 0.054 & 0.078 & 105,500 & 243,750 & 5,676 & 18,939 \\
\hline $\begin{array}{l}\text { Expected total } \\
\text { cost }\end{array}$ & - & - & - & - & $\$ 9,507$ & $\$ 30,156$ \\
\hline
\end{tabular}

Table 3-8 presents very rough estimates of the total annual cost to the 42 lowa firms engaged in JIT operations of late shipments. To make these estimates, we multiplied 
the number of JIT shipments by the average fraction of these shipments that were late, according to survey respondents. The resulting estimate of late shipments was then multiplied by the cost estimates from Table 3-7.

Table 3-8. Annual cost estimates of late delivery of JIT shipments for 42 lowa JIT firms

\begin{tabular}{|c|c|c|c|c|c|c|}
\hline & \multirow[b]{2}{*}{$\begin{array}{c}\text { Average } \\
\text { number of } \\
\text { annual } \\
\text { shipments }\end{array}$} & \multicolumn{2}{|c|}{$\begin{array}{l}\text { Portions of } \\
\text { shipments } \\
\text { that are late }\end{array}$} & \multirow[b]{2}{*}{$\begin{array}{c}\text { Expected } \\
\text { cost } \psi\end{array}$} & \multicolumn{2}{|c|}{$\begin{array}{c}\text { Total } \\
\text { annual cost }\end{array}$} \\
\hline & & Average* & Median* & & $\begin{array}{c}\text { Based on } \\
\text { average }\end{array}$ & $\begin{array}{c}\text { Based on } \\
\text { median }\end{array}$ \\
\hline Inbound & 791 & 21.6 & 10 & $\$ 9,507$ & $\$ 1,624,328$ & $\$ 752,004$ \\
\hline Outbound & 2,043 & 15.3 & 5 & 30,156 & $9,426,132$ & $3,080,435$ \\
\hline Total cost & & & & & $\$ 11,050,460$ & $\$ 3,832,439$ \\
\hline
\end{tabular}

*These figures are derived from Table $3-4$ by subtracting the on-time deliveries from the total deliveries.

$\psi$ The expected costs are from Table 3-7.

While very approximate, the resultant estimates of $\$ 3.8$ to $\$ 11.1$ million indicate that the cost of late JIT shipments can be sizable. One must be cautious in interpreting the cost of late deliveries based on the statistics in Table 3-8 for two reasons. First, our response rate for the cost portion of the survey was so low that we cannot claim those who responded represent JIT firms as a whole. Second, the average and the median portion of late shipments are quite different; the difference suggests that some firms have tight JIT requirements, while other responding firms are not so exacting (which brings up the average but not the median portion of shipments that are late). Firms for which the costs of late shipments are great tend to have tight JIT schedules; for firms with less rigorous JIT schedules, the costs of a late shipment are not as high.

An average cost figure does not represent either type of firm but will instead overestimate the costs to a more lenient firm and underestimate the costs to a more exacting firm. The range may not be definitive, but the costs of late delivery are far from trivial—even for businesses in lowa where, we could argue, delivery performance and delivery windows are not as small as those reported elsewhere in the JIT literature.

\section{ASSESSMENT OF FACTORS AFFECTING TRUCK TRANSPORTATION SERVICE}

Respondents from both JIT and non-JIT firms were asked to indicate the frequency of late shipments due to three external causes: traffic congestion, traffic accidents, and weather. Figure 3-4 is a summary of respondents' reporting of each frequency. Only one respondent said that traffic congestion or accidents frequently cause late deliveries. Similarly, only a few respondents said they frequently had late deliveries because of weather. Traffic congestion appears to pose more of a problem to JIT 
shippers than to non-JIT shippers, as almost one-fourth indicated that they sometimes experience late deliveries for this reason (compared to about ten percent of non-JIT shippers).

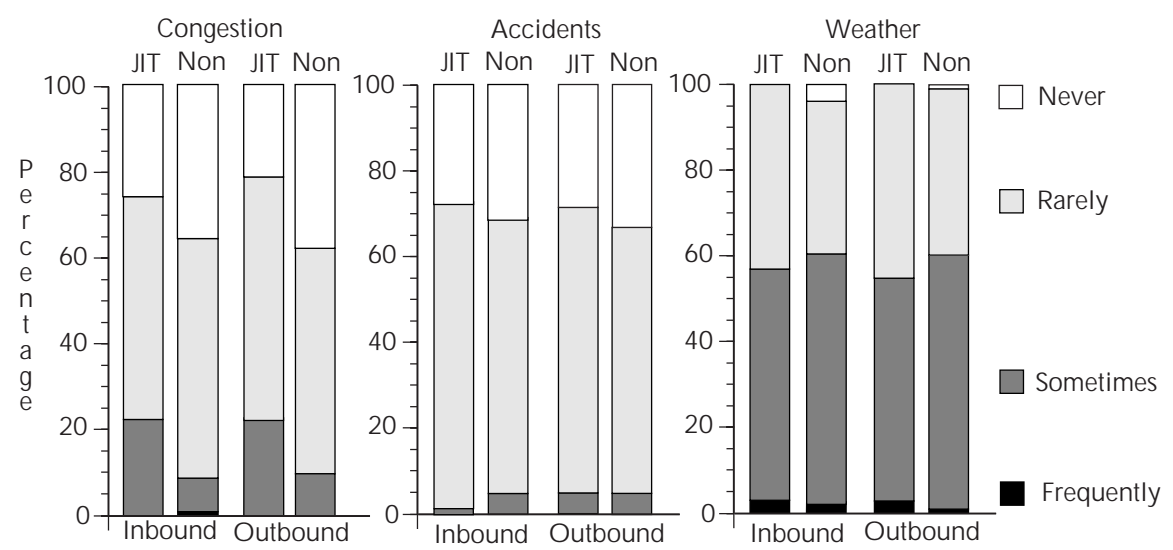

Figure 3-4. Frequency of the external causes of late shipment deliveries

We cannot conclude, however, that incidents are immaterial to shippers. If an incident is cleared before traffic moves, a driver may never discover the cause of the congestion delay. Also, respondents often were not completely familiar with the daily travails of drivers or dispatchers who may know the reasons why a particular shipment was late.

That noted, Figure 3-5 summarizes respondents' perceptions of JIT truck transportation service. The sample firms disclosed their level of agreement with each of 17 statements using a seven-point measurement scale in which:

$$
\begin{aligned}
& 1=\text { strongly agree } \\
& 4=\text { neither agree nor disagree } \\
& 7=\text { strongly disagree }
\end{aligned}
$$

The mean scores for both JIT and non-JIT respondents are shown at the ends of the bar graphs. We conducted t-tests on differences between the mean scores of the JIT and non-JIT respondents; results of these tests are indicated by asterisks in Figure 3-5.

Both JIT and non-JIT respondents agree that problems unrelated to transportation are more often the cause of late deliveries: that is, late shipments result more often from supplier-production or order-processing problems than from transportation glitches.

Non-JIT firms attribute late inbound shipments even more to suppliers than do the JIT firms. Perhaps, as the literature suggests, the JIT firms have established closer relationships with and higher time-reliability standards for their suppliers; their emphasis on managing and cooperating with suppliers has led to fewer problems with late inbound deliveries. Both sets of respondents tend to agree that delivery windows for both inbound and outbound shipments are going to get even tighter in the future. 


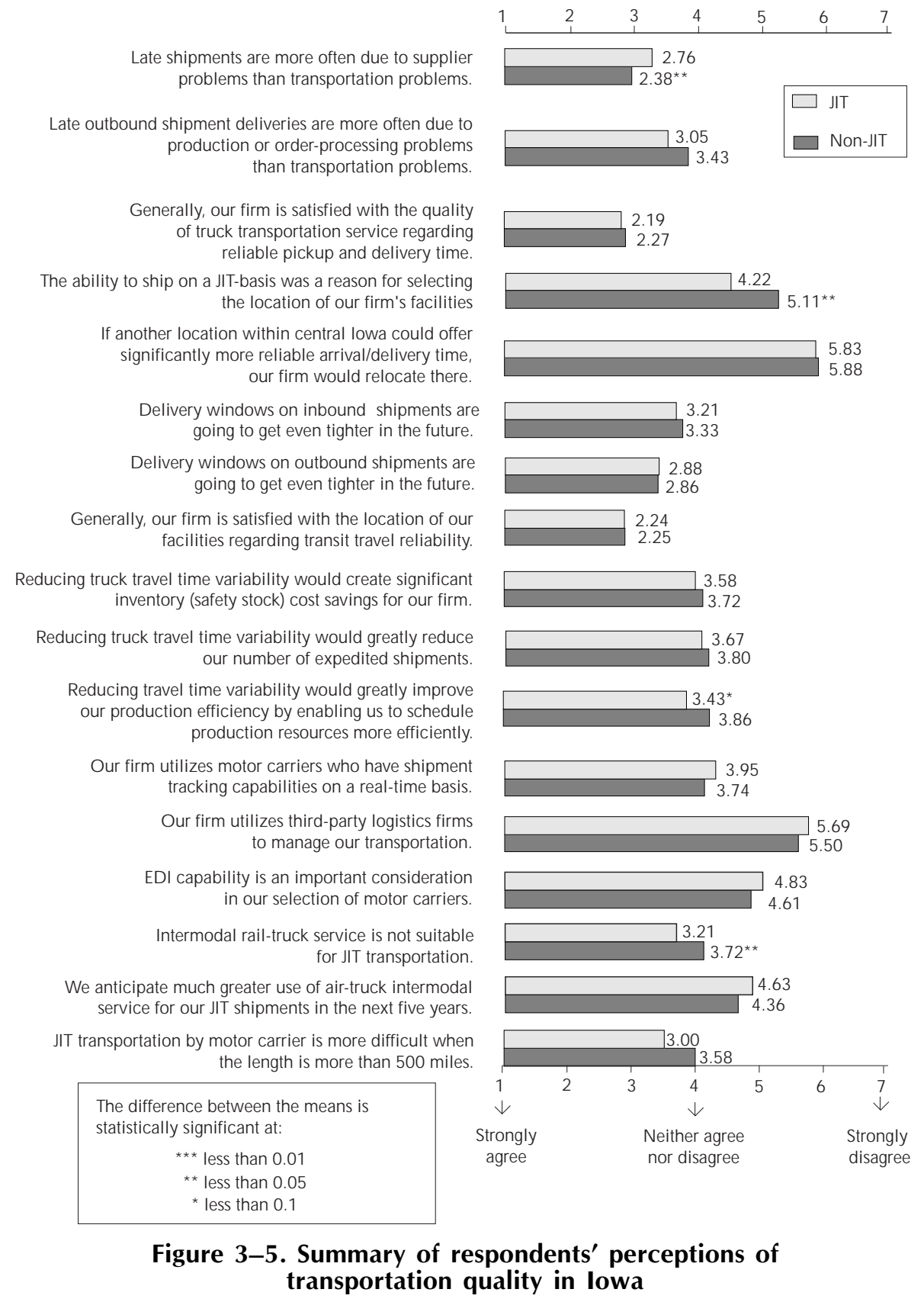

Counter to the findings of literature discussed in Chapter 2, however, is the result that neither JIT nor non-JIT respondents consider carrier real-time shipment tracking and EDI (electronic data interchange) capabilities as productive for their firms.

Both the JIT and non-JIT sample firms appear very satisfied with the quality of truck transportation service, as well as with the location of their facilities. JIT capabilities 
were not a particularly important consideration in the choice of facility location for either set of respondents (though it was more important to JIT firms); nor would respondents relocate their facilities if another central lowa location with significantly better transit time reliability were to become available. Also, the benefits of reduced truck travel time variability do not appear to be vitally important to either set of respondents, but the JIT firms tended to be more convinced about the value of reliable shipment arrival times in improved production efficiency.

Lastly, the respondents seem to view intermodal service as generally incompatible with JIT transportation. Both JIT and non-JIT firms feel that rail-truck intermodal service is not suitable for JIT operations. The JIT firms tend to hold the perception more strongly. Furthermore, neither set of respondents expects air-truck intermodal service for JIT shipments to increase substantially over the next five years. But the perception that JIT transportation by motor carrier is more difficult when the length of haul is more than 500 miles offers a potential role for intermodal JIT.

\section{SUMMARY AND CONCLUSIONS}

Currently, the customers of lowa's businesses dictate the demand for JIT operations in central lowa. The survey found consistent evidence that lowa's businesses are most likely to practice JIT production of goods they ship to others. Specifically, the survey shows:

- higher percentages of outbound than inbound shipments moving JIT;

- delivery windows that are tighter for outbound shipments;

- higher percentages of on-time delivery for outbound shipments; and

- far greater costs result from late JIT delivery_-from losing a customer and sales-than from production shutdowns in a firm's own plant.

As the sample firms become more adept at JIT operations on the outbound side, the firms may attempt to achieve the same discipline and dependability (with the attendant cost efficiencies discussed in Chapter 2) on the inbound side. Further, the results of other national logistics studies indicate that transportation service standards will continue to increase. Thus, the respondent firms and the central lowa region can be expected to require time-dependable transportation service to maximize their competitiveness.

Approximately one-third of the surveyed firms reportedly practice JIT transportation, with the total value of JIT shipments estimated to be around $\$ 2$ billion per year. While only a few firms provided information about the cost of late deliveries of JIT shipments, these costs can be quite significant for both inbound and outbound shipments. Though in general respondents do not view improvements in truck transit time variability as crucial at the present time, there are some indications that delays could become burdensome in the future. While a small number of respondents reported frequent problems with traffic congestion, accidents, or weather, almost one-fourth of the JIT respondents said they sometimes experience late shipment deliveries because of traffic congestion, and more than one-half of all respondents blamed weather for occasional late shipments. Though traffic congestion is not 
usually perceived to be a problem in a rural state like lowa, the rapid population growth and influx of new businesses in metropolitan Des Moines could result in more congestion problems in the future.

A sizable percentage of the respondents said their tightest shipment delivery windows are less than one hour, and more than half have windows of less than three hours. The current average on-time delivery percentage for inbound JIT shipments is less than 80 percent and for outbound shipments about 85 percent-already somewhat low for JIT movements. With more stringent time requirements, the percentages would decline even more unless transportation performance were to increase. Currently, both JIT and non-JIT firms tend to be satisfied with the on-time dependability of their truck transportation service and with the location of their facilities. 


\section{CHAPTER 4 TRAVEL TIME UNCERTAINTY INDUCED BY INCIDENTS}

Time-sensitive firms place a premium value on the quality and reliability of transportation facilities when evaluating prospective locations for new facilities. Planning transportation facilities that serve time-sensitive firms calls for new ways of measuring highway performance; overall travel time savings, the benchmark of highway investment analysis, may be less important to time-sensitive businesses than overall reliability of travel time. Firms operating on a tight JIT schedule, for instance, would likely trade a few minutes of extra time per trip in exchange for less variability in arrival times. The primary cause of such variability is congestion delays. Traffic congestion arises under two conditions:

- when travel demand exceeds existing road capacity, and

- when traffic incidents temporarily reduce road capacity.

The first condition usually occurs at peak periods, when the onset and duration of congestion are relatively predictable. Congestion caused by incidents is unpredictable because incidents are random and can range in severity from a disabled vehicle on the shoulder that does not reduce capacity to an overturned hazardous materials truck that can cause hours of road closure (Zografos et al. 1993, p. 535). Lindley (1986) estimated that about 60 percent of congestion delay is incident-related and only 40 percent is predictable gridlock. In addition, the Michigan Department of Transportation in 1990 reported that more than 13 percent of all accidents on freeways involved trucks (Roper 1990, p. 4). There is the potential for a "domino effect" on corridors with high volumes of truck traffic; that is, if for some reason a heavy vehicle blocks traffic on a corridor frequented by other trucks, the incident will delay many other shippers.

While numerous transportation experts have proposed strategies to alleviate incidentrelated congestion using Advanced-Traveler-Information-Systems (ATIS) and Incident Management (IM) programs (see Arnott et al. 1991; Mahmassani and Jayakrishnan 1991; and Caplice and Mahmassani 1992), Hall (1993) refined Lindley's research to show that delays would not be as lengthy if highways were not overloaded or nearing capacity. If Hall's findings are correct, a roadway project that increases capacity would allay incident-related congestion at least until traffic volumes increase and the road again reaches capacity. For instance, an incident that blocks one lane of traffic on a four-lane highway will (depending on conditions which we examine in this chapter) cause less delay than if the same incident were to occur on a two-lane exit ramp. Thus, the ability to calculate incident delays would enhance the capability of state and local planners to plan for road network capacity.

The delay caused by incidents constitutes the major part of travel time uncertainty and is the focus of our analysis. We use the arterial and freeway network in the Des 
Moines area as an example to illustrate our methodology. This methodology includes four parts:

1) developing an incident occurrence model,

2) estimating average delay caused by an incident,

3) obtaining link traffic flows through stochastic assignment, and

4) calculating delay statistics for various cases.

\section{A PROBABILISTIC MODEL FOR INCIDENT OCCURENCES AND DURATIONS}

An incident is broadly defined as a traffic event that disrupts normal traffic flow. Such events include stalled vehicles, debris on a road, a vehicle crash, or an overturned truck. The occurrence of an incident is a random event and depends on numerous factors such as road conditions, traffic volume, and road geometry.

\section{Assumptions}

Because it is not realistic to develop a probabilistic incident occurrence model that considers all possible factors (the data are not available for every road), we use empirical evidence gathered from national studies to make three simplifying assumptions when creating an incident occurrence model for our study.

- We assume that the occurrence of an incident is a rare event; its frequency observes the characteristics of a negative exponential distribution, which is a suitable distribution for data that represent the waiting time between random events (i.e., the time between traffic incidents) (Mendenhall et al. 1991, p. 145; Ross 1989, p. 209).

- We assume that all incidents on the road segment are independent and random events. This is a somewhat restrictive assumption, since the traffic disturbance generated by one incident can increase the likelihood of subsequent incidents as vehicles going freeway speeds approach the first incident. But secondary incidents usually reduce the demand for the bottleneck caused by the primary incident, and neglecting incident interdependence tends to overestimate the delay. Because the probability of multiple incidents occurring is much smaller than that of a single incident, the overestimated delay probably is negligible. Moreover, we can treat multiple incidents as independent events that occur on road segments so short in length that the likelihood is inconsequential that two incidents would occur concurrently on the same segment.

- Finally, we assume that traffic volume alone can provide a reasonable indicator of incident occurrence rates. This assumption preempts the need to collect data on the various other factors that also influence incident rates: shoulder widths, lane widths, surface materials, functional class, and so on for every road segment. While road design does affect accident rates, we analyze freeways only, and freeways are built to a specific standard. We 
therefore can assume that all freeways in the Des Moines area are similar in design and that the number of incidents varies with traffic volume only. ${ }^{10}$

\section{National incident statistics}

Because no incident database exists that contains all the necessary information for the Des Moines road network, we use incident statistics collected by a national study to develop our incident probability models. Sullivan et al. (1995) compiled freeway incident data from eight U.S. cities: Charlotte, North Carolina; Chicago, Illinois; Houston, Texas; Minneapolis, Minnesota; Los Angeles and San Francisco, California; Seattle, Washington; and Orlando, Florida. Data were collected from incident logs kept by Motorist Assistance Patrol and Highway Helper programs, from vehicle-mounted data terminals used by Freeway Service Patrols, and from major incident response reports. The authors, after examining the cities' datasets, categorized incidents into seven common types:

- abandoned vehicles;

- accidents and fires;

- debris on the highway;

- mechanical, electrical, fuel, and cooling system failures;

- stalled vehicles; ${ }^{11}$

- tire problems, and

- other, including rare hazardous materials spills or pedestrian assistance.

Once they had identified the seven types of incidents, the researchers estimated incident rates and severity (measured by the road capacity that remains following an incident; capacity remaining depends on the location and type of incident). Because data were from cities that kept detailed incident data, Sullivan et al. were able to formulate a model of incident rates using:

- climate (rainy and snowy days)

- road design

- centerline length

- number of lanes

— shoulder type (eight-foot or better shoulders on the left side, right side, both sides, or none)

$10 \mathrm{I}-235$ has several left lane exits that are nonstandard in freeway design, but the overall design standards of the freeways are consistent.

11 According to Sullivan et al. $(1995$, p. 2), vehicles out of fuel or stalled cause less severe delays than more serious vehicle system failures that require the vehicle to be towed away. For simple stalls, brief roadside attention to the vehicle can often get it running and out of the way. 
- traffic information

- two-way annual average daily traffic (AADT)

— number of peak hours per day

- percentage of weekday average daily traffic (ADT) occurring during the typical peak hour

- percentage of total peak hour traffic in the heavier direction (two or more lanes)

- percentage of peak hour traffic that consists of trucks

- ratio of average weekday traffic to AADT

As shown in Table 4-1, Sullivan et al. (1995, p. 85) have devised for freeways average incident rates (by incident type) per million vehicle miles traveled (VMT). The rates are different according to the ratio of the average daily traffic over the total road capacity. The ratio measures the level of traffic on the road: the higher the ratio, the more crowded the road and the more likely it is that incidents other than accidents and those falling into the category "other" will occur. The increase in average incident rates grows slightly as the ratio goes from seven to ten, but the rates jump when the ratio is greater than ten (when average daily traffic is ten times capacity [see Table 4-1]). The rates are higher for peak periods than for off-peak times, and the difference between periods grows as the traffic density ratio increases.

Table 4-1. Freeway incident rates as a function of $A D T / C^{*}$ (per million vehicle miles)

\begin{tabular}{|c|c|c|c|}
\hline Incident rates & $\mathrm{ADT} / \mathrm{C}<7$ & $7<\mathrm{ADT} / \mathrm{C}<10$ & $10<\mathrm{ADT} / \mathrm{C}$ \\
\hline \multicolumn{4}{|l|}{ Peak } \\
\hline Abandoned & 1.830 & 1.911 & 2.679 \\
\hline Accidents & 0.549 & 0.463 & 2.347 \\
\hline Debris & 0.127 & 0.199 & 0.538 \\
\hline Mechanical/electrical & 1.553 & 1.828 & 5.857 \\
\hline Stalled & 1.392 & 1.579 & 3.936 \\
\hline Flat tire & 1.125 & 1.392 & 3.907 \\
\hline Other & 0.773 & 0.330 & 3.295 \\
\hline Total & 7.349 & 7.702 & 22.559 \\
\hline \multicolumn{4}{|l|}{ Off-peak } \\
\hline Abandoned & 1.830 & 1.224 & 2.330 \\
\hline Accidents & 0.549 & 0.281 & 0.552 \\
\hline Debris & 0.127 & 0.131 & 0.188 \\
\hline Mechanical/electrical & 1.553 & 0.893 & 1.315 \\
\hline Stalled & 1.392 & 0.801 & 0.833 \\
\hline Flat tire & 1.125 & 0.849 & 0.912 \\
\hline Other & 0.773 & 0.248 & 0.516 \\
\hline Total & 7.349 & 4.427 & 6.646 \\
\hline
\end{tabular}

*ADT = Average daily traffic; $\mathrm{C}=$ hourly capacity.

SOURCE: Sullivan et al. (1995, Table 15). 
The most common types of incidents are abandoned and stalled vehicles, followed by mechanical and electrical system failures. The type of incident, however, is only one of a number of factors that influence traffic delay caused by incidents. For instance, a stalled vehicle located on the shoulder of a road is less of an obstacle to other motorists than a stalled vehicle blocking a lane. The duration of an incident, which depends jointly on the type of incident, the lateral location of the incident on the road, and the overall incident severity, also plays an important role in deciding incident delays.

Sullivan et al. (1995) calculated weighted averages of the frequency of each type of incident at each lateral location. Table 4-2 shows the percentage of each type of incident occurring at various road locations. Most incidents occur on the right shoulder of a road; abandoned cars, system failures, stalls, or flat tires seldom block traffic the way accidents occasionally do. About 31 percent of accidents block one lane and six percent block two lanes. Only one percent block three lanes of traffic, and less than one percent occupy all four lanes.

Table 4-2. Lateral locations of incidents and percentage of lanes blocked

\begin{tabular}{|c|c|c|c|c|c|c|c|}
\hline \multirow[b]{3}{*}{ Incident type } & \multicolumn{7}{|c|}{ Incident location (percent) } \\
\hline & \multicolumn{2}{|c|}{ Shoulder } & \multicolumn{5}{|c|}{ Number of lanes blocked } \\
\hline & Median & Right & 1 & 2 & 3 & $4+$ & Total \\
\hline Abandoned & 5.2 & 92.7 & 2.1 & 0.0 & 0.0 & 0.0 & 100 \\
\hline Accidents & 10.4 & 50.2 & 31.8 & 6.2 & 1.1 & 0.3 & 100 \\
\hline Debris & 1.4 & 25.0 & 71.1 & 2.4 & 0.0 & 0.0 & 100 \\
\hline Mechanical/electrical & 7.1 & 82.9 & 9.8 & 0.2 & 0.0 & 0.0 & 100 \\
\hline Stalled vehicles & 5.9 & 87.7 & 6.2 & 0.1 & 0.0 & 0.0 & 100 \\
\hline Flat tire & 9.7 & 87.4 & 2.8 & 0.1 & 0.0 & 0.0 & 100 \\
\hline Other & 5.0 & 90.0 & 4.6 & 0.3 & 0.0 & 0.0 & 100 \\
\hline
\end{tabular}

SOURCE: Sullivan et al. (1995, Tables 26 and 27).

The lateral location of accidents is important because the severity of an accident blocking two lanes generally is greater than an accident blocking only one lane. Location alone does not explain total capacity reduction, however. An accident on two lanes can block the entire road on a two-lane highway, while the same incident would block only half the available space on a four-lane highway.

Sullivan et al. (1995) calibrated a weighted average of the capacity remaining following incidents with evidence they found in previous research. Their results are shown in Table 4-3. Previous research (Goolsby 1971, and Lari et al. 1982) found larger capacity reductions than did Sullivan et al., who surmised the discrepancy might be due to forced merging and gawkers. The estimates of Sullivan et al. are therefore more conservative than some other empirically-based estimates. 
Table 4-3. Percent capacity remaining after incidents of different severity by number of lanes

\begin{tabular}{lrcrc}
\hline $\begin{array}{l}\text { Incident type and } \\
\text { amount of blockage }\end{array}$ & 1 & 2 & 3 & $4+$ \\
\hline $\begin{array}{l}\text { Accidents and debris } \\
\text { Median shoulder }\end{array}$ & 74.0 & 69.0 & 64.0 & 59.0 \\
Right shoulder & 85.0 & 83.0 & 81.0 & 79.0 \\
1-lane & 62.0 & 53.0 & 39.0 & 0.0 \\
2-lane & 26.7 & 18.4 & 0.0 & 0.0 \\
3-lane & 13.9 & 0.0 & 0.0 & 0.0 \\
4-lane & 0.0 & 0.0 & 0.0 & 0.0 \\
All other incidents & & & & \\
Median shoulder & 80.0 & 76.0 & 71.0 & 67.0 \\
Right shoulder & 96.0 & 90.0 & 84.0 & 78.0 \\
1-lane & 66.7 & 57.0 & 42.0 & 0.0 \\
2-lane & 28.7 & 19.8 & 0.0 & 0.0 \\
3-lane & 14.9 & 0.0 & 0.0 & 0.0 \\
4-lane & 0.0 & 0.0 & 0.0 & 0.0 \\
\hline
\end{tabular}

SOURCE: Sullivan et al. (1995, Table 28).

There are no surprises in Table 4-3. Large-capacity roads have more capacity remaining after an incident than smaller roads. Incidents that occur on the median or the shoulder reduce capacity least; even on a one-lane facility, as much as 59 percent of the capacity remains when an accident occurs on the median and 79 percent remains when an accident occurs on the right shoulder. The incident types listed in Table 4-3 include only accidents and presence of debris, and "other" types of incidents, because of the extreme improbability that an incident not in these categories will occur any place but on the shoulder or the median.

Unlike incident location and type, which are discrete variables, incident duration is a continuous variable. To make the estimation of incident delay tractable, we approximate incident duration by creating a discrete variable. We divide time into intervals (zero to nine minutes, ten to 19 minutes, etc.) and calculate the average duration for each interval as shown in Table 4-4. The probability of an average duration occurring is then taken as the probability that the continuous duration falls in the time interval where the average is taken. The resulting probabilities are displayed in Table $4-5 .^{12}$

12 Appendix B explains the methodology used in calculating the probabilities, as well as all the other calculations done for this chapter. 
Table 4-4. Average duration by type of incident (minutes)

\begin{tabular}{|c|c|c|c|c|c|c|c|c|}
\hline \multirow{2}{*}{$\begin{array}{l}\text { Duration } \\
\text { (minutes) }\end{array}$} & \multicolumn{2}{|c|}{ Accident and debris } & \multicolumn{2}{|c|}{ Accident } & \multicolumn{2}{|c|}{ Mechanical/Electrical } & \multicolumn{2}{|c|}{ Tires, stalls/other } \\
\hline & Shoulder & In-lane & Shoulder & In-lane & Shoulder & In-lane & Shoulder & In-lane \\
\hline $0-9$ & 6.2 & 6.4 & 7.5 & 7.6 & 7.9 & 7.7 & 7.2 & 7.7 \\
\hline $10-19$ & 14.6 & 14.6 & 15.2 & 15.4 & 15.5 & 15.3 & 15.0 & 15.2 \\
\hline $20-29$ & 24.6 & 24.6 & 24.8 & 24.9 & 24.9 & 24.8 & 24.7 & 24.8 \\
\hline $30-39$ & 34.6 & 34.6 & 34.7 & 34.8 & 34.7 & 34.7 & 34.7 & 34.6 \\
\hline $40-49$ & 44.7 & 44.6 & 44.7 & 44.7 & 44.7 & 44.7 & 44.7 & 44.6 \\
\hline $50-59$ & 54.7 & 54.7 & 54.7 & 54.7 & 54.7 & 54.7 & 54.7 & 54.6 \\
\hline $60-69$ & 64.7 & 64.8 & 64.7 & 64.7 & 64.7 & 64.7 & 64.7 & 64.6 \\
\hline $70-79$ & 74.7 & 74.7 & 74.7 & 74.7 & 74.7 & 74.7 & 74.7 & 74.7 \\
\hline 80-89 & 84.8 & 84.7 & 84.7 & 84.8 & 84.7 & 84.7 & 84.7 & 84.7 \\
\hline 90-99 & 94.8 & 94.8 & 94.7 & 94.8 & 94.7 & 94.7 & 94.7 & 94.7 \\
\hline $100+$ & 161.8 & 153.7 & 141.9 & 147.3 & 136.0 & 137.9 & 147.9 & 134.1 \\
\hline
\end{tabular}

The probabilities in Table 4-5 show that most incidents last 30 minutes or less from the time the incident occurs to the time it is cleared (note this does not include the time it takes for the traffic to clear). Figure 4-1 attests that some types of incidents (in this case, an abandoned vehicle or debris on the shoulder) are most likely to have durations of zero to nine, ten to 19 , or 20 to 29 minutes. The slight peak for incidents of 100 minutes or more is the accumulation of all other incidents including vehicles stalled for more than two hours to vehicles left for days.

Table 4-5. Probability of each incident duration by type and location*

\begin{tabular}{|c|c|c|c|c|c|c|c|c|}
\hline \multirow{2}{*}{$\begin{array}{l}\text { Duration } \\
\text { (minutes) }\end{array}$} & \multicolumn{2}{|c|}{ Accident and debris } & \multicolumn{2}{|c|}{ Accident } & \multicolumn{2}{|c|}{ Mechanical/Electrical } & \multicolumn{2}{|c|}{ Tires/stalls/other } \\
\hline & Shoulder & In-lane & Shoulder & In-lane & Shoulder & In-lane & Shoulder & In-lane \\
\hline $0-9$ & 0.25 & 0.23 & 0.06 & 0.04 & 0.04 & 0.06 & 0.10 & 0.07 \\
\hline $10-19$ & 0.26 & 0.28 & 0.22 & 0.17 & 0.19 & 0.22 & 0.24 & 0.25 \\
\hline $20-29$ & 0.16 & 0.17 & 0.21 & 0.19 & 0.22 & 0.22 & 0.20 & 0.23 \\
\hline $30-39$ & 0.10 & 0.10 & 0.15 & 0.15 & 0.17 & 0.16 & 0.14 & 0.16 \\
\hline $40-49$ & 0.06 & 0.06 & 0.11 & 0.12 & 0.12 & 0.11 & 0.09 & 0.10 \\
\hline $50-59$ & 0.04 & 0.04 & 0.07 & 0.08 & 0.08 & 0.07 & 0.06 & 0.06 \\
\hline $60-69$ & 0.03 & 0.03 & 0.05 & 0.06 & 0.06 & 0.05 & 0.04 & 0.04 \\
\hline $70-79$ & 0.02 & 0.02 & 0.03 & 0.04 & 0.04 & 0.03 & 0.03 & 0.03 \\
\hline $80-89$ & 0.02 & 0.01 & 0.02 & 0.03 & 0.03 & 0.02 & 0.02 & 0.02 \\
\hline $90-99$ & 0.01 & 0.01 & 0.02 & 0.02 & 0.02 & 0.02 & 0.02 & 0.01 \\
\hline $100+$ & 0.05 & 0.04 & 0.05 & 0.08 & 0.05 & 0.04 & 0.05 & 0.03 \\
\hline
\end{tabular}

*Probabilities may not sum to exactly 1.0 by column because of rounding.

Incident duration is not a synonym for delay; how long a vehicle sits on the shoulder, for instance, is not by itself a measure of how much delay motorists endure. Delay 


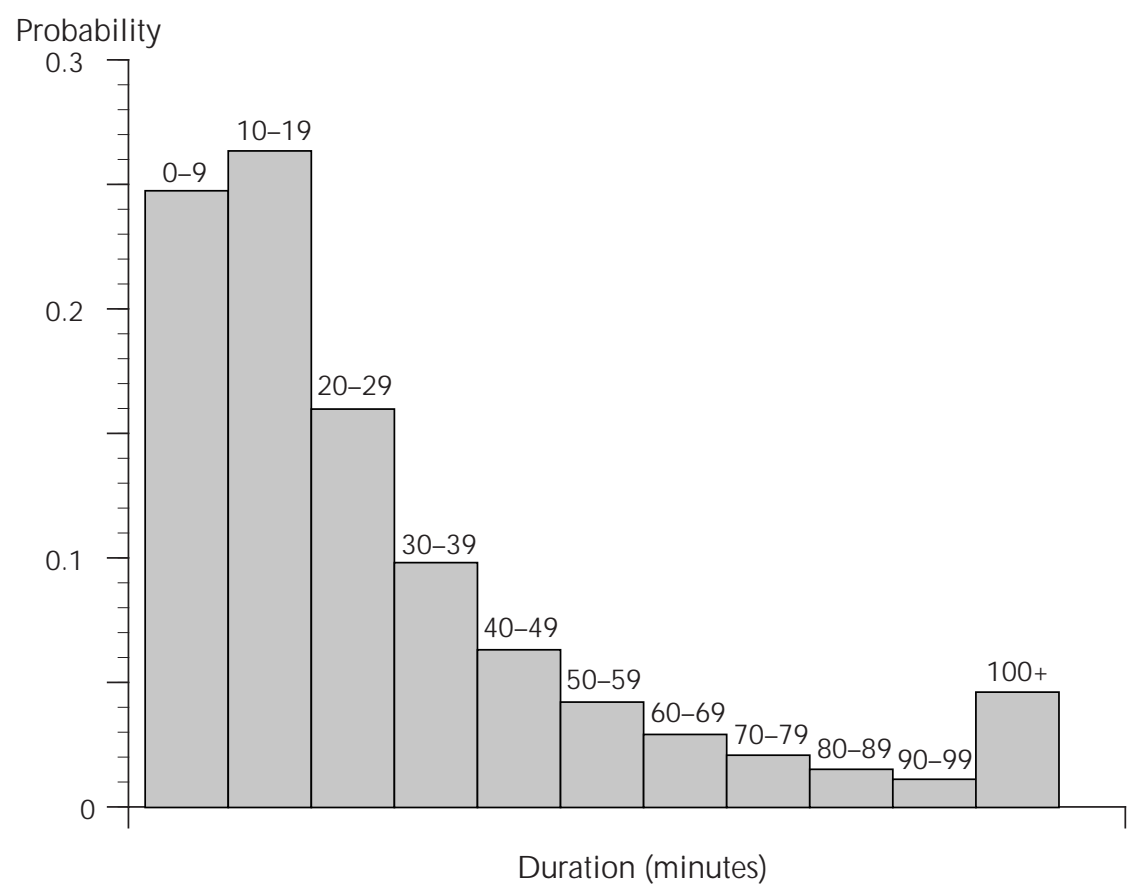

Figure 4-1. Probability of incident duration: abandonment and debris located on the shoulder

calculation, based on the conditional probabilities discussed in this section, is the next step in the analysis of travel time uncertainty.

\section{CALCULATION OF DELAY}

The total delay caused by an incident can be found using deterministic queuing theory. Referring to Figure 4-2, C is the design capacity (flow rate) of the road, A is the arrival traffic flow rate-that is, the rate at which cars arrive at the incident location - and $\mathrm{R}$ is the remaining road capacity. Before an incident occurs, $\mathrm{C}$ and $\mathrm{R}$ are equal and there is no delay. Similarly, when $R$ is greater than $A$, there is excess capacity on the road because vehicles are arriving at a rate that is even lower than the road's reduced capacity. But when an incident occurs and it blocks traffic for some time, the effective capacity (R) might be less than the arrival rate (A) and traffic congestion sets in.

Based on the relationship shown in Figure 4-2, the delay caused by an incident is computed using the following equation:

Equation (4-1).

$$
D_{t, l, d_{i}}=\left\{\frac{C d_{i}^{2}}{O^{2}}\left(1-\frac{R}{C}\right) \frac{A-R}{C-A}, A>R\right.
$$


where:

$D_{t, l, d_{i}}=$ total delay caused by incident type $t$ occurring at location $/$ and having duration $d_{i}$

$d_{1}=$ duration of incident $i$

$R=$ remaining capacity in vehicles per unit time

$\mathrm{C}=$ capacity in vehicles per unit time

A $=$ arrival rate in vehicles per unit time.

Total delay is proportional to the square of incident duration. To some extent, the longer the incident duration, the longer the delay, depending on the remaining capacity and the arrival rate. The larger the remaining capacity $(R)$ relative to the flow capacity ( $C$, the number of vehicles moving through the segment), the shorter the delay because the remaining capacity is sufficient for the vehicles flowing through the segment. If the difference between the arrival rate $(A)$ and the remaining capacity $(R)$ is large (i.e., more vehicles are arriving than can be handled by the remaining capacity) then vehicles can queue up and the total delay becomes longer. The function we use here can only apply to roads where capacity $(C)$ is greater than the arrival rate $(A)$; otherwise, the last term in the expression is negative.

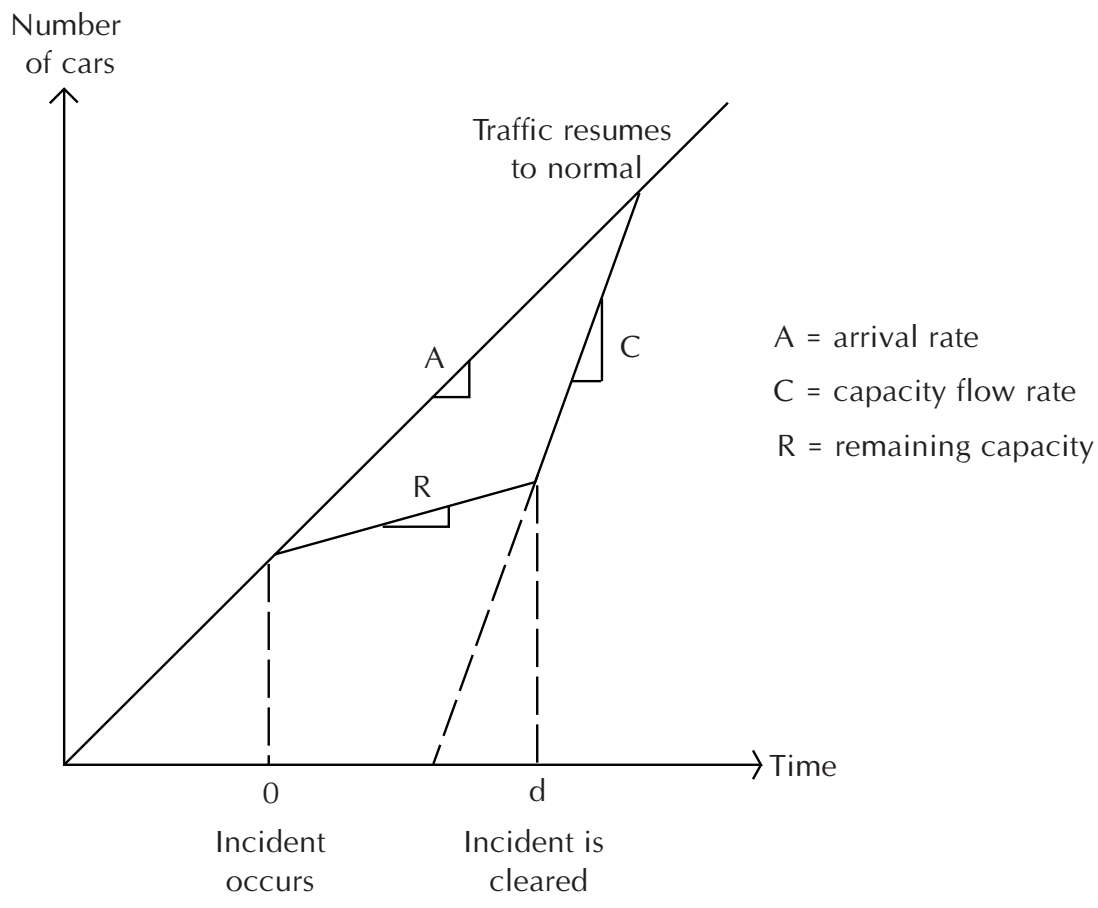

Figure 4-2. Calculation of delay caused by an incident 
Once the total delay for each incident is known, it is possible to calculate the average delay on a freeway segment. The average (or expected) delay caused by all incidents on a freeway is

Equation (4-2). $\quad D_{i m}=\sum_{t, l, d_{i}} D_{t, l, d_{i}} \times P(t, l, d \mid I)$

$P(t, l, d \mid I)$ is the conditional probability that an incident is of a specific type and occurs at a specific location and is of a specific severity and is of a specific duration given that an incident (I) has occurred. A hypothetical example is the probability that should an incident happen, it will be a stalled vehicle (type) in the right lane (location) blocking 20 percent of traffic (severity) for 25 minutes (duration).

Assuming the delay caused by each incident is not affected by other incidents, we can calculate the total delay caused by incidents per million vehicle miles traveled (VMT) by multiplying the incident rate per million VMT by the expected delay $\left(D_{i m}\right)$, yielding a measure of travel time uncertainty for a freeway link.

What remains unknown are the values of $\mathrm{A}$ (arrival rate) and $\mathrm{C}$ (capacity flow rate) in Figure $4-2$. The capacity $C$ can be obtained based on the type and geometry of the road. The arrival rate, on the other hand, is determined in the next section through traffic-assignment procedures.

\section{TRIAL APPLICATION}

As discussed in the first chapter, Highway 5/65 is currently being relocated in Des Moines, lowa, and being upgraded to freeway standards. The rerouting will provide a major east-west corridor in the southern part of Des Moines, connecting I-80 in the northeast and I-35 in the southwest. From the existing Des Moines road network, we have extracted 397 road links (comprising 84 freeway links, 203 major arterial links, and 110 centroid connectors that connect 51 centroids) and 210 nodes to form the base-year study network.

\section{Traffic analysis}

Both the base-year network and horizon-year network are coded into a computer and serve as part of the input to a stochastic assignment program that we have developed for this project. The characteristics of the network, including link length, number of lanes for each link, link capacity, free-flow speed, base-year (1990) volume count, and origin-destination (O-D) demand are from a 1990 transportation survey provided by the Des Moines Area Metropolitan Planning Organization. The O-D demand for the horizon year 2020, is obtained by applying an annual growth rate of one percent to the base-year O-D pattern. ${ }^{13} \mathrm{~A}$ skeleton of the horizon-year network and O-D districts is shown in Figure 4-3.

13 One percent is a conservative figure for traffic growth. 


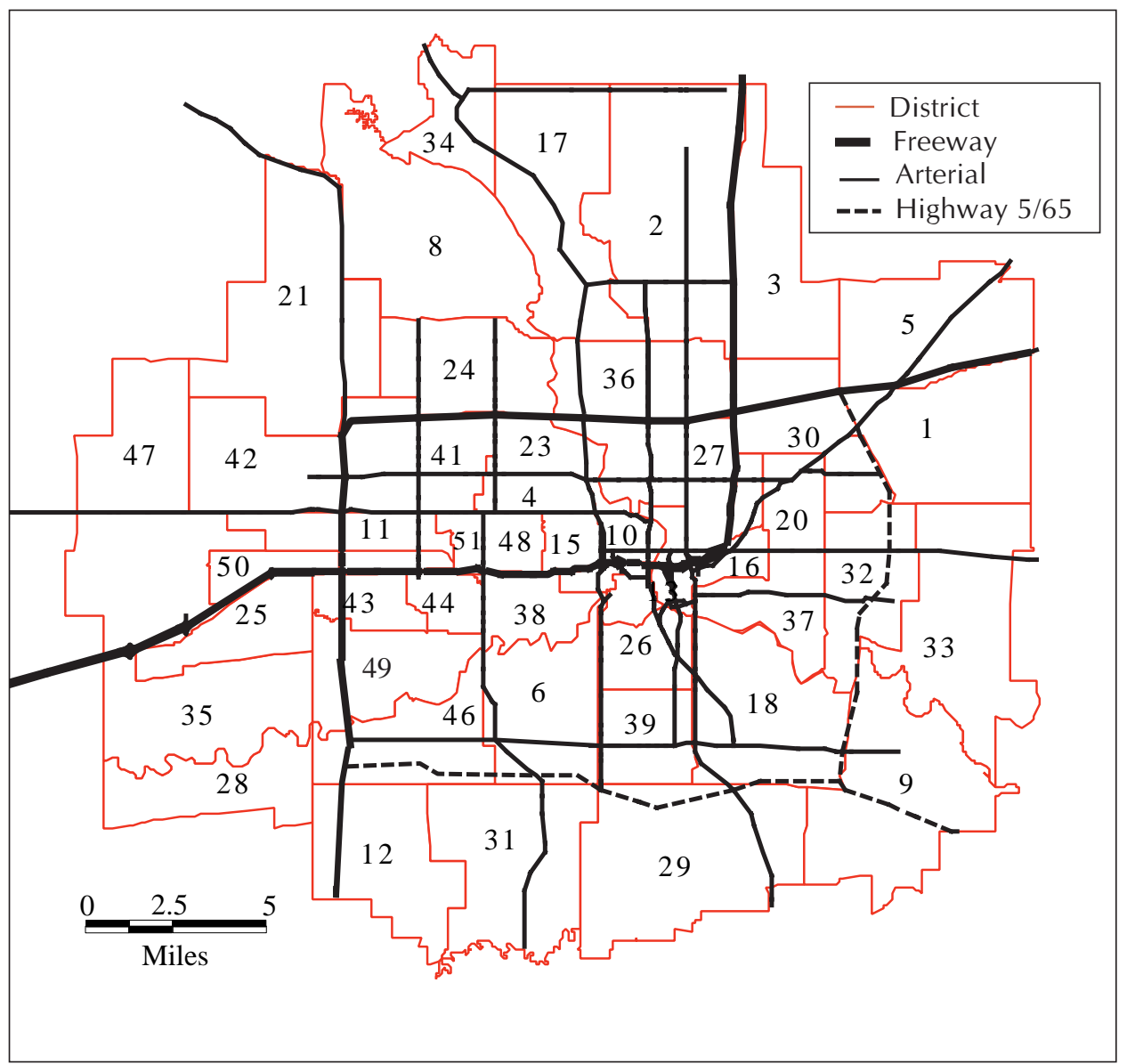

Figure 4-3. Network and O-D districts in the Des Moines area

A stochastic assignment procedure is used to assign O-D demand onto the road network. Apart from O-D demand, the information required by the assignment procedure includes:

- road capacity;

- free-flow speed (vehicle speed under ideal conditions, taken as $65 \mathrm{mph}$ on freeways and $30 \mathrm{mph}$ on arterials);

- practical capacity (the flow rate at which link travel time is approximately 115 percent of free flow link travel time); and

- a link performance function (how well the road segment is likely to serve traffic). 
The link performance function we use is from the Bureau of Public Roads (BPR). ${ }^{14}$ In the BPR function, total travel time equals free-flow travel time (the ideal) plus additional travel time that accrues in proportion to some power of the ratio of the flow rate over the road's practical capacity. The practical capacity of a link is a flow value at which the link travel time is 15 percent higher than the free-flow link travel time, or, equivalently, the link travel speed is 87 percent of the free-flow speed.

Using the speed-density relationship described in Appendix B, we can calculate the practical capacity as 0.925 times the ideal capacity.

Each lane of a road has an ideal capacity of 2,000 vehicles per hour (Transportation Research Board 1994, pp. 2-14); the capacity of a freeway is the number of lanes multiplied by 2,000 vehicles per hour. Because an arterial link has interrupted traffic, the capacity calculation is slightly more complex. Arterial capacity is the number of lanes times 2,000 vehicles per hour times the "green ratio" (the portion of time that traffic lights are green) for the arterial in question. We use a green ratio of 0.5, which is conservative for an arterial. Since freeways have no lights, a green ratio of 1.0 is a given.

To perform the static stochastic assignment, we divide the day into the four periods shown in Figure 4-4: morning peak (three hours), evening peak (five hours), midday period (six hours) and night period (ten hours). The time periods are long enough to make it likely that an incident would start and end within a single time period. We also assume that the arrival rate does not change within each period.

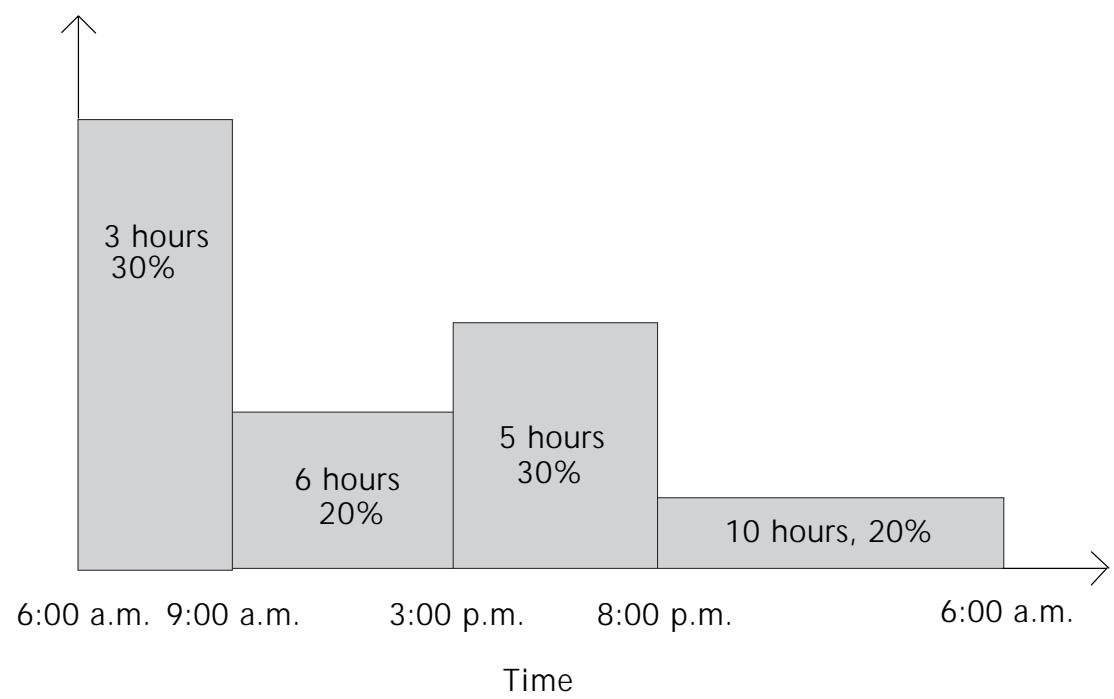

Figure 4-4. Time-of-day demand patterns

Daily traffic demand is allocated to the four time periods. The morning peak and evening peak each carry 30 percent of the total daily traffic, and the two nonpeak

14 See Sheffi (1985) for an explanation and application of the BPR function. The Bureau of Public Roads was the predecessor of the current Federal Highway Administration. 
periods each carry 20 percent of the total daily demand. Static assignment procedures are then used to obtain link flows on the study network in both the base year and the horizon year.

\section{Estimates of system delays}

We apply the methodology developed in previous sections to quantify the average incident-induced travel time uncertainties for the Des Moines network. Because we lack incident statistics on arterial streets, our travel time uncertainty model applies to freeways only. The methodology, however, can be used to develop similar models for arterial streets when arterial incident statistics become available. For each case, the average demand in the morning peak, the average capacity, and the parameters are listed in Table 4-6. Our traffic data come from a 1990 traffic survey: we estimate travel levels from 1998 to 2020 using a growth factor of one percent per year, beginning in 1990.

We calculate for each freeway link and for the entire freeway network the incidentinduced delay (travel time uncertainty) for the base and test networks. The test network includes the Highway 5/65 upgrade.

Table 4-6. Results of traffic assignment analysis and delay calculation (average segment, morning peak)

\begin{tabular}{lcccc}
\hline & \multicolumn{2}{c}{ Base network } & \multicolumn{2}{c}{ Test network } \\
\cline { 2 - 5 } & 1998 & 2020 & 1998 & 2020 \\
\hline $\begin{array}{l}\text { Average annual daily } \\
\text { traffic }\end{array}$ & 94,493 & 113,560 & 94,548 & 113,956 \\
$\begin{array}{l}\text { Average arrival rate (A) } \\
\text { (vehicles/min) }\end{array}$ & 9.9 & 35.2 & 13.5 & 35.5 \\
$\begin{array}{l}\text { Average capacity (C) } \\
\text { (vehicles/min) }\end{array}$ & 90 & 90 & 90 & 90 \\
Average A/C ratio & 0.11 & 0.39 & 0.15 & 0.39 \\
\hline
\end{tabular}

The analysis shows that on average, the test network in the horizon year will have slightly more freeway traffic than the base case by 2020 . The forecast average annual daily traffic (AADT) for the test case in 2020 is 113,956, which is roughly 400 more trips daily than for the base case. Also, the test network has more mileage than the base network, so 400 more trips means a sizeable difference between the VMT in the base and test cases.

For both the test and the base cases, trips divert to the freeways. While we assumed a metropolitan-area-wide growth rate for trips of one percent for both cases, the growth rate for both freeway networks is higher than one percent year-to-year. The growth rate on the test network is even higher than the growth rate for the base case, reflecting more diversion to the freeway network in the test case. Comparison of 
arterial trip assignment with the freeway trip assignment shows the diversion as well.

The basis for diversion to freeways is that a more complete freeway network enables more O-D pairs to be accommodated on freeways. These trips take less time than if they were made on arterials. Use of the new routes, however, results in more trips on the other segments of the freeway system - trips that otherwise would be assigned to arterials in the base case. For instance, $1-235$ is a fast, direct link to downtown Des Moines from the east and the west. Relocated Highway 5/65 provides links to I-235 and I-35/I-80 (to the west) that, unlike Army Post Road going east-west, or $14^{\text {th }}$ Street going north-south, have no traffic lights. Because the new routes draw trips to the existing freeways, there is a difference between the VMT for the busiest segment in the test case and the busiest segment in the base case. By 2020, the VMT for the busiest segment of the test case carries 136.3 million VMT annually, while for the base case the figure is 134.3 million.

What does the diversion portend for our analysis of incident-produced delays? Figure 4-5 illustrates the results of the traffic assignment analysis and the delay calculation for the highest traffic segment of both the base and the test networks. ${ }^{15}$ The results are the year-to-year averages of AADT, flow speed, travel time, and delay. The higher AADT on the test case will lead to lower speeds, greater travel times, and greater incident rates (see Table 4-1) on the freeways. As a result, the total incidentproduced delay for the entire Des Moines area freeway network is greater on the test network. Because the test network has more capacity and higher AADT, however, the average delay per VMT is lower on the test network than the base. ${ }^{16}$ Table $4-1$ shows that in general, roads with ADT/C less than ten (like most of the segments for both the base and the test networks) experience incident rates that increase at a decreasing rate with traffic volume. The growth in trips for both networks exceeds the small marginal increase in incident occurrences, and the per-VMT delay falls as trips rise until 2012, when the traffic load on the freeways reaches a critical point. In our analysis, we have assumed that save for the relocation of Highway 5/65, the freeway and arterial capacity will remain unchanged for the entire Des Moines network during the analysis period. As growth causes constraints on the network, extra capacity or traffic management measures will be necessary to avoid the increase in delay projected for 2012 and later years.

For businesses that rely on the freeways, the potential clog on the busiest segment is a warning. With the slightly higher travel times on the test network, it is possible that the freeway portion of a freight shipment could experience a greater variability in travel times on the most congested segments. Although the travel times for freeway links are forecast to increase on average for the new network, the travel

15 The same segment has the highest AADT in both the base and the test networks. The segment is located on $\mathrm{I}-235$.

16 As Figure 4-5 shows, the average delay per vehicle mile traveled due to incidents is tiny, about a thousandth of a second per VMT. The reason for the very small average value is that the preponderance of VMT do not involve any delay due to an incident, severely skewing the average values for the segment. 

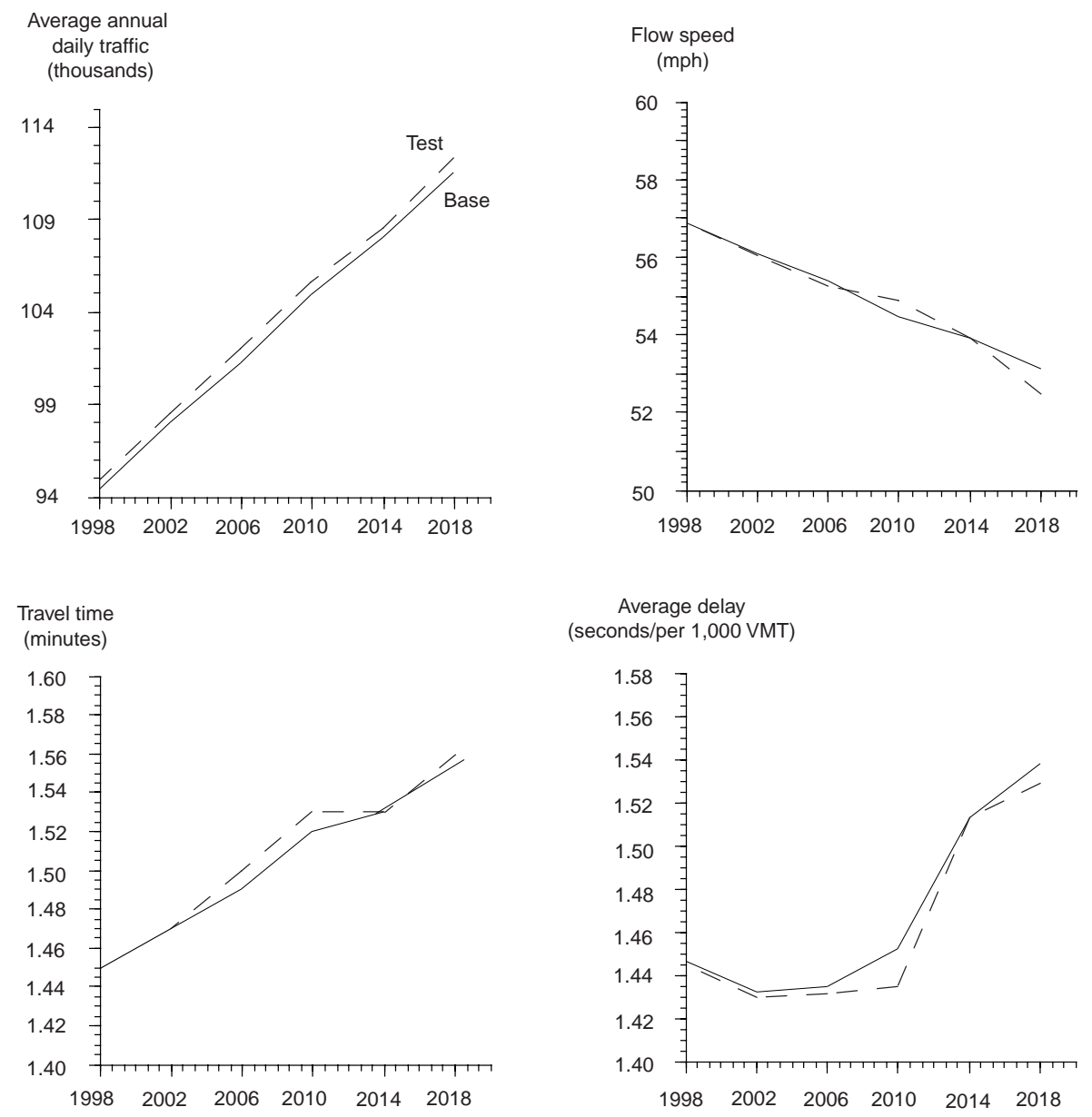

\section{Figure 4-5. AADT, flow speed, travel time, and delay} on the highest-traffic freeway segment

times on the arterials, especially those in southeastern Des Moines, on average should be lower for the new network than for the base network, due to greater diversion to freeways.

The dearth of statistics and data about incident occurrence and subsequent delays on arterials led us to examine freeways only. We are unable to show exactly how closely a decrease in trips and, therefore, incident delays on arterial streets would mirror the growth in trips and delays on the freeway system demonstrated in the test network. The freeway network with the added Highway 5/65 improvement may create very large net time savings due to substantial decreases in incident delays on arterials by redistributing traffic (and incidents) to the freeways from crowded arterials. The trips diverted to the freeways and the subsequent increase in average annual daily traffic on the freeways will cause more of both incident-produced and 
peak-hour congestion on the freeway system, but we cannot be certain of the net effects without evidence from the arterials.

The locations of businesses reporting that they have JIT operations are depicted in Figure 3-1 (see page 19). The figure shows that the test network does offer improved freeway access to those businesses with JIT operations that are clustered in the downtown area. For downtown businesses, it is possible to send trucks east and west on I-80 by taking an arterial to relocated Highway 5/65 without using I-235 or the congested north-south arterial, $14^{\text {th }}$ Street. JIT businesses nestled along $14^{\text {th }}$ Street and Euclid Avenue also are likely to benefit from decreasing incidents on those two arterial streets as traffic is diverted to the freeway system. The traffic assignment analysis shows that it is easier for freight traffic and motorists alike to travel to the Des Moines International Airport using relocated Highway 5/65.

\section{Range of delay durations}

We have constructed a range of possible delays that a firm could use to plan for its JIT routing on the Des Moines area freeway system. With a mean and standard deviation of the expected delay, for instance, a firm would be able to plan how much safety lead time is required in order to be on time for 99 percent of their trips. Unfortunately, there are no data that show what probability distribution incident delays observe; we are therefore unable to calculate a standard deviation or percentile values for delays. ${ }^{17}$

To approximate a range of likely delay values, we instead constructed three examples, including one for the worst possible delay, the smallest delay, and the delay that is most likely to occur. The results of the example delay calculations for I-235 during the morning peak are presented in Table 4-7.

The most common accident type includes minor "fender-benders" that reduce relatively little of the road's effective capacity. In such accidents, both vehicles still function, and the drivers involved can navigate their vehicles to the shoulder of the road. Because they do not disrupt traffic much, the total expected delays associated with the most common accident are quite low: by the year 2020 the total delay during the three-hour morning peak is only 2,252 minutes per million VMT on the base network and 2,281 minutes per million VMT on the test network. The pervehicle delays associated with a single accident are also very minor; 0.27 minutes per vehicle is a tap on the brakes for a motorist passing the accident.

Unlike the most common accident type, the total delay associated with the most severe accident type is great. This analysis considered the worst possible accident that could conceivably occur. An example of such an accident would be a crash involving an overturned hazardous materials truck that spills its load, blocks traffic entirely, and requires a long time to clean up. By the year 2020 the total expected

17 A probability distribution of incident-produced delays would need to include the chance that an incident may precipitate other incidents. As discussed earlier, the cumulative effects of incidents have not been measured. 
Table 4-7. Delays for various accidents and incidents during the three-hour morning peak

\begin{tabular}{|c|c|c|c|c|}
\hline \multirow[b]{2}{*}{ Incident type } & \multicolumn{4}{|c|}{ Case } \\
\hline & $\begin{array}{c}\text { Base network } \\
1990\end{array}$ & $\begin{array}{c}\text { Base network } \\
2020\end{array}$ & $\begin{array}{c}\text { Test network } \\
1990\end{array}$ & $\begin{array}{c}\text { Test network } \\
2020\end{array}$ \\
\hline \multicolumn{5}{|l|}{ Most common accident } \\
\hline $\begin{array}{l}\text { Total delay } \\
\text { (vehicle minutes per } \\
\text { million VMT) }\end{array}$ & 1,112 & 2,252 & 1,111 & 2,281 \\
\hline $\begin{array}{l}\text { Per vehicle delay } \\
\text { (minutes) }\end{array}$ & 0.16 & 0.27 & 0.16 & 0.27 \\
\hline \multicolumn{5}{|l|}{ Most severe accident } \\
\hline Total delay & $1,320,287$ & $1,607,967$ & $1,321,448$ & $1,619,460$ \\
\hline Per vehicle delay & 187 & 192 & 187 & 192 \\
\hline \multicolumn{5}{|l|}{$\begin{array}{l}\text { Most common incident: } \\
\text { Mechanical failure }\end{array}$} \\
\hline Total delay & 59,394 & 95,030 & 59,380 & 96,006 \\
\hline Per-vehicle delay & 8 & 11 & 8 & 11 \\
\hline
\end{tabular}

delay caused by the most severe accident is $1,607,967$ minutes per million VMT on the base network, or 187 minutes per vehicle (a little over three hours). For the test network, the total delay is 1,619,460 minutes, slightly higher than for the base network. Such severe accidents almost never occur, but when such an event happens, the consequences for time-sensitive motorists are considerable.

Unlike the most severe accident, mechanical and electrical failures, which are the most common incident type, occur often, but each individual event causes little delay. The accumulated delay of such frequent events is expected to delay each vehicle about eight minutes in 1990 and 11 minutes in 2020.

This last example, the most common incident, is probably the most useful for logistic planning. According to national statistics, the most common incident is a mechanical or electrical system failure. Logistics managers can know that, should an incident occur, their trip on I-235 will be delayed roughly eight minutes in 1990 and 11 minutes in 2020; to be conservative, a safety lead time of 15 minutes would cover most contingencies.

\section{CONCLUSIONS}

Our inquiry has revealed that highway improvements can have multiple and opposing effects on incident-related congestion. Many factors interact to determine the eventual delay associated with an incident. The likelihood that an incident-any kind of traffic-disturbing event-will occur at all depends on traffic volume. Some types of incidents are more likely to occur than others, however, and how long incidents muddle traffic depends on each incident's duration and the capacity that 
remains following the incident (i.e., its severity). The duration in turn depends on the location of the incident and the incident type, while the remaining capacity also depends on location and the original capacity of the road.

Using national incident statistics, we created a probabilistic incident occurrence model. Unable to justify using the freeway statistics for arterials, we obtained data for the Des Moines metropolitan area to create a skeleton road network to measure the change in delays for freeways only, with and without the relocation of Highway $5 / 65$. We used stochastic assignment procedures for the network to obtain link traffic flows. Once calculated, the traffic flow variables completed the incident-produced delay model, and it was possible to find the expected (average) delays for the freeway network for all the cases. It was also possible to examine specific segments or routes.

The results of our analysis highlight the problem of diverted demand: with the relocation of Highway 5/65, trips on Des Moines area freeways increase because of the increase in capacity on a desirable route. Because it is easier to travel to a high demand area like downtown Des Moines on the freeways rather than on arterials, the growth in trips on the high-demand portion of the freeway exceeds our assumed overall growth rate of one percent for the entire network. As traffic diverts onto the freeways, the likelihood of incidents and delay on them grows as well.

It is reasonable to conclude from our model results that relocated Highway 5/65 will help take traffic pressure-and associated incidents_off of Des Moines's most congested arterials. The safety implications are important: of the 100 most significant accident sites ${ }^{18}$ in the state from 1992 to 1996, 53 are located in Des Moines or in the metro area. Only six sites are associated with freeways or highways in Des Moines; the rest are arterials. Ten of the 100 are intersections of $14^{\text {th }}$ Street, and five are intersections of Douglas Avenue (lowa Department of Transportation, 1998). Decreasing the incidents on $14^{\text {th }}$ Street and Douglas Avenue definitely would help those JIT businesses located along those two streets meet their deadlines.

While the benefits to JIT businesses of fewer incidents on arterials are clear, we reiterate that there is no way to know how much of a net decrease in incidentcaused delay will result from redistributing traffic to the freeways. Freeways, because of their higher capacity and better design (e.g., more generous shoulders) have more capacity remaining should an accident occur; yet, if a major incident occurs on a freeway with high traffic volumes, a high arrival rate, and restricted departure, the delays can burgeon. Conversely, an arterial or a two-lane road might have less remaining capacity following an incident, but arterials also might have lower arrival rates and more alternative routes on nearby side streets so that motorists can see an incident and detour around it.

The difference between arterials, with their traffic lights and low speeds, and freeways prohibited the use of the freeway incident statistics as a proxy for those pertaining to arterials. In order to extend the method we used in this chapter, the

18 Accidents, as we discuss earlier in the chapter, are only one type of incident, but the statistics here provide an example of the implications for arterial performance of an improved freeway system. 
work done by Sullivan at al. (1995) for freeways would also need to be carried out for arterial streets. Also, using national statistics is less satisfactory than using data collected from the actual roadways we model. Several initiatives at the lowa DOT will advance our ability to model incident-produced delays. In particular, the National Model for Statewide Application of Data Collection and Management Technology to Improve Highway Safety Program will improve data acquisition for roadway incidents. ${ }^{19}$

The last analysis in this chapter developed three incident scenarios to predict a range of incident delays. On I-235, the scenarios included the smallest delay likely, the worst possible delay, and finally, the delay most likely to occur. Using the most likely delay, businesses can estimate the per-vehicle delay they are most likely to experience on I-235.

19 The National Model is sponsored by a consortium effort involving the lowa DOT, the lowa Department of Public Safety, the lowa State Patrol, and the Federal Highway Administration. 


\section{CHAPTER 5 CONCLUSIONS AND RECOMMENDATIONS}

We have stressed the great importance of freight movement in lowa's economy and concluded that minimizing variations in travel time is especially valuable to businesses using just-in-time (JIT) inventory management. To assess the effects of proposed highway investments on variation in travel time due to incident-produced delay, we have concentrated on the Des Moines area freeway system's ability to meet the needs of time-sensitive businesses. Our research addressed three basic issues:

1. Why has JIT inventory management become so important to businesses, and how does the transportation system contribute to or detract from a business's JIT performance?

2. To what extent do lowa's businesses use JIT inventory and production methods, how do businesses perceive their truck freight transportation, and what is the approximate cost of late deliveries to lowa's firms?

3. Because incident-produced congestion is a major cause of delays that confound delivery schedules, how can planners evaluate and ameliorate the number of incident-produced delays on a street network?

\section{CONCLUSIONS}

In Chapter 2 we observed that U.S. firms originally used JIT methods to escape growing inventory costs. As JIT firms began to report efficiencies and costs savings, JIT manufacturing evolved from what was essentially a Japanese production strategy to a mainstay of many U.S. firms.

Modern time-based competition emphasizes rapid shipment to market, made-to-order products, and an expanded role for information technologies such as electronic data interchange (EDI) and sophisticated logistics and inventory management systems. The consequences for the transportation system include

- frequent, smaller shipments;

- preference for higher-quality, reliable trucking and transportation services; and

- greater emphasis on reliable travel times relative to shorter travel times. 
Just-in-time operations are an important and growing aspect of many businesses in the United States. Transportation providers are vital to these operations; they must ensure that goods arrive within a closely specified time frame. Shifting emphasis to certainty of arrival requires changes in transportation planning methods.

The trends for time-sensitive businesses nationally are clear, but how are these trends affecting lowa businesses? To explore this question, we presented in Chapter 3 the results of a survey of businesses located in central lowa. Firms in lowa have customtailored JIT manufacturing and inventory methods to their own needs. Contrary to the evidence of exacting delivery windows found in the logistics literature, lowa's firms reported that on average, their tightest delivery windows were one to three hours and their on-time percentages were 78.4 inbound and 84.7 outbound. Both JIT and non-JIT firms generally consider intermodal transportation to be incompatible with JIT operations. Possibly this opinion will change as metropolitan areas in lowa like Des Moines and Cedar Rapids invest in new, efficient intermodal facilities.

In addition, firms with JIT operations reported they

- have far higher cost consequences for outbound shipments (e.g., losing sales or customers) than for inbound (e.g., closing down their own production line);

- consider weather to be the greatest obstacle to on-time deliveries, although problems with congestion do occur (albeit rarely);

- were very satisfied with their locations and trucking performances; and

- agreed that delivery windows would get tighter in the future.

lowa firms have less stringent JIT delivery windows than often is found in national studies. Nonetheless, survey results show that businesses in lowa benefit from reductions in transportation delays, especially for outbound freight.

In Chapter 4 we explored the causes of uncertainty in travel time on urban freeways. There are two fundamental causes of congestion, and thus delays, that beget uncertain travel time: demand exceeding capacity and occurrence of incidents that temporarily reduce effective road capacity. Incidents are defined as traffic events that disrupt normal traffic flow, such as stalled vehicles, debris on the road, or a vehicle crash. 
Incidents are a major source of congestion, and hence, of delay on urban freeways. The frequency of incidents, in turn, is related to traffic volume. As a freeway approaches its capacity, the likelihood of incident-prompted delays increases. The implication is that the certainty of travel time diminishes as traffic volumes increase.

We applied statistics from a national study of incidents on urban freeways to develop a probabilistic model of delays. The model enables the user to enter a standard origin-destination (O-D) matrix of trip behavior and to derive the usual estimates of VMT on a freeway segment, as well as the expected number of incidents and the associated delay. Results are calculated separately for four time periods: morning peak, midday period, afternoon peak, and evening period, both for the base year and a designated horizon year.

Our methodology was applied to the freeway system of Des Moines, lowa, with and without a major new freeway alignment, Highway 5/65. Adding this new freeway alignment led our traffic assignment model to forecast substantial increases in traffic on the freeway system. Trips assigned to arterials without the new alignment divert to the freeway system when the alignment is added. Even though trip times en route between most O-D pairs decreased with the additional freeway alignment, the number of incidents, and the total amount of incident-produced delay on freeways is higher. What we suspect, but cannot say definitively (given the paucity of data on incident delays on arterials), is that a decrease in incidents on the arterials in Des Moines more than offsets the increase in incidents on the freeways shown in this study. Researchers have yet to develop delay models for incidents on arterials; further research on incident-produced delays on arterials would broaden the benefit calculation of proposed investments on either freeways or arterials.

Improving the ability of a metropolitan freeway system to serve multiple origins and destinations may well lead to reduced travel times for many trips, but also to substantially higher traffic volumes on the entire freeway system. In large measure these increases are due to diverted arterial traffic. As a result, incident-produced delays may increase on freeways. Delays per VMT across the metro area, however, are likely to diminish.

The implications for time-sensitive industries along improved corridors such as Highway 5/65 are mixed. Increasing freeway capacity and connectivity improves the performance of the freeway system, but the gains in performance will lead to adjustments in traffic patterns. As traffic diversion to a more complete freeway system occurs, increased traffic volumes lead to more incident-related delays. Such delays reduce the certainty of arrival time at destinations served by the freeway system. 
Particularly in the long run, it is doubtful that freeway construction will greatly improve the certainty of arrival time at sites served by these freeways. Overall performance of the metropolitan road and street system may improve significantly, however. Time-sensitive industries are likely to gradually locate on the edge of the metropolitan area if arrival times at locations within the city served by freeways become less certain.

\section{RECOMMENDATIONS}

Our research has examined the role of increased freeway capacity on reliability of travel time and hence arrival time. Variability in arrival time is antithetical to JIT manufacturing or warehousing, as well as to other time-sensitive industries. Our survey showed that while JIT economic activity is not yet as prevalent in lowa as in some other areas of the U.S., it is important to the state.

To continue developing better approaches for including freight transportation in the urban planning process, we offer three recommendations that emerged during the course of our work.

1. More research should be carried out to develop urban travel demand models capable of realistically simulating the transportation of freight. Our work is a beginning, but much more research lies ahead.

Traditional travel demand models are structured to accurately represent passenger trip-making behavior. Freight flows within cities generally are sufficiently different from passenger trips to render traditional demand models inappropriate for modeling freight movements. Among the special considerations for freight modeling that need to be taken into account are:

- route constraints (e.g., some streets and roads are off limits to trucks);

- effects of economic conditions on traffic volume;

- trip generation and attraction rates of various types of industries;

- trip-chaining practices, including pick-up and delivery route optimization; and

- emerging business logistic practices.

Honing the precision of disaggregate choice models to incorporate more realistic freight demand requires that we learn more about the factors shaping the choice of route by trucks in metropolitan areas. As freight travel demand modeling methods become more distinct from passenger travel methods, it will become possible to enhance assignment models by including time-sensitive network loadings and 
departure-time decisions in addition to the work in incident-produced delay that we addressed in this study.

2. Better data about incident occurrence on other types of urban highways, arterials, and streets are needed to more accurately evaluate the effects of transportation system changes on freight movements.

Programs such as the lowa DOT's National Model for Statewide Application of Data Collection and Management Technology to Improve Highway Safety furnish the opportunity to collect a comprehensive database about incident types, severities, and the associated traffic delays. The data from the project could form a subset of the lowa DOT's PC-ALAS database currently used for accident data retrieval and analysis. ${ }^{20}$ The incident database will provide a profile of incident delays unique to the metro areas in lowa and the opportunity to develop models of incident delay on urban arterials and freeways specific to lowa's roadways using the same general methodology developed in this report.

Work has already begun on a version of ALAS on a geographical information system (GIS) platform to extend its functionality. Future applications of the GIS-ALAS system include accident estimation. As more information about incidents and incident-produced delays become available, the GIS-ALAS system could also be used to predict not only accidents, but also incidents. A study undertaken by the lowa DOT's National Program will evaluate the use of global positioning systems (GPS) to locate incidents and accidents; the success of such a system would ease the data entry burden of including incident-related data in a GIS.

As part of the incident management system discussed earlier, the Des Moines Metropolitan Area ITS Strategic Plan suggests the creation of an incident Extranet system that would provide incident responding agencies (such as police departments) with information through a restricted computer network using a standard browser (Center for Transportation Research and Education et al. 1997, pp. 113-114). As the metro areas in lowa grow, this idea could be extended to include incident delay information - as well as alternative route identification - to motorists via the Internet (rather than through a restricted network). Keeping data current is crucial if such systems are to minimize traveler delay. How information from the emergency responder could flow from the dispatcher to the database to the GIS map server and finally out to the Internet-connected public is an important area of future study. Server technology, though, continues to improve: the Environmental Systems Research Institute (ESRI), for instance, is developing a new type of Internet map server (IMS) based on current MapObjects architecture; the IMS is to work across platforms and with all of ESRI's existing mapping products. Such middleware

20 The PC-ALAS database (Accident Location and Analysis System for the PC computer) is a detailed data file on conditions present at road accidents, vehicles involved, and persons injured or killed. 
technology has great potential to expedite the communication between specialized mapping engines and the public (Harder 1998, p. 118).

3. Increased attention should be given to the location of freight generating and receiving facilities in land use planning.

Factories, warehouses, and shopping centers are among the types of land use that generate and attract substantial volumes of freight traffic. To the extent that these land uses involve time-sensitive freight transportation, conscious attention should be paid to transportation system performance. Our modeling efforts reinforce the wellknown adage that freeways and other high-capacity urban highways tend to attract diverted traffic. Ultimately, even expanded urban highways will become congested, placing into question the long-term viability of time-sensitive industries that are dependent on those highways.

In land use planning, two implications emerge. First, land use plans should avoid proximity of time-sensitive industries to other land uses that generate or attract high volumes of traffic. Second, time-sensitive industries should be located in areas where there is reasonably direct access to rural interstates. As improved freight models are developed, better predictions will be possible of how alternative land use arrangements will affect the performance of time-sensitive industries.

Modeling and anticipating changes in freight travel demand for infrastructure planning is more efficient when local areas include freight considerations in regional transportation plans, corridor studies, project funding criteria, and overall policy objectives. A metropolitan area benefits from a cohesive set of goals for freight policy and planning; such goals can include local, regional, and state economic vitality. Transportation can contribute to economic vitality by increasing the efficiency of freight movements. Positive strategies include improving productivity by reducing highway system performance degradation such as incident-produced delay and by locating time-sensitive industries in areas where dependable arrival times can be assured in the long run.

We have explored the nature of JIT business practices and the magnitude of incidentproduced delays under different traffic and network conditions. Our work is a beginning toward a more complete understanding of how urban transportation planning can facilitate time-sensitive economic activity. There is little doubt that time will become an increasingly critical factor in the economic futures of metropolitan areas in lowa. The more effectively we plan for this change, the better our prospects in the global marketplace. 


\section{APPENDIX A SURVEY INSTRUMENT}

\section{SURVEY OF TRUCK TRANSPORTATION PRACTICES AND ISSUES OF CENTRAL IOWA FIRMS}

You can be assured your specific responses to this survey will be held in strict confidence and will be reported only as part of summarizing the larger survey.

\section{Company Information}

1. Street address

2. City, zip code

3. Title of person completing this survey

4. Please list the primary products shipped from this facility (include SIC code for these products, if known)

5. Please list the primary products received at this facility (include SIC code for these products, if known)

6. During the last fiscal year, what was the approximate value of your facility's sales or output, in millions of dollars? (Check one only)

\begin{tabular}{|c|c|c|c|c|c|}
\hline $\begin{array}{c}\text { under } \$ 5 \\
\text { mil. }\end{array}$ & $\begin{array}{c}\$ 5-10 \\
\text { mil. }\end{array}$ & $\begin{array}{c}\$ 10-50 \\
\text { mil. }\end{array}$ & $\begin{array}{c}\$ 50- \\
100 \text { mil. }\end{array}$ & $\begin{array}{c}\$ 100- \\
250 \text { mil. }\end{array}$ & $\begin{array}{c}\$ 250 \\
\text { mil. }+\end{array}$ \\
\hline 29 & 29 & 38 & 9 & 5 & 8 \\
\hline
\end{tabular}


7. What is the approximate number of employees at this facility? (Check one only)

\begin{tabular}{|c|c|c|c|c|c|c|}
\hline $1-25$ & $26-50$ & $51-100$ & $101-250$ & $251-500$ & $\begin{array}{l}501- \\
1,000\end{array}$ & $\begin{array}{c}\text { Over } \\
1,000\end{array}$ \\
\hline 24 & 33 & 33 & 23 & 4 & 5 & 3 \\
\hline
\end{tabular}

8. Which of the following best describes the functions of your facility?

(Check more than one if necessary)

\begin{tabular}{|c|c|c|c|c|c|c|}
\hline $\begin{array}{c}\text { Light } \\
\text { manufacturing }\end{array}$ & $\begin{array}{c}\text { Heavy } \\
\text { manufacturing }\end{array}$ & $\begin{array}{c}\text { Warehousing/ } \\
\text { distribution }\end{array}$ & $\begin{array}{c}\text { Retailing or } \\
\text { wholesaling }\end{array}$ & $\begin{array}{c}\text { Finance/real } \\
\text { estate/insurance }\end{array}$ & $\begin{array}{c}\text { Public } \\
\text { utility }\end{array}$ & $\begin{array}{c}\text { Other - } \\
\text { specify }\end{array}$ \\
\hline 41 & 36 & 28 & 10 & 0 & 0 & 9 \\
\hline
\end{tabular}

\section{Nature and Level of Trucking Activity}

1. During the last fiscal year, what were the approximate truck transportation costs incurred for shipping products to (inbound) and from (outbound) your facility?

(Check one range for inbound and one range for outbound.)

\begin{tabular}{|l|c|c|c|c|c|c|c|}
\hline & $\begin{array}{c}\text { Under } \\
\mathbf{\$ 5 0 , 0 0 0}\end{array}$ & $\begin{array}{c}\mathbf{\$ 5 0 , 0 0 0}- \\
\mathbf{\$ 1 0 0 , 0 0 0}\end{array}$ & $\begin{array}{c}\mathbf{\$ 1 0 0 , 0 0 0}- \\
\mathbf{\$ 2 5 0 , 0 0 0}\end{array}$ & $\begin{array}{c}\mathbf{\$ 2 5 0 , 0 0 0}- \\
\mathbf{\$ 5 0 0 , 0 0 0}\end{array}$ & $\begin{array}{c}\mathbf{\$ 5 0 0 , 0 0 0}- \\
\mathbf{\$ 1} \text { million }\end{array}$ & $\begin{array}{c}\mathbf{\$ 1} \text { million- } \\
\mathbf{\$ 2 . 5} \text { mil. }\end{array}$ & $\begin{array}{c}\text { Above } \\
\mathbf{\$ 2 . 5} \text { mil. }\end{array}$ \\
\hline Inbound & 21 & 20 & 19 & 17 & 14 & 2 & 8 \\
\hline Outbound & 13 & 17 & 21 & 18 & 10 & 11 & 13 \\
\hline
\end{tabular}

2. Of your facility's total annual expenditures on truck transportation, approximately what percentage is spent on each of the following? (Please round to the nearest percentage.)

\begin{tabular}{|l|cc|cc|}
\hline & \multicolumn{2}{|c|}{ Inbound } & \multicolumn{2}{c|}{ Outbound } \\
\hline For-hire truckload (TL) & Ave: 36.1 & Med: 20.0 & Ave: 30.42 & Med: 10.0 \\
\hline For-hire less-than-truckload (LTL) & 28.2 & 17.5 & 24.4 & 10.0 \\
\hline Private fleet & 17.3 & 0 & 22.0 & 0 \\
\hline Parcel carriage (e.g., UPS, FedEx) & 18.8 & 5.0 & 22.6 & 8.0 \\
\hline
\end{tabular}


3. Approximately what percentage of your total annual expenditures on truck transportation is spent on each of the following? (Please round to the nearest percentage.)

\begin{tabular}{|c|c|c|c|c|}
\hline & \multicolumn{2}{|c|}{ Inbound } & \multicolumn{2}{c|}{ Outbound } \\
\hline Air-truck intermodal shipments & Ave 6.1 & Med: 0 & Ave: 4.5 & Med: 0 \\
\hline Rail-truck intermodal shipments & 3.5 & 0 & 1.8 & 0 \\
\hline Truck only shipments & 87.6 & 100 & 100 & 88.1 \\
\hline TOTAL & $\mathbf{1 0 0}$ & & $\mathbf{1 0 0}$ & \\
\hline
\end{tabular}

4. During the most recent fiscal year, what was the approximate number of truck shipments to and from your facility?

\begin{tabular}{|l|c|c|}
\hline & \multicolumn{1}{|c|}{ Inbound } & \multicolumn{2}{c|}{ Outbound } \\
\hline $\begin{array}{l}\text { Approximate number of } \\
\text { shipments last fiscal year }\end{array}$ & Ave: 1,969 Med: 520 & Ave: 7,365 Med: 1,225 \\
\hline
\end{tabular}

5. What is the average percentage of shipments by truck that arrive by the scheduled delivery time? (Please indicate average percentage for both inbound and outbound shipments by truck.)

\begin{tabular}{|l|c|c|}
\hline & \multicolumn{1}{|c|}{ Inbound } & \multicolumn{2}{c|}{ Outbound } \\
\hline $\begin{array}{l}\text { Average percentage of } \\
\text { shipments that are delivered } \\
\text { on time }\end{array}$ & Ave: $85.2 \quad$ Med: 90.0 & Ave: $88.6 \quad$ Med: 95.0 \\
\hline
\end{tabular}

\section{Just-in-Time (JIT) Truck Transportation}

The questions in this section refer to shipments made on a just-in-time (JIT) basis. If you do not ship on a JIT-basis by truck to or from this facility, please skip ahead to the next section of the survey (Section IV. Assessment of Factors Affecting Truck Transportation Service).

1. What is the current percentage of truck shipments that occur on a JIT basis and what is the expected percentage five years from now? (Please round to the nearest percentage.)

\begin{tabular}{|l|c|c|}
\hline & \multicolumn{1}{|c|}{ Inbound } & \multicolumn{2}{c|}{ Outbound } \\
\hline $\begin{array}{l}\text { Current percentage of truck } \\
\text { shipments on JIT basis }\end{array}$ & Ave: $49.9 \quad$ Med: 50.0 & Ave: $60.0 \quad$ Med: 70.0 \\
\hline $\begin{array}{l}\text { Expected percentage on JIT } \\
\text { basis five years from now }\end{array}$ & Ave: $53.7 \quad$ Med: 60.0 & Ave: $59.9 \quad$ Med: 70.0 \\
\hline
\end{tabular}


2. Please estimate the average shipment value for your JIT inbound and outbound shipments, and the average transit time in days for each.

\begin{tabular}{|l|l|lc|}
\hline & \multicolumn{1}{|c|}{ Inbound } & \multicolumn{2}{c|}{ Outbound } \\
\hline $\begin{array}{l}\text { Average shipment value } \\
\text { per JIT shipment }\end{array}$ & Ave: $\$ 14,564 \quad$ Med: $\$ 6,500$ & Ave: $\$ 16,651 \quad$ Med: $\$ 8,000$ \\
\hline $\begin{array}{l}\text { Average transit time in } \\
\text { days per JIT shipment }\end{array}$ & Ave: $1.94 \quad$ Med: 2.0 & Ave: 1.78 & Med: 1.75 \\
\hline
\end{tabular}

3. Please indicate the average or usual delivery time windows for your inbound and outbound JIT shipments and the tightest or most demanding delivery time windows for these shipments.

\begin{tabular}{|l|c|c|c|c|c|c|c|c|}
\hline & $\begin{array}{c}\mathbf{0 - 1 5} \\
\text { min. }\end{array}$ & $\begin{array}{c}\mathbf{1 6 - 3 0} \\
\text { min. }\end{array}$ & $\begin{array}{c}\mathbf{3 1 - 6 0} \\
\text { min. }\end{array}$ & $\begin{array}{c}\mathbf{1 - 3} \\
\text { hrs. }\end{array}$ & $\begin{array}{c}\mathbf{3 - 6} \\
\text { hrs. }\end{array}$ & $\begin{array}{c}\mathbf{6 - 1 2} \\
\text { hrs. }\end{array}$ & $\begin{array}{c}\mathbf{1 2 - 2 4} \\
\text { hrs. }\end{array}$ & $\begin{array}{c}\mathbf{2 4} \\
\text { hrs. }\end{array}$ \\
\hline $\begin{array}{l}\text { Usual delivery } \\
\text { window, inbound JIT }\end{array}$ & 1 & 1 & 3 & 5 & 6 & 2 & 2 & 12 \\
\hline $\begin{array}{l}\text { Tightest delivery } \\
\text { window, inbound JIT }\end{array}$ & 1 & 2 & 4 & 11 & 3 & 3 & 5 & 3 \\
\hline $\begin{array}{l}\text { Usual delivery } \\
\text { window, outbound JIT }\end{array}$ & 1 & 2 & 3 & 4 & 3 & 4 & 4 & 12 \\
\hline $\begin{array}{l}\text { Tightest delivery } \\
\text { window, outbound JIT }\end{array}$ & 1 & 4 & 1 & 11 & 4 & 2 & 4 & 3 \\
\hline
\end{tabular}

4. What percentage of the time does each of the following occur when your firm experiences a late delivery of an inbound JIT shipment (please check one box for each), and (if known) what is the approximate average cost of each?

\begin{tabular}{|c|c|c|c|c|c|c|c|}
\hline \multirow{2}{*}{$\begin{array}{l}\text { Consequence of a late } \\
\text { delivery of inbound } \\
\text { JIT shipment }\end{array}$} & \multicolumn{6}{|c|}{ How often does this occur? } & \multirow{2}{*}{$\begin{array}{l}\text { Approximate } \\
\text { average cost }\end{array}$} \\
\hline & $0 \%$ & $1-25 \%$ & $26-50 \%$ & $51-75 \%$ & $76-99 \%$ & $100 \%$ & \\
\hline Plant shutdown & 23 & 5 & 0 & 0 & 0 & 0 & $\begin{array}{l}\text { Ave: } \$ 2,888 \\
\text { Med: } \$ 0\end{array}$ \\
\hline $\begin{array}{l}\text { Production line } \\
\text { shutdown }\end{array}$ & 10 & 15 & 3 & 1 & 0 & 0 & $\begin{array}{l}\text { Ave: } \$ 5,166 \\
\text { Med: } \$ 2,750\end{array}$ \\
\hline $\begin{array}{l}\text { Production line } \\
\text { changeover }\end{array}$ & 8 & 20 & 25 & 28 & 29 & 31 & $\begin{array}{l}\text { Ave: } \$ 2,773 \\
\text { Med: } \$ 1,500\end{array}$ \\
\hline $\begin{array}{l}\text { Lost or postponed } \\
\text { sales }\end{array}$ & 8 & 17 & 1 & 1 & 1 & 0 & $\begin{array}{l}\text { Ave: } \$ 16,166 \\
\text { Med: } \$ 3,500\end{array}$ \\
\hline Lose a customer & 17 & 12 & 0 & 0 & 0 & 0 & $\begin{array}{l}\text { Ave: } \$ 105,500 \\
\text { Med: } \$ 0\end{array}$ \\
\hline
\end{tabular}


5. What percentage of the time does each of the following occur when your firm experiences a late delivery of an outbound JIT shipment (please check one box for each), and (if known) what is the approximate cost of each?

\begin{tabular}{|c|c|c|c|c|c|c|c|}
\hline \multirow{2}{*}{$\begin{array}{l}\text { Consequence of a late } \\
\text { delivery of outbound } \\
\text { JIT shipment }\end{array}$} & \multicolumn{6}{|c|}{ How often does this occur? } & \multirow{2}{*}{$\begin{array}{l}\text { Approximate } \\
\text { average cost }\end{array}$} \\
\hline & $0 \%$ & $1-25 \%$ & $26-50 \%$ & $51-75 \%$ & $76-99 \%$ & $100 \%$ & \\
\hline Plant shutdown & 19 & 10 & 1 & 0 & 0 & 0 & $\begin{array}{l}\text { Ave: } \$ 4,000 \\
\text { Med: } \$ 0\end{array}$ \\
\hline $\begin{array}{l}\text { Production line } \\
\text { shutdown }\end{array}$ & 11 & 13 & 4 & 1 & 1 & 0 & $\begin{array}{l}\text { Ave: } \$ 5,100 \\
\text { Med: } \$ 1\end{array}$ \\
\hline $\begin{array}{l}\text { Production line } \\
\text { changeover }\end{array}$ & 12 & 22 & 25 & 28 & 29 & 30 & $\begin{array}{l}\text { Ave: } \$ 1,430 \\
\text { Med: } \$ 150\end{array}$ \\
\hline $\begin{array}{l}\text { Lost or postponed } \\
\text { sales }\end{array}$ & 7 & 19 & 3 & 0 & 2 & 0 & $\begin{array}{l}\text { Ave: } \$ 57,230 \\
\text { Med: } \$ 10,000\end{array}$ \\
\hline Lose a customer & 14 & 15 & 1 & 0 & 0 & 0 & $\begin{array}{l}\text { Ave: } \$ 243,750 \\
\text { Med: } \$ 225,000\end{array}$ \\
\hline
\end{tabular}

6. What is the average percentage of on-time delivery for all inbound and outbound JIT shipments by truck?

\begin{tabular}{|l|c|c|}
\hline & \multicolumn{1}{|c|}{ Inbound } & \multicolumn{2}{c|}{ Outbound } \\
\hline $\begin{array}{l}\text { Average percentage of on- } \\
\text { time delivery of JIT shipments }\end{array}$ & Ave: $98.43 \% \quad$ Med: $90.0 \%$ & Ave: $84.71 \% \quad$ Med: $95 \%$ \\
\hline
\end{tabular}

\section{Assessment of Factors Affecting Truck Transportation Service}

1. Please indicate how often each of the following contributes to the late inbound deliveries your firm experiences. (Please check one box for each.)

\begin{tabular}{|l|c|c|c|c|}
\hline & Frequently & Sometimes & Rarely & Never \\
\hline Transit delays due to traffic congestion on highways & 1 & 15 & 66 & 37 \\
\hline Transit delays due to traffic accidents on highways & 0 & 5 & 80 & 34 \\
\hline Transit delays due to adverse weather & 3 & 69 & 46 & 2 \\
\hline
\end{tabular}


2. Please indicate how often each of the following contributes to the late outbound deliveries your firm experiences. (Please check one box for each.)

\begin{tabular}{|l|c|c|c|c|}
\hline & Frequently & Sometimes & Rarely & Never \\
\hline Transit delays due to traffic congestion on highways & 0 & 17 & 65 & 37 \\
\hline Transit delays due to traffic accidents on highways & 0 & 6 & 77 & 36 \\
\hline Transit delays due to adverse weather & 2 & 69 & 48 & 1 \\
\hline
\end{tabular}

3. Please indicate your level of agreement with each of the following statements by checking the appropriate box for each.

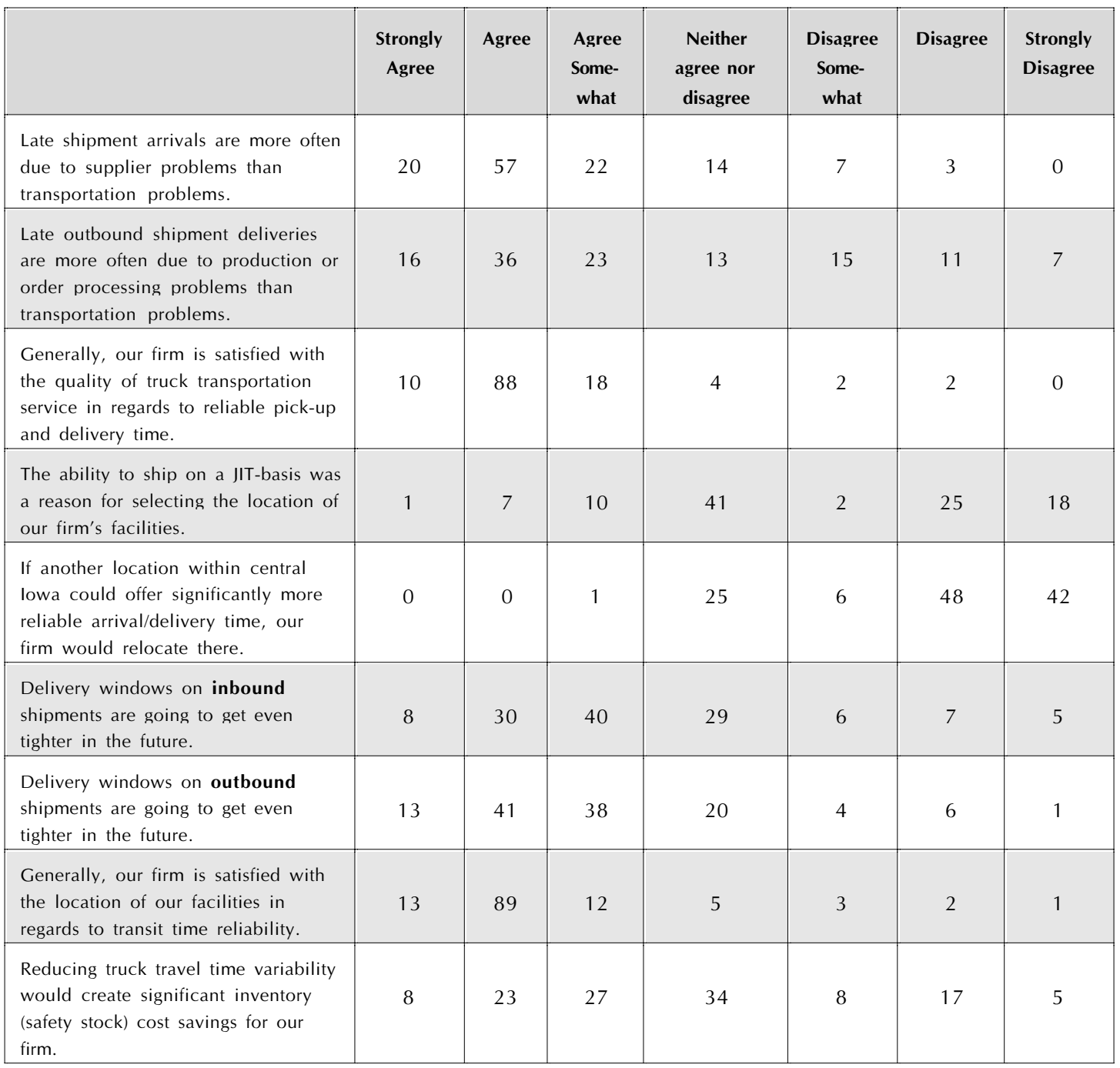




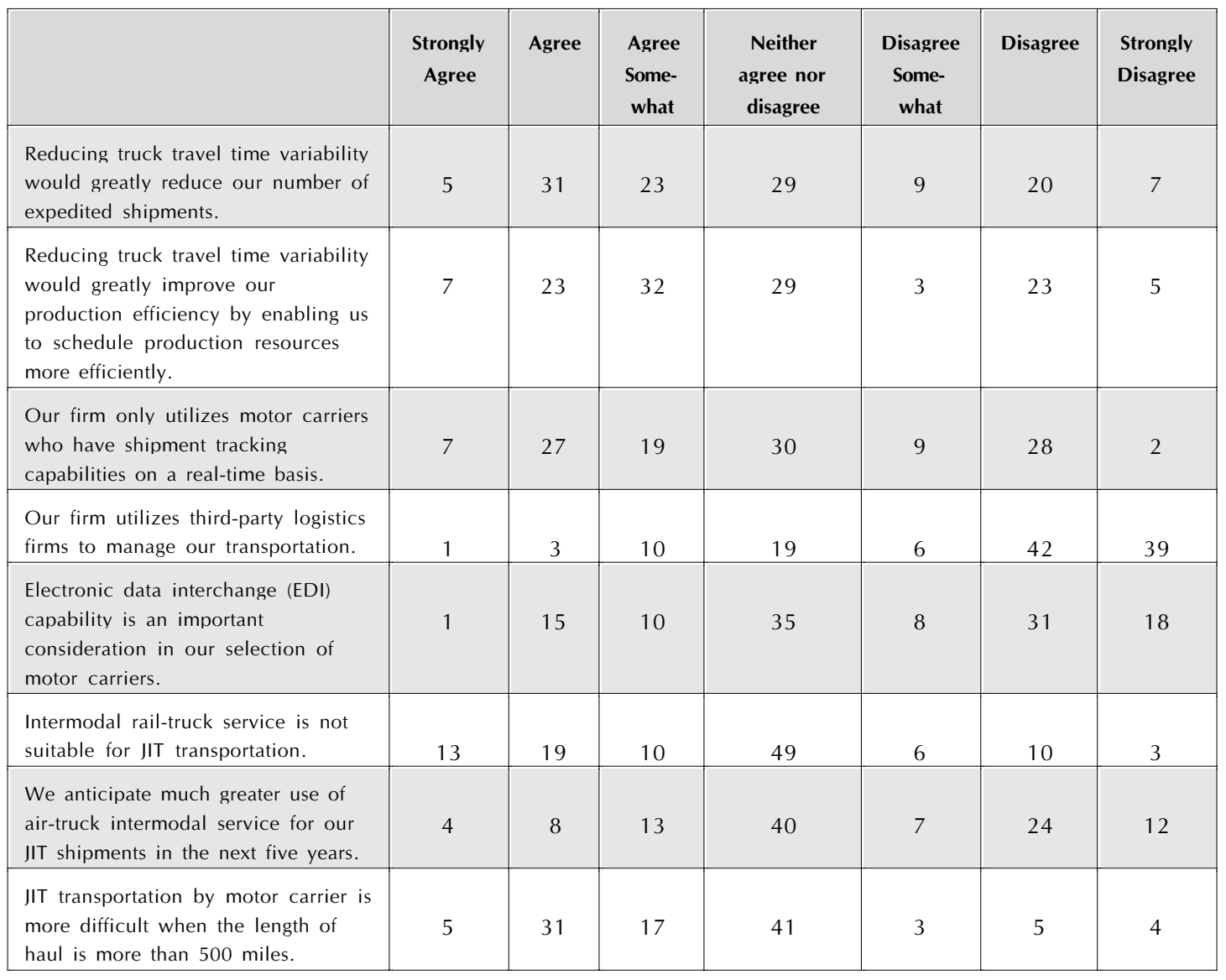

YOU CAN BE ASSURED THAT YOUR SPECIFIC RESPONSES TO THIS SURVEY WILL BE HELD IN STRICT CONFIDENCE AND WILL BE REPORTED ONLY AS PART OF SUMMARIZING THE LARGER SURVEY.

Would you like a summary of the results of this survey? Yes No

Thank you for participating in this study! Your responses will provide valuable input on the practices and needs of the freight transport sector to lowa's transportation policy makers. Please fold the survey booklet in half and return in the enclosed postage-paid envelope. 


\section{APPENDIX B INCIDENT OCCURRENCES AND DURATIONS, OBTAINING LINK FLOWS, AND AVERAGE EXPECTED DELAY}

An incident is broadly defined as a traffic event that disrupts normal traffic flow. Such events include stalled vehicles, debris on a road, a vehicle crash, or an overturned truck. The occurrence of an incident is a stochastic phenomenon that depends on numerous environmental factors, such as road conditions, traffic volume, and road geometry. Because it is not realistic to develop a probabilistic incident occurrence model that considers all these factors, we make, based on empirical evidence, certain simplifications when proposing such a model in our study. Specifically, we assume that:

- The occurrence of an incident on a road segment is a rare event whose interarrival time observes the negative exponential distribution with an occurrence intensity $\lambda^{21}$;

- The occurrences of multiple incidents on the road segment are independent events; and

- Traffic volume alone can provide a reasonable indicator of incident occurrence rates.

Because there is no incident database for the Des Moines network that contains all the information we need to calculate the various incident-related probabilities, we use the incident statistics collected by a national study (Sullivan et al. 1995) to develop our incident probability models. These statistics, all for freeways, include average incident rate (by incident type) per million vehicle miles traveled (VMT) (Table 4-1 on page 34); the frequencies of incident locations by incident type (Table 4-2 on page 35); the frequencies of the number of lanes blocked by incidents (Table 4-3 on page 36); and incident durations by incident type and location of occurrence (Table $4-4$ on page 37 ).

Let $t$ be one of the seven types of incidents and $\lambda_{t}$ be its occurrence intensity, then the probability that $i$ incidents of type $t$ occur in $v$ units of million VMTs is given by

$$
p(t=i)=\frac{v^{i} e^{-\lambda_{t} v}}{i !}
$$

\footnotetext{
${ }^{21}$ Occurrence intensity $(\lambda)$ is a parameter that defines the shape of the distribution of event occurrences per unit of time.
} 
Further, the probability that $i$ incidents (of any type) occur is

$$
p(I=i)=\frac{v^{i} e^{-\lambda v}}{i !}, \lambda=\sum_{t=1}^{7} \lambda_{t}
$$

Given that an incident occurred, the probability that it is of type $t$ is

$$
p(t \mid I)=\frac{\lambda_{t}}{\lambda}
$$

From Tables 4-2 and 4-3 (on pages 35 and 36 respectively) one can also calculate the joint probabilities that a type $t$ incident occurs at location $l$ and has duration $d_{c} \in\left[d_{1}, d_{2}\right]:$

$$
p\left(t, l, d_{c} \mid I\right)=p(t \mid I) p(l \mid t, I) p\left(d_{c} \mid l, t, I\right)
$$

Because the duration $d_{c}$ is a continuous variable and other random variables are discrete, we approximate $d_{c}$ by a discrete random variable $d$ in the following way: let $f\left(d_{c}\right)$ be the probability density function of duration $d_{c} \in[0, \infty)$, divide $[0, \infty)$ into $k$ non-overlapping intervals $\left[0, x_{1}\right],\left[x_{1}, x_{2}\right], \cdots,\left[x_{k-1}, x_{k}\right]$, calculate the mean $d_{i}$ for the interval $\left[x_{k-1}, x_{k}\right]$ :

and probability

$$
d_{i}=\frac{\int_{x_{i-1}}^{x_{i}} x f(x) d x}{\int_{x_{i-1}}^{x_{i}} f(x) d x}
$$

$$
p\left(d_{i} \mid t, l, I\right)=\int_{x_{i-l}}^{x_{i}} f(x) d x
$$

The resulting values are presented in Table 4-4.

Given a type $t$ incident occurs at location $l$, one can obtain the remaining road capacity $R$ from Table $4-5$ on page 37 . Assuming that the arrival traffic flow rate is $A$, the total delay caused by this incident can be determined using deterministic queuing theory:

$$
D_{t, l, d_{i}}= \begin{cases}\frac{C d_{i}^{2}}{2}\left(1-\frac{R}{C}\right) \frac{A-R}{C-A}, & A \geq R \\ 0, & A \leq R\end{cases}
$$

where $C$ is the flow capacity of a link. Figure $4-2$ on page 39 shows the geometric interpretation of (1). 
The average delay caused by an incident, taking into account the incident type, location, severity, and duration distributions is simply:

$$
D_{I}=\sum_{t, l, d_{i}} p\left(t, l, d_{i} \mid I\right) D_{t, l, d_{i}}
$$

Assuming that the delay caused by each incident is not affected by other incidents, we can calculate the average delay caused by incidents per million VMT, yielding a measure of travel time uncertainty (for a freeway link):

$$
\bar{D}=(\lambda \times V M T) D_{I}
$$

\section{OBTAINING LINK FLOWS}

We have used the freeway/arterial network of Des Moines, lowa, to perform our test application. From the existing Des Moines road network, we have extracted 397 road links (comprising 84 freeway links, 203 major arterial links and 110 centroid connectors that connect 55 centroids) and 210 nodes to form our base-year study network.

With the relocation and upgrade of Highway 5/65, the route will provide a major east-west corridor in the southern part of Des Moines, connecting $1-80$ in the northeast and I-35 in the southwest. The expanded network with the planned Highway 5/65 forms the horizon-year network.

Both the base-year network and horizon-year network are coded into a computer and serve as part of the input to a stochastic assignment program developed for this project. The characteristics of the network, including link length, number of lanes for each link, link capacity, free-flow speed, base-year (1990) volume count and origin-destination (O-D) demand are obtained from a 1990 transportation survey, provided by the Des Moines Area Metropolitan Planning Organization (DMAMPO).

The O-D demand for the horizon year, 2020, is obtained by applying an annual growth rate of one percent to the base year O-D pattern.

A stochastic assignment procedure is used to assign O-D demand onto the road network. Apart from O-D demand, the inputs required by the assignment procedure include road capacity, free-flow speed, practical capacity, and a link performance function.

The capacity of a road is determined as follows:

$$
\begin{aligned}
& \text { for a freeway link: } C= 2000 \text { veh/hour/lane } x \text { number of lanes } \\
& \text { for an arterial link: } C= 2000 \text { veh/hour/lane } x \text { number of lanes } x 0.5 \text { green } \\
& \text { ratio }
\end{aligned}
$$

The free-flow speed for freeway links is taken to be $65 \mathrm{mph}$, and for arterial links, $30 \mathrm{mph}$. 
The practical capacity of a link is a flow value at which the link travel time is 15 percent higher than the free-flow link travel time, or equivalently, the link travel speed is $1 / 1.15$ of the free-flow speed. Using the following equilibrium speeddensity relationship

$$
V_{e}(p)=V_{f}\left[1-\exp \left(1-\exp \left(\frac{\left|C_{j}\right|}{V_{f}}\left(\frac{p_{j}}{p}-1\right)\right)\right)\right]
$$

we can calculate the practical capacity as

$$
C_{p}=0.925 C
$$

Here $V_{e}(p)$ is the equilibrium speed, $V_{f}$ is the free-flow speed, $p$ is the density, $p_{j}$ is the jam density, and $C_{j}$ is the characteristic speed at $p_{j}$.

The link performance function that we use is the Bureau of Public Roads function (see Sheffi 1985)

$$
t_{a}=t_{a}^{o}\left[1+\alpha\left(\frac{x_{a}}{C_{p, a}}\right)^{\beta}\right]
$$

where $t_{a}, t_{a}^{o} x_{a}$ and $C_{p, a}$ are respectively the travel time, free-flow travel time, flow rate, and practical capacity on link a. $\alpha$ and $\beta$ are model parameters, usually taking values of 0.15 and 4.0 , respectively.

To perform the static stochastic assignment, we divide the day into four periods: morning peak (3 hours), evening peak (five hours), midday period (6 hours), and midnight period ( 10 hours), and make the time periods long enough to make it likely that an incident would start and end in the same time period. We also assume that the arrival rate in each period does not change within that period. The daily demand was allocated to correspond with the four time periods: the morning peak and evening peak each carries 30 percent of the total daily traffic demand, and the non-peak periods carry the remaining 40 percent of the total daily demand. Static assignment procedures are then used to obtain link flows on the study network in both the base year and the horizon year.

\section{TRIAL APPLICATION}

In this section we calculate the delays caused by incidents and accidents that are most likely to occur or are most severe. To perform such an analysis, we need to select a particular freeway segment and a particular time period. Our analysis below is a carried out for a segment of $\mathrm{I}-235$ from the west mixmaster (interchange of $\mathrm{I}-235, \mathrm{I}-80$, and $\mathrm{I}-35$ ) to the east mixmaster (interchange of $\mathrm{I}-235, \mathrm{I}-80$, and $\mathrm{I}-35$ ) in the morning peak. ${ }^{22}$ This segment consists of 16 links, most of which have

22 The two major interchanges are about 6.5 miles apart. See Figure 1-2 on page 4. 
two to four lanes. To simplify our analysis, we use the following aggregated flow data to calculate incident occurrence probability and delays:

1. Total VMT $(V)$

$$
V=\sum_{i} A_{i} \times L_{i} \times T
$$

where $A$ is the arrival rate at link $i, L_{i}$ is the length of link $i$, and $T$ is the length of the morning peak period.

2. Average flow rate $\bar{A}$

$$
\bar{A}=\frac{V}{T \sum_{i} L_{i}}
$$

3. Average capacity $\bar{C}$

$$
\bar{C}=\frac{\sum_{i} C_{i} L_{i}}{\sum_{i} L_{i}}
$$

where $C_{i}$ is the capacity of link $i$.

\section{The most frequently occurring incident, $I_{m}$}

Depending on ADT/C, the most frequently occurring incident could be an abandoned vehicle or a mechanical/electrical system failure.

The probability of $I_{m}$ occurring is

$$
p\left(I_{m} \geq 1\right)=1-e^{-\lambda_{m} V M T}=0.932
$$

for base network, during base year, as an example.

The average delay for a single $I_{m}$ :

$$
\bar{D}_{I_{m}}=\sum_{l, d} p(l, d) D_{l} d=22,094 \text { minutes }
$$

The average total delay caused by the most likely incidents is:

$$
\left(\lambda_{m} \times V M T\right) \bar{D}_{I_{m}}=59,394 \text { minutes }
$$

\section{The most frequently occurring accident, $A_{m}$}

The occurrence rate of the most frequently occurring accident $\lambda_{A_{m}}$ also depends on ADT/C. The most likely location is on the right shoulder, with probability

$$
p\left(l=r . s . \mid A_{m}=0.502\right)
$$


The capacity reduction for a right shoulder (r.s.) accident on a three-lane freeway is $1-0.83=0.17$. The most likely duration for such an accident is $d_{m}=15.2$ minutes with probability

$$
p\left(10 \leq d \leq 20 \mid l=\text { r.s., } A_{m}=0.2191\right)
$$

The average delay for such an accident $D_{A}$ is

$$
\bar{D}_{A_{m}}=\sum_{l, d} p(l, d) D_{l} d=1,112 \text { minutes }
$$

The total delay $D_{A}$ is

$$
D_{A}=\left(\lambda_{A} \times V M T\right) \bar{D}_{A_{m}}=1,032 \text { minutes }
$$

Let $E_{m}$ denote the event that at least one such accident occurs, then the probability that event $E$ happens is

$$
\begin{gathered}
p\left(E_{m}\right)=p\left(A_{m} \geq 1, l_{A_{m}}=r . s ., d_{A_{m}}=d_{m}\right) \\
\sum_{i=1}^{\infty} p\left(A_{m}=i ; l_{1}=r . s ., d_{1}=d_{m} ; \cdots ; l_{i}=r . s ., d_{i}=d_{m}\right)= \\
\sum_{i=1}^{\infty} p\left(A_{m}=i\right) p\left(l_{1}=r . s ., d_{l}=d_{m} ; \cdots ; l_{i}=r . s ., d_{i}=d_{m} \mid A_{m}=i\right)= \\
\sum_{i=1}^{\infty} p\left(A_{m}=i\right) p\left(l_{1}=r . s ., d_{l}=d_{m} \mid l\right) \cdots p\left(l_{i}=r . s ., d_{i}=d_{m} \mid i\right)= \\
\sum_{i=1}^{\infty} p\left(A_{m}=i\right)\left(p\left(l_{1}=r . s ., d_{l}=d_{m} \mid l\right)\right)^{i}= \\
p\left(l_{l}=r . s ., d_{1}=d_{m} \mid A_{m}\right) \sum_{i=1}^{\infty} p\left(A_{m}=i\right) \leq \\
p\left(l_{l}=r . s ., d_{l}=d_{m} \mid A_{m}\right)\left(1-p\left(A_{m}=0\right)\right)= \\
p\left(l=r . s . \mid A_{m}\right) p\left(d_{m} \mid l=r . s ., A_{m}\right)\left(1-p\left(A_{m}=0\right)\right)
\end{gathered}
$$

Here we assumed that the location and duration of each incident are independent of the locations and durations of other incidents. To obtain upper and lower bounds for $p\left(E_{m}\right)$, we have

$$
\sum_{i=1}^{3} p\left(A_{m}=i\right) p\left(l_{1}=r . s ., d_{i}=d_{m} \mid l\right)^{i}<P\left(E_{s}\right)<p\left(l_{1}=r . s ., d_{1}=d_{m} \mid I\right)\left(1-p\left(A_{m}=0\right)\right)
$$




\section{The most severe accident, $\mathrm{S}$}

The longest duration interval for an accident that blocks three lanes $(l=3 l b)$ falls between 100 minutes and infinity $(\infty)$. Suchdurations occur with a probability $p\left(d_{s} \in[100, \infty] l=3 l b, S\right)=0.0825$. Its mean duration is $d_{s}=147.338$ minutes. The probability of an accident occurring that blocks all three lanes of a three-lane freeway is $p(l=3 l b \mid S=0.0106)$. For such a case, the capacity reduction is 100 percent. Using equation 4-1 (see page 38), it is possible to calculate the delay caused by such an accident during the peak period for both base and horizon year demand. 


\section{REFERENCES}

Aggarwal, Sumer C. 1985. "MRP, JIT, OPT, FMS? Making Sense of Production Operations Systems." Harvard Business Review, Vol. 85, No. 5

(September-October), pp. 8-16.

Allen, Benjamin, C. Philip Baumel, and David J. Forkenbrock. 1994. "Expanding the Set of Efficiency Gains of a Highway Investment: Conceptual, Methodological, and Practical Issues." Transportation Journal, Vol. 34, No. 1 (Fall), pp. 38-47.

Anderson, David L. 1990. "Freight Transportation Data Needs, Resources, and Issues." Transportation Research Record 1253, pp. 25-40.

Ansari, Ahsanuddin. 1986. "Survey Identifies Critical Factors in Successful Implementation of Just-in-Time Purchasing Techniques." Industrial Engineering, Vol. 18, No. 10 (October), pp. 44-50.

Arnott, Richard, Andre de Palma, and Robin Lindsey. 1991. "Does Providing Information to Drivers Reduce Traffic Congestion?" Transportation Research, Vol. 25A, No. 5 (September), pp. 309-318.

Barker, B., and K. Barber. 1997. "Development of Time Based Frameworks: Manufacturing System Analysis and Value Adding Performance." Omega, Vol. 25, No. 2, pp. 171-179.

Beman, Lewis. 1981. "A Big Payoff from Inventory Controls." Fortune, July 27, pp. 76-80.

Billesbach, Thomas J. 1991. "A Study of the Implementation of Just-in-Time in the United States." Production and Inventory Management Journal, Vol. 32, No. 3, pp. 1-4.

Billesbach, Thomas J., and Roger Hayen. 1994. "Long-Term Impact of Just-in-Time on Inventory Performance Measures." Production and Inventory Management Journal, Vol. 35, No. 1, pp. 62-66.

Blumenfeld, Dennis E., Lawrence D. Burns, Carlos F. Daganzo, Michael C. Frick, and Randolph W. Hall. 1987. "Reducing Logistics Costs at General Motors." Interfaces, Vol. 17, No. 1 (January-February), pp. 26-47. 
Caplice, Chris, and Hani S. Mahmassani. 1992. "Aspects of Commuting Behavior: Preferred Arrival Time, Use of Information and Switching Propensity." Transportation Research, Vol. 26A, No. 5 (September), pp. 409-418.

Carter, Phillip L., Steven A. Melnyk, Robert B. Handfield. 1995. "Identifying the Basic Process Strategies for Time-Based Competition." Production and Inventory Management Journal, Vol. 36, No. 1, pp. 65-70.

Center for Transportation Research and Education, AlliedSignal, and Booz-Allen and Hamilton. 1997. Des Moines Metropolitan Area ITS Strategic Plan. Ames, IA: Center for Transportation Research and Education.

Chin, Shih-Miao, Janet Hopson, and Ho-Ling Hwang, 1998. "Estimating State-Level Truck Activities in America." Journal of Transportation and Statistics, Vol. 1, No. 1 (January), pp. 63-74.

Coyle, John J., Edward J. Bardi, and C. John Langley, Jr. 1996. The Management of Business Logistics. Minneapolis/St. Paul, MN: West Publishing.

Crawford, Karlene M., John H. Blackstone, and James F. Cox. 1988. "A Study of JIT Implementation and Operating Problems." International Journal of Production Research, Vol. 26, No. 9, pp. 1561-1568.

Crawford, Karlene M., and James F. Cox. 1991. "Addressing Manufacturing Problems Through the Implementation of Just-in-Time." Production and Inventory Management Journal, Vol. 32, No. 1, pp. 33-36.

Crum, Michael R., and Benjamin J. Allen. 1990. "Shipper EDI, Carrier Reduction, and Contracting Strategies: Impacts on the Motor Carrier Industry." Transportation Journal, Vol. 29, No. 4 (Summer), pp. 18-32.

Cusumano, Michael A. 1994. "The Limits of 'Lean'." Sloan Management Review, Vol. 35, No. 4, pp. 27-32.

Dunn, John. 1992. "Just-in-Time Gets Stuck in the Traffic." The Engineer, Vol. 275, No. 7127/8 (November 26), p. 18.

Ferrin, Bruce. 1994. "Planning Just-in-Time Supply Operations: A Multiple-Case Analysis." Journal of Business Logistics, Vol. 15, No. 1, pp. 53-69.

Gilbert, James P. 1990. "The State of JIT Implementation and Development in the USA." International Journal of Production Research, Vol. 28, No. 6, pp. 1099-1109.

Goldhar, Joel D., and David Lei. 1991. "The Shape of Twenty-first Century Global Manufacturing." The Journal of Business Strategy, Vol. 12, No. 2 (March-April), pp. 37-41. 
Goolsby, Merrell E. 1971. "Influence of Incidents on Freeway Quality of Service." Highway Research Record 349, pp. 41-46.

Hall, Randolph W. 1993. "Non-recurrent Congestion: How Big is the Problem? Are Traveler Information Systems the Solution?" Transportation Research, Vol. 1C, No. 1 (March), pp. 89-103.

Hallihan, A., P. Sackett, and G. M. Williams. 1997. "JIT Manufacturing: The Evolution to an Implementation Model Grounded in Current Practice." International Journal of Production Research, Vol. 35, No. 4, pp. 901-920.

Harder, Christian. 1998. Serving Maps on the Internet: Geographic Information on the World Wide Web. Redlands, CA: Environmental Systems Research Institute, Inc.

Hayes, Robert H., and Gary P. Pisano. 1994. "Beyond World-Class: The New Manufacturing Strategy," Harvard Business Review, Vol. 72, No. 1 (January-February), pp. 77-84.

Henning, Allen. 1994. "Just-in-Time Manufacturing and Transportation." Videotape of lecture presented during the Problems in Transportation series sponsored by lowa State University and the University of lowa. Available from the University of lowa Public Policy Center, lowa City, lowa.

Hill, Arthur V., and Thomas E. Vollmann. 1986. "Reducing Vendor Delivery Uncertainties in a JIT Environment." Journal of Operations Management, Vol. 6, No. 4 (August), pp. 381-389.

Hobbs, O. Kermit. 1997. "Managing JIT Toward Maturity." Production and Inventory Management Journal, Vol. 38, No. 1, pp. 47-50.

Holcomb, Mary Collins. 1994. "Customer Service Measurement: A Methodology for Increasing Customer Value Through Utilization of the Taguchi Strategy." Journal of Business Logistics, Vol. 15, No. 1, pp. 29-52.

Hong, Jae-Dong, and Jack C. Hayya. 1992. "Just-in-Time Purchasing: Single or Multiple Sourcing?" International Journal of Production Economics, Vol. 27, No. 2 (May), pp. 175-181.

Im, Jin H., and Sang M. Lee. 1989. "Implementation of Just-in-Time Systems in US Manufacturing Firms." International Journal of Operations and Production Management, Vol. 9, No. 1, pp. 5-14.

lowa Department of Transportation. 1998. "100 Most Significant Crash Sites: 19921996". http://www.state.ia.us/government/dot/crashsite.htm. Available August 27, 1998. 
Iyer, Ananth V., and Mark E. Bergen. 1997. "Quick Response in ManufacturerRetailer Channels." Management Science, Vol. 43, No. 4 (April), pp. 559-570.

Krupp, James A. G. 1991. "JIT in Distribution and Warehousing." Production and Inventory Management Journal, Vol. 32, No. 2, pp. 18-21.

Lambert, Douglas M., James R. Stock, and Lisa M. Ellram. 1998. Fundamentals of Logistics Management. Boston, MA: Irwin/McGraw Hill.

Lari, Adeel, David Christianson, and Sue Porter. 1982. I-35W Incident Management and Impact of Incidents on Freeway Operations. Office of Traffic Engineering. St. Paul, MN: Minnesota Department of Transportation.

Lieb, Robert C., and Robert A. Miller. 1988. "JIT and Corporate Transportation Requirements." Transportation Journal, Vol. 27, No. 3, pp. 5-10.

Lindley, Jefferey A. 1986. Quantification of Urban Freeway Congestion and Analysis of Remedial Measures. RD-87/052. Washington DC: Federal Highway Administration.

Loar, Tim. 1992. "Patterns of Industry Management and Policy: A Study of Four Industries." Journal of Business Logistics, Vol. 13, No. 2, pp. 69-96.

Mahmassani, Hani S. and R. Jayakrishnan. 1991. "System Performance and User Response Under Real-Time Information in a Congested Traffic Corridor." Transportation Research, Vol. 25 A, No. 5 (September), pp. 291-307.

Manoochehri, G. H. 1985. "Improving Productivity with the Just-in-Time System." Journal of Systems Management, Vol. 36, No. 1 (January), pp. 23-26.

Mendenhall, William, and Robert J. Beaver. 1991. Introduction to Probability and Statistics. Boston, MA: PWS-Kent Publishing Company.

Miltenburg, J. 1997. "Comparing JIT, MRP and TOC, and Embedding TOC into MRP." International Journal of Production Research, Vol. 35, No. 4, pp. 1147-1169.

Moore, E. William, Jr., Janice M. Warmke, and Lonny R. Gorban. 1991. "The Indispensable Role of Management Science in Centralizing Freight Operations at Reynolds Metals Company." Interfaces, Vol. 21, No. 1 (January-February), pp. 107-129.

Musselwhite, W. Christopher. 1987. "The Just-in-Time Production Challenge." Training and Development Journal, Vol. 41, No. 2 (February), pp. 27-29.

Ohno, Taiichi. 1988. Toyota Production System: Beyond Large-Scale Production. Cambridge, MA: Productivity Press.

Perry, James H. 1988. "Firm Behavior and Operating Performance in Just-in-Time Logistics Channels." Journal of Business Logistics, Vol. 9, No. 1, pp. 19-33. 
Ptak, Carol A. 1991. "MRP, MRP II, OPT, JIT, and CIM-Succession, Evolution, or Necessary Combination." Production and Inventory Management Journal, Vol. 32, No. 2, pp. 7-11.

Raia, Ernest. 1990. "JIT Delivery: Redefining 'On-Time'." Purchasing, Vol. 109, No. 3 (September 13), pp. 64-76.

Rao, Kant, William Grenoble, and Richard Young. 1991. "Traffic Congestion and JIT." Journal of Business Logistics, Vol. 12, No. 1, pp. 105-121.

Rinehart, James, and Carolyn Stokes. 1988. "Corporate Site Selection Adjusts to Justin-Time Inventory Management." Site Selection, Vol. 33, No. 5 (October), pp. $10-12$.

Roper, David H. 1990. Freeway Incident Management. NCHRP 156. Washington DC: Transportation Research Board.

Ross, Sheldon. 1989. Introduction to Probability Models. Boston, MA: Academic Press, Inc.

Santarisi, Nadir Said Moh'd. 1993. "Mathematical Modeling and Analysis of Just-inTime Manufacturing Kanban System." Ph.D. dissertation, University of Iowa.

Schonberger, Richard I. 1986. World Class Manufacturing: The Lessons of Simplicity Applied. New York, NY: The Free Press.

Sepehri, Mehran. 1986. Just-in-Time, Not Just in Japan. Falls Church, VA: American Production and Inventory Control Society.

Sheffi, Yosef. 1985. Urban Transportation Networks. Englewood Cliffs, NJ: Prentice-Hall.

Stalk, George, Jr. 1988. "Time-The Next Source of Competitive Advantage." Harvard Business Review, Vol. 88, No. 4 (July-August), pp. 41-51.

Stamm, Carol Lee, and Damodar Y. Golhar. 1991. "Customer and Supplier Linkages for Small JIT Manufacturing Firms." Journal of Small Business Management, Vol. 29, No. 3 (July), pp. 43-49.

Steltzer, Theresa M. 1991. "Cashing in on Quicker Delivery Times." Distribution, Vol. 90, pp. 34-38.

Sullivan, Edward, Sam Taff, and James Daly. 1995. A Methodology for Measuring and Reporting of Incidents and the Prediction of Incident Impacts on Freeways. Report for the Federal Highway Administration. San Diego, CA: Ball Systems Engineering Division, San Diego Operations.

Turnquist, Mark A. 1993. "Manufacturing Logistics for the 21st Century."

Transportation Research Record 1395, pp. 129-134. 
Transportation Research Board. 1994. Highway Capacity Manual. Special Report 209, Third Edition. Washington DC.

Vickery, Shawnee K., Cornelia L. M. Droge, James M. Yeomans, and Robert E. Markland. 1995. "Time-Based Competition in the Furniture Industry."

Production and Inventory Management Journal, Vol. 36, No. 4, pp. 14-21.

Vining, Thomas A. 1994. "Transportation, Labor Key Factors in Whirlpool's Selection of Tulsa." Site Selection, Vol. 39, No. 4 (August), pp. 716-719.

Vokurka, Robert J., and Robert A. Davis. 1996. "Just-in-Time: The Evolution of a Philosophy." Production and Inventory Management Journal, Vol. 37, No. 2, pp. 56-58.

Westbrook, Roy. 1988. "Time to Forget 'Just-in-Time'? Observations on a Visit to Japan." International Journal of Operations and Production Management, Vol. 8, No. 4, pp. 5-21.

White, Richard E. 1993. "An Empirical Assessment of JIT in U.S. Manufacturers." Production and Inventory Management Journal, Vol. 34, No. 2, pp. 38-42.

Womack, James P., Daniel T. Jones, and Daniel Roos. 1990. The Machine that Changed the World. New York, NY: MacMillan.

Zografos, Kostas G., Teti Nathanail, and Panos Michalopoulous. 1993. "Analytical Framework for Minimizing Freeway-Incident Response Time." Journal of Transportation Engineering, Vol. 119, No. 4 (July/August), pp. 535-549. 